This is a non-peer reviewed preprint submitted to EarthArXiv 


\title{
Characterisation and controls on mineral-sorbed organic matter from a variety of groundwater environments.
}

\author{
Phetdala Oudone ${ }^{1,5^{*}}$, Helen Rutlidge ${ }^{3,5}$, Martin S. Andersen ${ }^{3,5}$, Denis O'Carroll ${ }^{3,5}$, Soshan \\ Cheong $^{2}$, Karina Meredith ${ }^{4}$, Liza McDonough ${ }^{1,5}$, Christopher E. Marjo ${ }^{4}$, Andy BakeR ${ }^{1,2}$ \\ ${ }^{1}$ School of Biological, Earth and Environmental Science, UNSW Sydney, NSW 2052, Sydney, Australia. \\ p.oudone@student.unsw.edu \\ 2 Mark Wainwright Analytical Centre, UNSW Sydney, NSW 2052, Sydney, Australia. \\ ${ }^{3}$ School of Civil and Environmental Engineering, UNSW Sydney, NSW 2052, Sydney, Australia. \\ ${ }^{4}$ Australian Nuclear Science and Technology Organization (ANSTO), New Illawarra Rd, Lucas Heights NSW 2234, Sydney, Australia. \\ ${ }^{5}$ Connected Waters Initiative Research Centre, UNSW Sydney, NSW, 2052, Australia \\ *Corresponding author: p.oudone@student.unsw.edu
}

\section{Abstract}

Detailed investigations into natural groundwater organic matter (OM) as carbon sources or sinks in the natural carbon cycle are generally limited. Groundwater OM concentration and composition is altered by biodegradation and sorption to minerals. In the saturated zone of an aquifer, dissolved organic matter (DOM) may represent a significant fraction of the natural groundwater dissolved organic carbon (DOC) pool, therefore understanding how mineral sorption influences OM will contribute to our understanding of how DOC is processed in groundwater. In this study we investigate the dominant fractions of natural DOC in groundwater and the extent of sorption on three common minerals found in the environment: iron-oxide coated sand, calcite and quartz sand. DOM sorption on these minerals was studied using groundwaters from three different geological environments in New South Wales, Australia: Anna Bay (quartz-sand coastal aquifer); Maules Creek (alluvial gravel and clay aquifer); and Wellington (alluvial karst limestone aquifer). Each groundwater and surface sample were characterised before and after sorption using size exclusion liquid chromatography with organic carbon detection (LC-OCD). Analysis revealed that humic substances (HS) are the dominant $(13-70 \%)$ fraction of natural groundwater DOC. HS sorption on iron-oxide coated sand was higher than that on calcite and quartz sand, respectively while sorption on the calcite was also higher than on quartz sand. In shallowsandy aquifer groundwater, due to less DOC sorption in sandy environment (Anna Bay), DOC concentration was found to be the highest compared to that from karst and other alluvial boreholes from Maules Creek and Wellington. HS sorption increases with the mineral mass and DOC concentration indicating that DOC sorption to the mineral surface did not reach saturation under the study conditions. Only the high-DOC alluvial groundwater produced significant sorption to each mineral phase and of the chemical fractions present $(85 \%$ of 72 batch systems that HS sorption was found).

Multiple linear regression showed that mineral mass, mineral type, depth of groundwater sample, DOC concentration, aqueous $\mathrm{Fe}^{2+}$ concentration and DOM aromaticity are the controlling factors of DOC sorption in the various groundwater environments. The regression analysis showed sorption decreases with depth, which could be because of DOC sorption along the groundwater flow path, resulting in less DOC at depth. The multiple linear 
regression predicts less DOC (HS) sorption in quartz sand system, agreeing with laboratory sorption results. HS sorption also correlated with aromaticity suggesting the chemical character of HS will control the degree of mineral sorption. The model also indicated that DOC sorption is negatively correlated with dissolved $\mathrm{Fe}^{2+}$ concentration in water samples presumably due to redox condition which is under anoxic environment iron oxide became electron acceptors under the process of DOC biodegradation leaving higher $\mathrm{Fe}^{2+}$ concentration and less available DOC for sorption.

\section{Introduction}

The dynamics of groundwater OM can be influenced by biological processing and mineral sorption. Rivers are physically and chemically connected to aquifers (Sophocleous, 2002, Kumar et al., 2009, Krause et al., 2007). Despite their interaction, natural organic matter (NOM) concentration in groundwater is much lower compared to rivers. The global median groundwater dissolved organic carbon (DOC) is only $1.0 \mathrm{mg} \mathrm{C} \mathrm{L}^{-1}$ (McDonough et al., 2020a). This leads to questions such as where does the missing fraction go? and could sorption be responsible for this decrease in concentration? The ability of DOC to sorb onto minerals has been investigated in many studies including sorption on spodosol (Ussiri and Johnson, 2004), clay (Kahle et al., 2003), iron coated pumice (Kitis et al., 2007), calcium carbonate (Suess, 1970, Suess, 1973), clay and sesquioxides (Singh et al., 2016), iron (Gu et al., 1995), hydrous iron oxide coated minerals (Saidy et al., 2015), iron coated material (Kim et al., 2009, Lai and Chen, 2001), aluminium oxide (Ochs et al., 1994). Some studies have found sorption over a range of minerals is different. For example, higher humic substances (HS) sorption was observed in iron coated sand than pure quartz sand (Kim et al., 2009). Chang et al. (1997) discovered that DOC sorption found on iron coated sand was higher than that on silica. DOC occurring naturally in groundwater is composed of a variety of organic compounds with different physiochemical characteristics. Many studies have tested DOC based on its physiochemical subgroups to assess relative DOC sorption. Gu et al. (1995) used 3000 Dalton and hydrophobic and hydrophilic properties as the cut-off and found that hydrophobic DOC contained about 1.34 times more $C$ than the $C$ count in hydrophilic DOC and because of this larger size hydrophobic DOC had higher sorption extent than that of lower size hydrophilic DOC due to the fact that this larger size hydrophobic fraction had a higher adsorption affinity and capacity. However, based on elemental composition, hydrophobic contains about 0.82 times less $\mathrm{O}$ than hydrophilic fraction and if sorption is calculated based on the amount of $\mathrm{O}$ sorbed, more hydrophilic fraction was adsorbed than Hydrophobic. Kaštelan-Macan and Petrovic (1995) investigate HS which is one type of DOC fraction. They analysed HS competition for particulate sand, calcite, bentonite and iron oxide sorption site and found that higher sorption extent was observed on iron oxide followed by calcite, bentonite and sand. One observation from this study is that HS sorption increases with molecular weight. Several mechanisms have been used to explain DOC sorption. For example Gu et al. (1995) found that surface complexation-ligand exchange is the main mechanism used to explain sorption. This mechanism is aided by carboxyl and hydroxyl functional groups of DOC (Gu et al., 1994), in which their steric arrangement was assumed to be controlling on the amount and fraction that is sorbed (Gu et al., 1995). DOC sorption can be affected by environmental conditions. For example, DOC sorption to montmorillonite was enhanced by temperature and the ionic strength of the solution (Arnarson and Keil, 2000, Kim et al., 2009). Sorption of DOC decreased with increased pH (Gu et al., 1995, Gu et al., 1994, Kim et al., 2009). Vermeer et al. (1998) used electrostatic interactions to describe humic acid sorption on hematite with 
variations in $\mathrm{pH}$ and salt concentration. In the presence of hexadecyltrimethyl ammonium, the mechanisms contributing to the DOC sorption on iron coated sand is hydrophobic interaction followed by ligand exchange (Ding et al., 2010). Organic matter processes have been intensively studied as they play an important role in the global carbon cycle (Falkowski et al., 2000, Brown and Lugo, 1982, Santín et al., 2015), degraded water quality (Li et al., 2013, Delpla et al., 2009), affected water treatment efficiency (Paria, 2008, Wang et al., 2007, Rosenberger et al., 2006), modified water chemistry such as acidity environment (Delpla et al., 2009, Evans et al., 2005) and affect the heterogenous and complex nature of OM (Middelburg and Herman, 2007). Recently, groundwater DOC has been of interest to numerous investigators for identifying climate change and urbanization on altering global groundwater organic carbon (McDonough et al., 2020a), examining how different sources and processes influence shallow coastal groundwater DOC (Meredith et al., 2020), investigating changes in groundwater DOC after rainfall (McDonough et al., 2020b). However, the existing studies focused on natural DOC processing in groundwater are limited.

To the best of our knowledge, this is the first study to characterise groundwater DOM from a range of environments using size exclusion liquid chromatography with organic carbon detection (LC-OCD) and specifically relate the DOM composition to sorption on different minerals. Data from LC-OCD techniques can be used to measure the concentrations of groundwater DOC fractions, identify the dominant fraction in natural DOC, investigate DOC fractions that sorb, estimate the sorption on selected common mineral phases and show the factors controlling DOC sorption from groundwater.

\section{Methodology}

\subsection{Sampling sites}

We collected a total of 24 water samples, including 21 groundwater and 3 adjacent surface water samples from three different sampling locations in New South Wales (UNSW), Australia see Figure 1. Bore screen depths and GPS coordinate are provided in Supplementary Table 1.

\subsubsection{Anna Bay, New South Wales.}

Extensive site description for Anna Bay is provided in Meredith et al. (2020), Andersen et al. (2012) and McDonough et al. (2020b). In brief, the site is located on the coastal environment of Samurai Beach to the north east of Anna Bay, New South Wales, Australia. We sampled groundwater from 8 bores located along a transect in Holocene aeolian and marine sands stretching from the coast to a freshwater wetland Meredith et al. (2020) located approximately $800 \mathrm{~m}$ from the shoreline. Three shallow porewater boreholes (MLSA, MLSB and MLSD) located between $0-2 \mathrm{~m}$ from the wetlands (McDonough et al., 2020b) with depths from 0.4 to $1.2 \mathrm{~m}$ below ground (Figure 1:C). The other 5 boreholes: S1_S, S1_M, S1_D, S2_D and S4_S (S: shallow, M: meddle, D: deep) are located further away up to $30 \mathrm{~m}$ from the wetlands (McDonough et al., 2020b) with the depth from 3.50 to $17.30 \mathrm{~m}$ below ground (Figure 1:D). The lithology of the area consists of unconsolidated sand and silt deposits, peat layers and a clay unit close to the shoreline (Andersen et al., 2012, McDonough et al., 2020b, Meredith et al., 2020). Wetland, rainwater and regional groundwater sources were identified in the aquifer (Clément, 2018, Meredith et al., 2020).

\subsubsection{Maules Creek, New South Wales.}


The site description has been summarized previously (McCallum et al., 2009, Giambastiani et al., 2012, Andersen et al., 2012, Andersen and Acworth, 2009, McCallum et al., 2014). In brief, Maules Creek catchment covers an area of approximately $1100 \mathrm{~km}^{2}$ and is characterized as a semi-arid region of north-western New South Wales, Australia. It is a sub-catchment of the considerably larger Namoi Valley (McCallum et al., 2009). The upper part of this site receives a large portion of groundwater recharge from ephemeral streams (NCRIS, 2014, Rau et al., 2017, Cuthbert et al., 2016). The alluvial aquifer of Maules Creek (Figure 1:B) is filled with heterogenous valley deposits in which the sediment has been subdivided into two main alluvial formations (Gates, 1980). The uppermost Narrabri formation consists of extensive overbank clays with minor sand and gravel beds deposited (from 10 to $30 \mathrm{~m}$ in thickness) by levied meandering streams (Giambastiani et al., 2012). Another is the Gunnedah Formation of Pliocene to Early Pleistocene age (Gates and Ross, 1980). It consists of fluvio-lacustrine sediment with predominant sand and gravel (Giambastiani et al., 2012). The cross section in Figure 2:B illustrates the lithology information taken from 7 bore samples and Elfin Crossing surface sample (Creek). Two bore samples were from bores located near Middle Creek (BH 18-2 and BH 19-2) which is intermittent (Rau et al., 2017). One surface sample (Elfin Crossing) and 5 bore samples (EC07, EC06, EC03, EC31 and BH 12-4 were collected at Elfin Crossing where Maules Creek and Horsearm Creek converge (around $11 \mathrm{~km}$ downstream from the Middle Creek sample site).

\subsubsection{Wellington, New South Wales.}

Two sampling sites at Wellington were selected, including Wellington Caves and Wellington Research Station. The lithology, screen depths and distance from surface water are shown in Figure 1:D. The Wellington Caves region is located in the Garra Formation of Early Devonian age limestone (Chatterton et al., 1979). It is about $8 \mathrm{~km}$ south of Wellington (NCRIS, 2014, Jex et al., 2012). The Garra Formation consists of shallow-water limestone, minor cherty and volcaniclastic sandstone, fissile shale and marly siltstone (Keshavarzi et al., 2017). One surface water (Bell river) and 3 groundwater samples (BH.Golf, BH01 and The Well: an expression of groundwater at the bottom of the cave) were collected at Wellington Caves. The area between Bell River and the caves is identified as river alluvium which overlies the Garra Formation and is comprised of fluvial channel sands and gravels mixed with overbank silt and clay deposits (Keshavarzi et al., 2017). This alluvial aquifer is characterized as an unconfined aquifer without any aquitard units. Bell River water levels and hydraulic head data from The Well suggests that Bell River recharges the groundwater at $\mathrm{BHO1}$ and The Well (Keshavarzi et al., 2017). Information on climatic and geological conditions at the Wellington Research Station (WRS) is explained in Graham et al. (2015b), Graham et al. (2015c) and Graham et al. (2015a). WRS is located in the central west of NSW. It is situated on Devonian fractured basalt and consolidated metasediments overlain by residual soil on the hill sides and alluvial deposits of sand, silts, clays and gravels in the valley. It is dominated by low density plant land area and grazing. One surface water (Macquarie River) and three groundwater (WRS03, WRS05 and WRS08) samples were collected at this site (Figure 1:D). Water releases from Burrendong Dam, located to the south-east of the site impacts on Macquarie River water flow and quality, and controls the interactions between the river and the downstream unconsolidated alluvial aquifer where the 3 bores are situated

\subsection{Preparation and character of minerals used in sorption experiment}


Three mineral types including quartz sand, calcite and iron coated sand. Quartz sand can represent sandy coastal Anna Bay sampling site while calcite and iron oxides represent Wellington Caves and WRS and Maules Creek samples, respectively. Commercial quartz sand (white quartz within 50-70 mesh size, Sigma Aldrich) was treated by heating to $400^{\circ} \mathrm{C}$ for 12 hours to remove residual organic carbon (based on Scanning Electron Microscope and EnergyDispersive $X$ - ray spectroscopy (SEM - EDX) results in Figure 2, no $C$ was found after ignition at $400^{\circ} \mathrm{C}$ ). An iron oxide coating sand procedure was adapted from Edwards and Benjamin (1989) and Thirunavukkarasu et al. (2001). It involved using $0.72 \mathrm{M} \mathrm{FeCl}_{3}$ solution that was prepared by dissolving $116.784 \mathrm{~g}$ of commercial $\mathrm{FeCl}_{3}$ (grade $97 \%$, Sigma Aldrich) into $1 \mathrm{~L}$ of Milli-Q water. The heated quartz sand (at $400^{\circ} \mathrm{C}$ ) was then saturated with the $\mathrm{FeCl}_{3}$ solution for at least 48 hours. Excess $\mathrm{FeCl}_{3}$ solution was decanted before the mixture was air dried for 12 hours. The iron coated sand was then heated for 12 hours at $400{ }^{\circ} \mathrm{C}$ before being rinsed with Milli-Q water until the decant became clear. Finally, the wet iron oxide-coated quartz sand was reheated for 12 hours at $400^{\circ} \mathrm{C}$ before use. Commercial $\mathrm{CaCO}_{3}$ marble chips (Assay: 98.5-100.5\%, Sigma Aldrich) (Meredith et al., 2020) were crushed and sieved to obtain the size range of 120-300 $\mu \mathrm{m}$ similar to the size range of commercial quartz sand and iron oxide coated sand. Before use, the grains were rinsed with Milli-Q water several times until the decant water became clear and the heated at $400{ }^{\circ} \mathrm{C}$ for 12 hours. All heated minerals were kept in a desiccator to cool down and immediately used to minimize contact time with the atmosphere. In this paper, iron-oxide coated quartz sand, $\mathrm{CaCO}$, quartz sand will be denoted as Iron Oxides, Calcite and Quartz, respectively.

Sub-samples of the 3 clean heated (sterile) minerals were analysed by Scanning Electron Microscope and Energy-Dispersive X-ray spectroscopy (SEM-EDX), showing the surface morphology and inorganic chemical distribution (see 2.6).

\subsection{Sediment sampling}

Two fresh sediments at Anna Bay were collected in 07 August 2018. The samples were located about $5 \mathrm{~m}$ (Anna 1) and $11 \mathrm{~m}$ (Anna 2) away bores located along a transect at the edge of the wetlands. The sediment was collected at $112 \mathrm{~cm}$ and $149 \mathrm{~cm}$ for Anna 1 (417602.00 m E, $6374462.00 \mathrm{~m} \mathrm{~S}$ : UTM coordinating system) and Anna 2, respectively. Almost no vegetation covering the surface area. The sediment samples were collected in acid washed glass containers and stored in esky under $4^{\circ} \mathrm{C}$ before sent back to the lab. Another two fresh sediments (Elfin Crossing and Middle Creek) at Maules Creek were collected in 26 September 2018. Elfin Crossing ( $220006.09 \mathrm{~m} \mathrm{E}, 6622676.85 \mathrm{~m} \mathrm{~S}$ ) was collected at about $5 \mathrm{~m}$ away from the Elfin Crossing bank (no flow was observed). Middle Creek sediment (220146.00 m E, $6622822.00 \mathrm{~m} \mathrm{~S}$ ) was collected at depth $60 \mathrm{~cm}$ and about $6 \mathrm{~m}$ away from Middle Creek bank (no flow was observed). Elfin Crossing and Middle Creek were sieved ( $2.00 \mathrm{~mm}$ mesh size) before being kept in acid washed $250 \mathrm{ml}$ glass containers under $4^{\circ} \mathrm{C}$. The samples were kept in dark to avoid photolysis.

\subsection{Water sampling}

Water sampling was conducted on 15 - 16 August 2017 (Wellington), 11 October 2017 (Maules Creek) and 13 - 14 February 2018 (Anna Bay). They were collected to analyse cations, anions, and DOC fractionation. In-situ measurements were also collected, included dissolved oxygen (DO), electrical conductivity (EC), $\mathrm{pH}$ and temperature. 
Surface water samples at Wellington (at Macquarie River and Bell River), Maules Creek (at Elfin Crossing) and shallow aquifers at Anna Bay (MLSA, MLSB and MLSD) were collected by using a peristaltic Series II Geopump attached to a $10 \mathrm{~mm}$ diameter steel sampling spear with a $50 \mathrm{~mm}$ screen. In-situ measurements of Dissolved Oxygen (DO), Electrical Conductivity (EC), $\mathrm{pH}$ and temperature were recorded by attaching an in-line Sheffield flow-cell to two Hach HQ40D multimeters. Before the recording, the bore was purged until stable values were achieved (ensuring no air bubbles or light penetration for DO). Deep groundwater samples were collected with a Monsoon 12 Volt Plastic Groundwater pump. Before collecting the samples, bores were purged and standing bore water levels and in-situ measurements parameters as above were recorded. Samples were filtered to $0.45 \mu \mathrm{m}$ for field chemistry analyses and water used in sorption experiments. Sorption experiment samples were collected in $3 \times 1 \mathrm{~L}$ high density poly-ethylene (HDPE) bottles (pre-washed with $10 \% \mathrm{HCl}$ solution overnight). Field samples were collected by $50 \mathrm{ml}$ polyethylene Falcon TM tubes (no headspace was observed). Cation samples were collected in $30 \mathrm{ml}$ ( $10 \%$ nitric acid pre-washed polyethylene vials). These samples were acidified using $1 \%$ of $65 \%$ Suprapur ${ }^{\circledR}$ nitric acid. All samples were kept in dark and refrigerated before analysis.

\subsection{Sorption experimental set up}

A batch system was set up by mixing $40 \mathrm{ml}$ of the field water samples with a range of clean mineral mass $(1,2.5,5,7.5$ and $10 \mathrm{~g})$ in $50 \mathrm{ml}$ pre-acid washed $(10 \% \mathrm{HCl})$ falcon tubes on a rotator $(2.5 \mathrm{rpm})$ in a dark and temperature-controlled $\left(20^{\circ} \mathrm{C} \pm 1^{\circ} \mathrm{C}\right)$ room. Samples were collected after $1 \mathrm{~h}$ (Neil et al., 2016) for DOC analysis by LC-OCD. The concentration of each DOC fraction is recorded after control correction and the sorbed amount were quantified by using the concentration after correction multiplied by volume of the samples used.

\subsection{Instrumental analysis}

\subsubsection{Liquid Chromatography-Organic Carbon Detection (LC-OCD)}

To quantify and characterize DOC, liquid Chromatography-Organic Carbon Detection (LCOCD) equipped with ChromCALC, DOC-LABOR, Karlsruhe (Germany) was used. The principle of the system and its physical description was described by Huber et al. (2011b). Total DOC concentration was obtained from the bypass while chromatographable dissolved organic carbon (CDOC, hydrophilic DOC) was derived and separated into 5 fractions: Biopolymers (BP), Humic substances (HS), Building Blocks (BB), Low Molecular Weight Acids (LMWA) and Low Molecular Weight Neutral (LMWN) with the size of $>>20,000, \sim 1000,300-350,<350$ and $<350 \mathrm{~g}$ mol-1, respectively. Hydrophobic DOC (HOC) is the retaining fraction in the resin inside the chromatography column. Thereby, it is the difference of total DOC and CDOC. Furthermore, HS fraction is also analysed for its aromaticity and molecular weight. The ChromCALC, DOC-LABOR is programmed to provide HS aromaticity and molecular weight. By using UVD detector at $254 \mathrm{~nm}, \mathrm{LC}-\mathrm{OCD}$ technique is not only able to detect aromatic HS, but also BB, LMWN and inorganic carbon. However, for these two DOC fractions, the aromatic BB and LMWN were reported in terms of Spectrum Absorbance Coefficients (SAC) with the unit of $\mathrm{m}^{-1}$. No SAC for BP and LMWA were detected due to they do not have aromaticity property (Huber et al., 2011a) and aromaticity of inorganic carbon was not included in this study.

\subsubsection{Scanning Electron Microscope and Energy-Dispersive X - ray spectroscopy (SEM - EDX)} The surface morphology and chemical distribution on the 3 heated (sterile) minerals was analysed by Scanning Electron Microscope and Energy-Dispersive $\mathrm{X}$ - ray spectroscopy (SEM 
- EDX). SEM-EDX was described extensively in Brodowski et al. (2005). This chemical microanalysis techniques equipped with SEM allow X-ray emitted from sample to be detected during the bombardment by an electron beam, which results in that the elemental composition of the target analytes can be characterized. With this technique 6 dominant (Fe, $\mathrm{O}, \mathrm{Al}, \mathrm{Si}, \mathrm{Ca}, \mathrm{C}$ ) atoms were analysed in percentage of coverage on mineral surface (Figure 1 : a-c).

\subsubsection{X-ray fluorescence (XRF) spectroscopy}

Two sediment from Anna Bay and Maules Creek sampling sites were analysed by XRF for the elemental composition of the sediment in percentage. Techniques and instrument was described in Shackley (2010) and Shackley (2011). In brief, X-ray fluorescence (XRF) spectroscopy uses an X-ray source to eject core-shell electrons from an atom to create an excited state. The emission (X-radiation/fluorescence) from excited state of electrons has a specific characteristic wavelength/energy for each element. The fluorescence of each element is quantified into concentration (part per million) and from part per million into percentage of each element. 21 elements were analysed but only the dominant elements were reported in this study.

\subsection{Statistical Analysis}

\subsubsection{Sorption of DOC fractions}

In order to identify if any DOC fractions sorb on minerals, linear regression model in Rstudio (version 1.2.5001) was used to predict the sorption of the 6 DOC fractions over a range of mineral mass (as explanatory) of the 3 minerals. 432 systems (24 samples, 3 minerals and 6 DOC fractions) were generated. Each system has the sorption (as mean response) of a DOC fraction (it could be either HOC or BP or HS or BB or LMWN or LMWA) over a range of mineral mass for a sample. From the linear model, post-hoc tests (Lenth, 2018) on the emmeans package (Version: 1.4.2), called emmean test, was used to test whether the predicted sorption from the linear regression model was statistically significant. Statistical significance can be measured by looking at the confidence interval (with confidence level of 95\%) obtained from the emmean test. Bonferroni method was used for confidence level adjustment and if any experimental systems with confidence interval $(\mathrm{Cl})$ range that includes zero, it can be statistically concluded that no sorption is observed.

\subsubsection{HS aromaticity and molecular weight and field DOC concentration}

In order to investigate if HS aromaticity and molecular weight and DOC concentration are correlated, a linear regression model was fitted to the field DOC concentration and HS aromaticity and molecular weight. The model is assumed to have segmented relationship in the linear predictor and to identify the segmented relationship "Segmented" package (version 1.0-0) in Rstudio (version 1.2.5001) was used. First, linear regression model was run. Then the model is fitted with segmented function to derive the "Break point" estimate with a statistical summary.

\subsubsection{Controlling factors on HS sorption}

In order to investigate the controlling factors on HS sorption, a tweedie generalized linear model (glm) was used. History graph of HS sorption (as response in the model) was found right skewed and this violates the linear assumption. To obtain the normal distribution of this 
response, tweedie glm was used where tweedie function will find the optimum variance power for the model to generate normal distribution of the response. This results in that fixed effect tweedie gIm was developed using 11 data set as explanatory variables including sites, mineral types (Iron Oxides, Calcite and Quartz) and mineral mass as well as situ data including sample depth, dissolved oxygen (DO), EC, $\mathrm{pH}, \mathrm{DOC}$ concentration, dissolved $\mathrm{Fe}^{2+}, \mathrm{HS}$ aromaticity and molecular weight.

Four variables including site, mineral type, HS aromaticity and molecular weight were treated as categorical explanatory variables while 7 variables including mineral mass, sample depth, dissolved oxygen, $\mathrm{EC}, \mathrm{pH}, \mathrm{DOC}$ concentration and dissolved $\mathrm{Fe}^{2+}$, were treated as continuous explanatory variables.

Any negative HS sorption value was removed as the log transformation of HS sorption required positive values. Any missing value was removed by applying na.omit function in Rstudio 1.2.5001, resulting in a set of 432 data points. In order to check for the assumption of constant variance and normality, each explanatory variable was fitted to a simple linear model using HS sorption as the response variable. This resulted in residual Vs fitted, Q-Q, Scale-location and residuals Vs leverage plots for each explanatory variable.

Multicollinearity of the explanatory could directly affect the model power in prediction, therefore it is important to minimize this effect by checking and removing the collinear variables. To assess this, variance inflation factors (VIFs) value was used to detect if the variables used displays a strong correlation with any other variable which may decrease the power of the model. Some studies suggested VIF with <10 (Abollino et al., 2003). However, to reassure collinearity issue, VIF less than 4 was used and this threshold was adopted by many studies such as Nassif et al. (2012) , Aranda et al. (2012) and (Ayadi and Ellouze, 2015). Two of the input explanatories (sites and $\mathrm{pH}$ ) were excluded because the two variables have multicollinearity with other explanatory variables. Site was first removed, followed by $\mathrm{pH}$ after rerunning the code. The remaining variables have VIFs less than 4.

After VIFs test, all explanatory variables were entered into an equation, called, full model, which includes the remaining 3 categorical explanatory variables (minerals types, HS aromaticity and HS molecular weight and 6 continuous explanatory variables (mineral mass, sample depth, dissolved oxygen, EC, DOC concentration and dissolved $\mathrm{Fe}^{2)}$ ).

Then full model was analysed with backward selection using the drop1() function test in Rstudio (version 1.2.5001). The function identified Akaike Information Criteria or AIC value. The explanatory variable with the lowest AIC value was deleted because the function justified that the removed variable did not contribute to the overall regression equation (Rubinstein et al., 2013). In this study, based on drop1() test, no explanatory variable was removed from the full model.

The final model can be interpreted in two ways depending on categorical or continuous explanatory variables. If we predict HS sorption based on 3 minerals (Iron Oxides, Calcite and Quartz), we will compare HS sorption between the 3 minerals because minerals are categorized as categorical explanatory variables. For example, a 1 unit change in categorical Iron Oxide, there will be X\% of HS sorption higher/lower than the HS sorption on Calcite/Quartz sand. For continuous explanatory variable, 1 unit change in continuous variable will directly command the changes of HS sorption. 
Sampling Sites, NSW, Australia

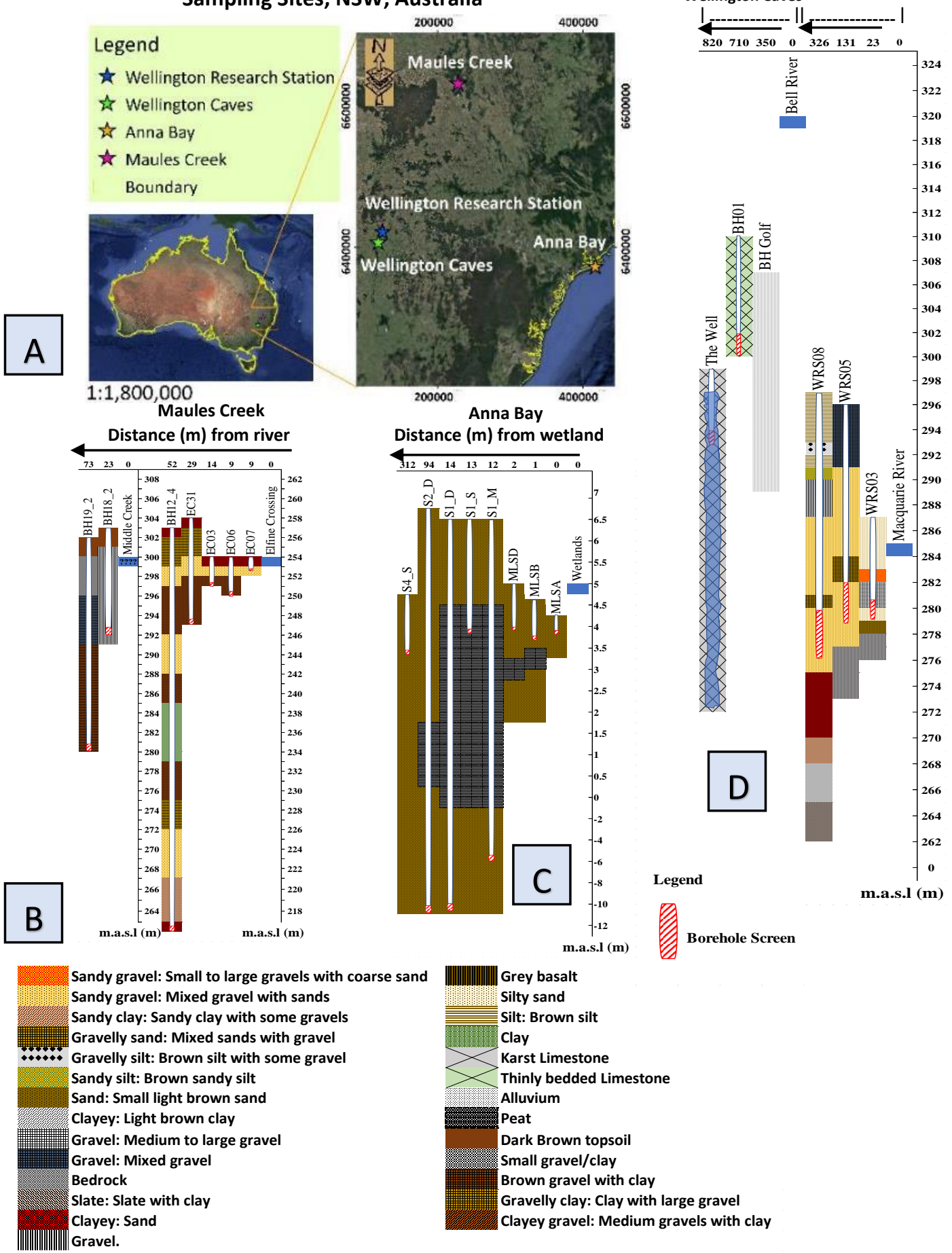

Figure 1: A: 3 Sampling sites locating in New South Wales, Australia. B, C and D: Cross Section of groundwater lithology where the samples were taken from based on the distance away from river (Elfin Crossing at Maules Creek with pink star symbol and Bell River Wellington Caves with green star and Macquarie River Wellington Research Station with blue star on the map) and wetland (Anny Bay with oranges collar on the map) and the depth in meter above sea level (m.a.s.l). Due to no lithological information, EC3, EC6, EC7 and EC31 are assumed to have similar soil composition as its nearby BH 12_4. Cross Section of groundwater lithology shows sediment composition and the borehole depth below ground surface which locates with the distance in meter away from surface river (the distance is not linear). The depth where the samples were taken were at the screen depth below ground surface except The Well, $\mathrm{BH} 01$ and $\mathrm{BH}$.Golf which were used based on the depth of the groundwater level taken from Keshavarzi (2017). On Australia map, $X$ and $Y$ axis show latitude (Southward) and longitude (Eastward) coordinates respectively which is associated with Universal Transverse Mercator in Zone $55 S$ (Maules Creek) and Zone 56S (Wellington Research Station, Wellington Caves and Anna Bay). Australia and sampling sites maps are derived from google earth 2018. 
(a) Iron oxide coated sand (Iron oxides)
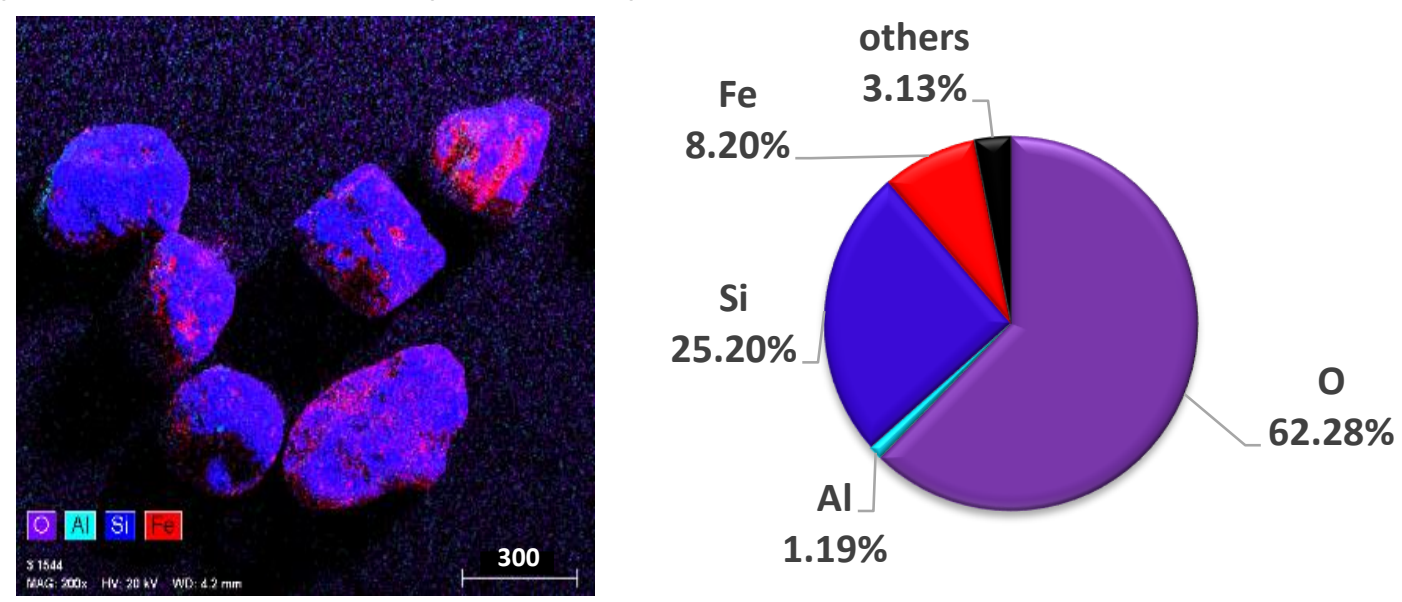

(b) Calcium carbonate (Calcite)
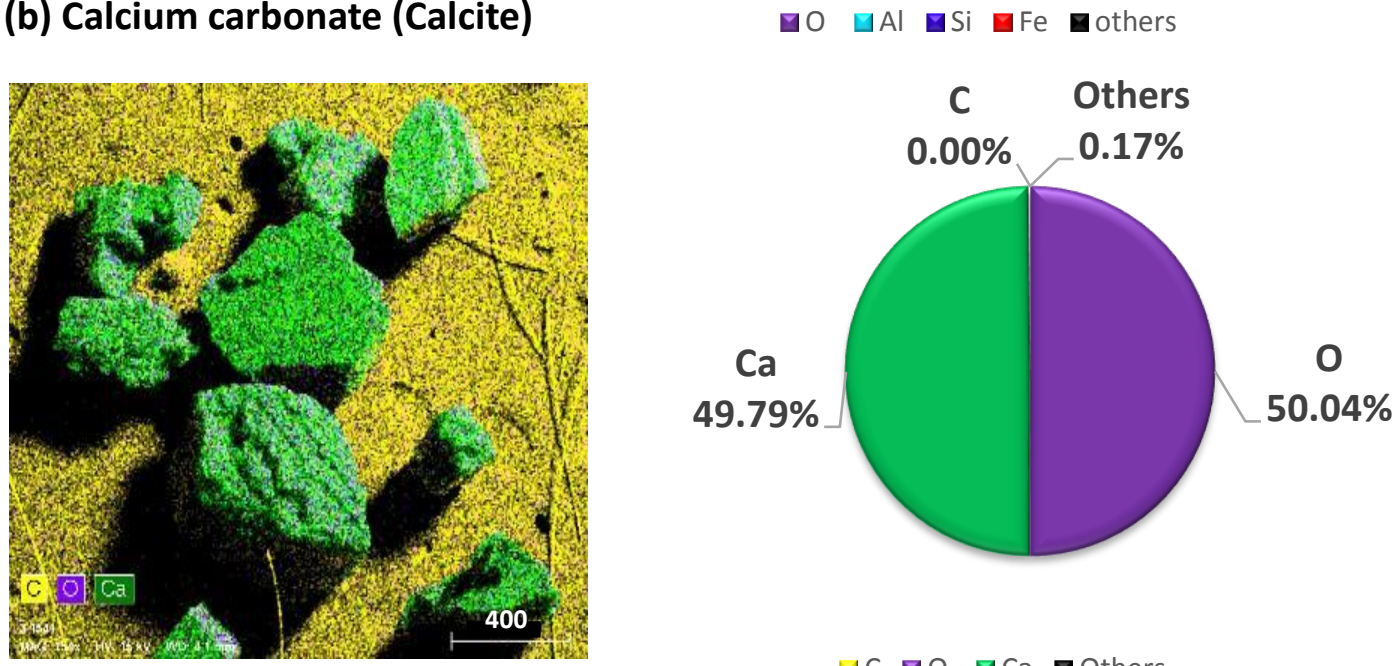

\section{(C) Quartz sand (Quartz)}
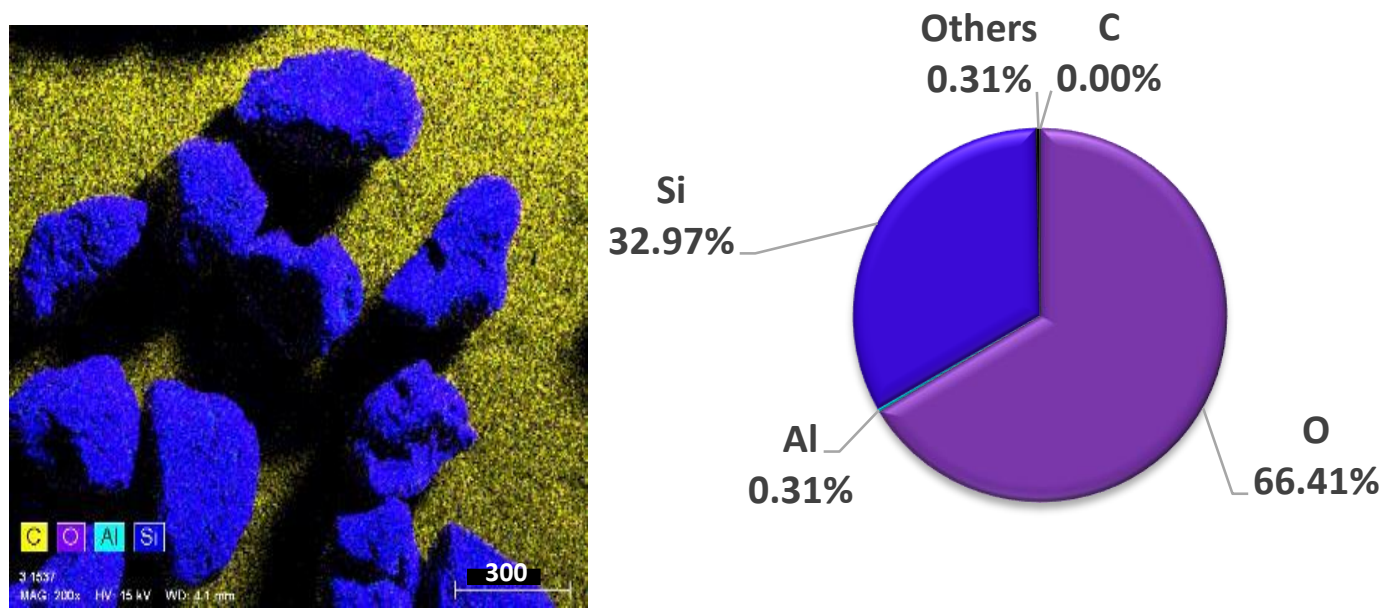

$\square C \square O \quad \mathrm{Al}$ 口Si $\mathbf{0}$ Others

Figure 2: (a-c) Scanning Electron Microscope and Energy-dispersive X-ray spectroscopy (SEM-EDX) images of mineral particles used in this study showing surface morphology and inorganic chemical distribution on iron oxide coated sand, calcium carbonate and quartz (In this paper, these minerals are referred as a) Iron Oxides; b) Calcite and c) Quartz, respectively). The pie chart next to the images are corresponding to the percentage coverage of elements appearing on mineral surface. 


\section{Results}

\subsection{Mineral characterization and chemical composition (XPS)}

Table 1 below indicated that oxygen is the highest fractions of the total elemental composition. It was found that oxygen and $\mathrm{Si}$ on Quartz decreases after being coated with iron. After submerging iron oxide solution to $Q S$, the surface of $Q S$ is about $8 \%$ covered by Fe. No $C$ was detected on the surface of the 3 minerals.

Table 1: Summary of the percentage elemental composition on the 3 mineral surfaces by SEM - EDM.

$\begin{array}{lcccccccc} & \mathbf{O} & \mathbf{A l} & \mathbf{S i} & \mathbf{F e} & \mathbf{C} & \mathbf{C a} & \text { Others } & \text { Total } \\ \text { Iron Oxides } & 62.28 & 1.19 & 25.2 & 8.2 & 0 & 0 & 3.13 & 100 \\ \text { Calcite } & 50.04 & 0.16 & 0 & 0 & 0 & 49.79 & 0 & 100 \\ \text { Quartz } & 66.62 & 0.31 & 33.08 & 0 & 0 & 0 & 0 & 100\end{array}$

\subsection{X-ray fluorescence (XRF) spectroscopy}

X-ray fluorescence (XRF) spectroscopy reported that the dominant elemental fraction at Anna Bay and Maules Creek are $\mathrm{SiO}_{2}$ (mean percentage is around 94 and $72 \%$, respectively). Elements at Maules Creek are more heterogenous (in terms percentage fractions) than Anna Bay. At Maules Creek, higher mean percentage of $\mathrm{Fe}_{2} \mathrm{O}_{3}$ than that of Anna Bay (around 3.15\% and $0.20 \%$, respectively). See Table 2 below.

Table 2: Showing the elemental composition (percentage) found in sediments from Maules Creek and Anna Bay sampling sites. Only 5 elements (percentage) were included as other elements were not dominants.

\begin{tabular}{|l|c|c|c|c|c|}
\hline \multirow{2}{*}{ Sample } & $\mathbf{N a}_{\mathbf{2}} \mathbf{O}$ & $\mathbf{A l}_{2} \mathbf{O}_{\mathbf{3}}$ & $\mathbf{S i O}_{\mathbf{2}}$ & $\mathbf{F e}_{\mathbf{2}} \mathbf{O}_{\mathbf{3}}$ & $\mathbf{K}_{\mathbf{2}} \mathbf{O}$ \\
\cline { 2 - 6 } & $\mathbf{( \% )}$ & $\mathbf{( \% )}$ & $\mathbf{( \% )}$ & $\mathbf{( \% )}$ & $\mathbf{( \% )}$ \\
\hline Elfin & 3.42 & 12.31 & 72.13 & 3.04 & 3.51 \\
\hline Middle Creek & 3.19 & 12.28 & 71.84 & 3.26 & 3.68 \\
\hline Anna 1 & 0.24 & 1.22 & 93.79 & 0.20 & 0.45 \\
\hline Anna 2 & 0.23 & 1.31 & 93.69 & 0.20 & 0.49 \\
\hline
\end{tabular}

\subsection{Groundwater DOC fraction concentration}

Field sample DOC concentration (Supplementary Table 2) varies among the 3 sites with a range of approximately $0.35-15.63 \mathrm{mg} \mathrm{L}^{-1}$ (Table 3 ), in which Anna Bay samples were found to have highest mean DOC concentration $\left(7.87 \pm 4.26 \mathrm{mg} \mathrm{L}^{-1}\right)$ followed by samples from Wellington $\left(2.01 \pm 2.71 \mathrm{mg} \mathrm{L}^{-1}\right)$ and from Maules Creek $\left(0.97 \pm 0.30 \mathrm{mg} \mathrm{L}^{-1}\right)$.

DOC concentration at Macquarie river $\left(8.53 \mathrm{mg} \mathrm{L}^{-1}\right)$ was found to be the highest of all surface water samples (Elfin Crossing and Bell river with DOC of 1.42 and $1.74 \mathrm{mg} \mathrm{L}^{-1}$, respectively) and higher than adjacent aquifers DOC, WRS03 and WRS05, presumed to be affected by Macquarie river recharge (Graham et al., 2015d). The samples with low DOC concentration were found from the Kast aquifers (at Wellington) including BH.Golf and BHO1 (1.42 and 1.74 $\left.\mathrm{mg} \mathrm{L}^{-1}\right)$ and $\mathrm{BH}_{12}$ 4 and $\mathrm{BH} 19 \_2$, fracture rock and alluvial aquifers at Maules Creek, were found to be quite low ( 0.66 and $0.60 \mathrm{mg} \mathrm{L}^{-1}$, respectively).

The hydrophilic fraction (CDOC) was the dominant DOC fraction (62-97\%) compared to HOC. While HS alone comprises $13-70 \%$ of total DOC, no LMWA was found in the samples. 
Table 3: Summary of groundwater DOC fraction concentration (as a percentage and concentration in $\mathrm{mg} \mathrm{L}^{-1}$ ). $D O C=H O C+C D O C$ and CDOC $=B P+H S B B+L M W A+L M W N$

$\begin{array}{ccccccc}\text { No } & \text { Variable } & \begin{array}{c}\text { Min } \\ \left(\mathbf{m g ~ L}^{-1}\right)\end{array} & \begin{array}{c}\text { Max } \\ \left(\mathbf{m g ~ L}^{-1}\right)\end{array} & \begin{array}{c}\text { Mean } \\ \left(\mathbf{m g ~ L}^{-1}\right)\end{array} & \begin{array}{c}\text { Median } \\ \left(\mathbf{m g ~ L}^{-1}\right)\end{array} & \begin{array}{c}\text { SD } \\ \left(\mathbf{m g ~ L}^{-1}\right)\end{array} \\ 1 & \text { DOC } & 0.35 & 15.63 & 3.62 & 1.33 & 4.12 \\ 2 & \text { HOC } & 0.05 & 2.41 & 0.52 & 0.22 & 0.64 \\ 3 & \text { CDOC } & 0.26 & 13.4 & 3.10 & 1.06 & 3.57 \\ 4 & \text { BP } & 0.00 & 0.18 & 0.03 & 0.01 & 0.05 \\ 5 & \text { HS } & 0.09 & 10.3 & 2.16 & 0.63 & 2.69 \\ 6 & \text { BB } & 0.03 & 1.95 & 0.49 & 0.18 & 0.57 \\ 7 & \text { LMWA } & 0.00 & 0.00 & 0.00 & 0.00 & 0.00 \\ 8 & \text { LMWN } & 0.07 & 1.13 & 0.42 & 0.25 & 0.33 \\ \text { No } & \text { variable } & \text { Min (\%) } & \text { Max (\%) } & \text { Mean (\%) } & \text { Median (\%) } & \text { SD (\%) } \\ 1 & \text { DOC } & 100 & 100 & 100 & 100 & 0 \\ 2 & \text { HOC } & 3 & 38 & 18 & 17 & 9 \\ 3 & \text { CDOC } & 62 & 97 & 82 & 83 & 9 \\ 4 & \text { BP } & 0 & 7 & 1 & 1 & 2 \\ 5 & \text { HS } & 13 & 70 & 49 & 51 & 16 \\ 6 & \text { BB } & 6 & 25 & 14 & 13 & 4 \\ 7 & \text { LMWA } & 0 & 0 & 0 & 0 & 0 \\ 8 & \text { LMWN } & 7 & 38 & 18 & 17 & 8\end{array}$

\subsection{HS chemical characteristics and DOC of field samples}

Apart from HS concentration, LC-OCD further analysed the aromaticity and molecular weight of HS. A summary in Supplementary Table 2 indicated that Anna Bay samples carried the highest HS aromaticity $\left(3.69-7.08 \mathrm{~L} \mathrm{mg}^{-1} \mathrm{~m}^{-1}\right)$, followed by surface water aromaticity range only $\left(2.13-3.47 \mathrm{~L} \mathrm{mg}^{-1} \mathrm{~m}^{-1}\right)$. Groundwater samples located close to surface water including WRS03 and WRS05 (connected to Macquarie River), EC03, EC06 and EC07 (nearby Elfin Crossing) and BH18_2 (nearby Middle Creek $^{1}$ ) also had higher aromaticity when compared to samples further from surface water including The Well, BH01 and BH.Golf (Bell River), EC31 and BH12_4 (Elfin Crossing) and BH19_2 (Middle Creek).

Samples from quartz sand environment at Anna Bay sampling site contain the highest HS molecular weight range (512-904 $\mathrm{g} \mathrm{mol}^{-1}$ ), followed by surface water samples (269-581 g $\mathrm{mol}^{-1}$ ) of which the highest molecular weight was observed at Macquarie river. Overall, HS aromaticity increased with its molecular weight except for BH18_2.

There is a strong significant relationship between DOC concentration and HS aromaticity $(\mathrm{p}=$ 3.34E-16, with adjusted $R^{2}$ of 0.6107$)$. We also observe a weaker linear relationship between DOC concentration and HS molecular weight $(p=2.32 E-09)$ with adjusted $R^{2}$ of 0.3929 (Linear regression plot and statistical summary is in Supplementary Figure 1).

\footnotetext{
${ }^{1}$ Middle Creek analysis in this study but assumed to have higher aromaticity as it locates close to Elfin Crossing.
} 


\subsection{Sorption of DOC fractions}

A batch experiment where groundwater and surface samples were exposed to a range of minerals and masses allowed us to obtain sorbed amount of DOC fractions. By looking at only $10 \mathrm{~g}$ mass system in Iron Oxides, the sorption indicated that HS sorption was found to be the highest, followed by BB, HOC, LMWN, BP and LMWA with the means of 2.31E-02, 4.78E-03, 2.57E-03, 1.44E-03, 7.79E-04 and 3.28E-05 mg, respectively (Supplementary Table 3).

Observed HS sorbs to different minerals to different extents. Sorption at $10 \mathrm{~g}$ mass systems range from about $0-4.4 \mathrm{E}+01 \%, 1.17 \mathrm{E}+00-2.1 \mathrm{E}+01 \%$ and $2.65 \mathrm{E}+00-1.27 \mathrm{E}+01 \%$ (Iron Oxides, Calcite and Quartz systems, respectively) to total DOC found in the samples with the mean of $1.18 \mathrm{E}+01 \quad(\mathrm{SE}=9.53), 8.94 \mathrm{E}+00 \quad(\mathrm{SE}=4.88), \quad 5.76 \mathrm{E}+00 \quad(\mathrm{SE}=3.52)$, respectively (Supplementary Table 5).

However, in order to figure out which fraction sorbs or does not, linear regression model is used to fit the sorption for all 6 DOC fractions in all 24 samples and 3 mineral types over the mass range $(0-10 \mathrm{~g})$. After the fitting, "emmeans" test is used to identify if the predicted sorption of each fraction is statistically significant by basing on the confidence interval (Cl) with 95\% confidence level. It is found that not all DOC fractions have sorption on to a range of mass and minerals (Figure 3). HS are the dominant fraction that sorbs for most water samples.

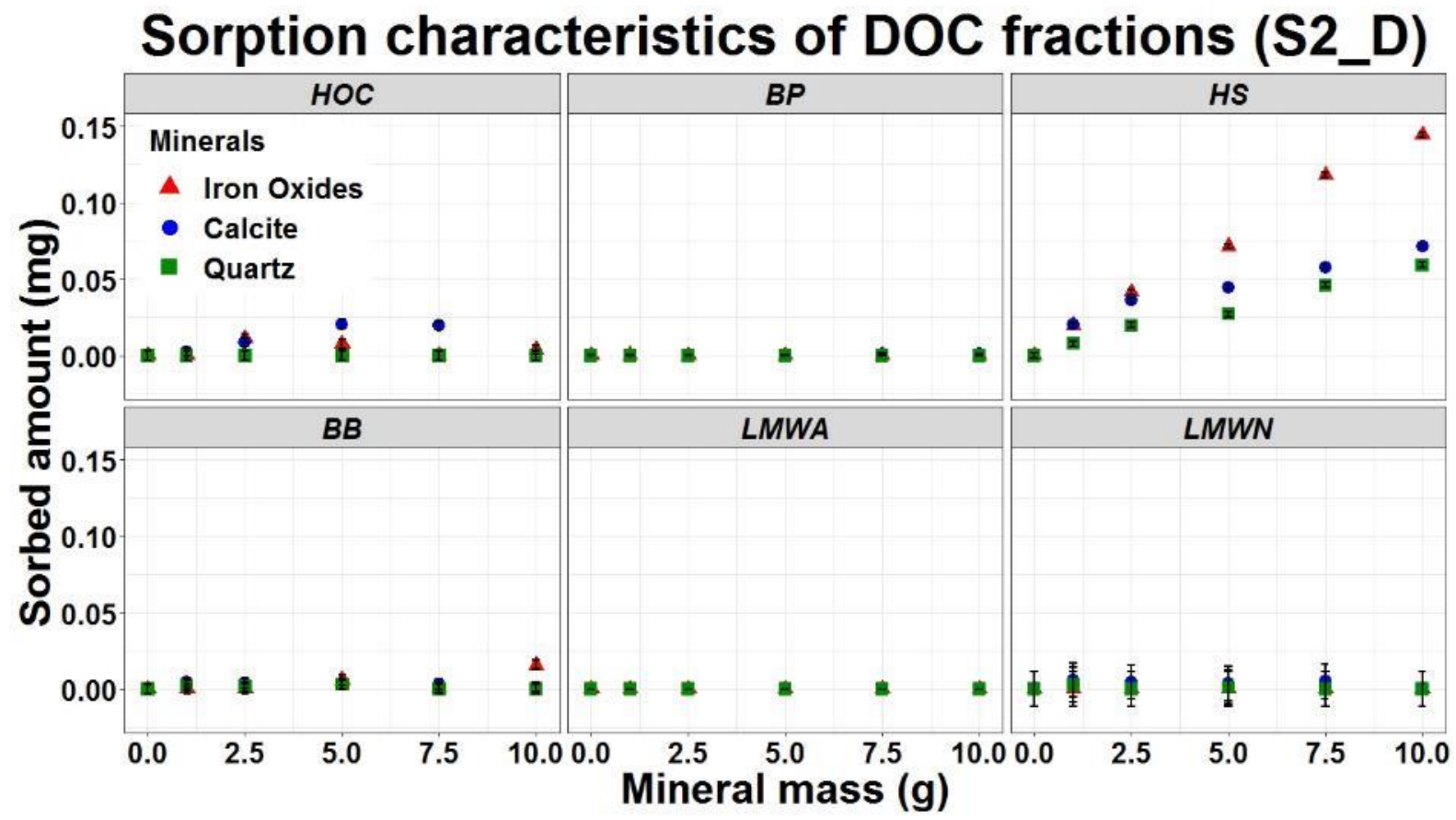

Figure 3: The comparison of sorbed amount of DOC fractions ( $\mathrm{mg}$ ) over a range of mass $(\mathrm{g})$ and minerals of Anna Bay sample (S2_D). $\triangle O$ represents the sorbed DOC fraction in the Iron Oxides, Calcite and Quartz systems, respectively. Other sample plots for all other groundwater samples with DOC fractions sorption are in Supplementary Figure 2).

The summery of total sorption count of 432 systems ( 24 samples X 3 minerals X 6 DOC fractions) in Table 4 shows that the number of counts of HS sorption is more than twice as much as that of other fractions (Plots of DOC sorption are in Supplementary Figure 2). HOC and LMWN sorption count are the second highest (33\% of sorption count). 
Table 4: The summary count of sorbing DOC fractions. The "System count" includes 3 treatments (Iron Oxides, Calcite, and Quartz) of 24 samples from sampling sites (Anna Bay, Maules Creek and Wellington). The number of "Sorbed count" is based on the estimated marginal means (lower-upper $95 \%$ confidence level) by "emmeans". If the confident interval (Cl) range does not include 0 , it means that the mean HS sorption (of each DOC fraction) is significantly linearly correlated to the mineral mass and sorption is observed. (Details of all "Emmean" test results for all samples and minerals is in Supplementary Table 4).

$\begin{array}{cccc}\text { DOC fraction } & \text { Total count } & \text { Sorbed count } & \text { Total sorbed } \\ \text { HOC } & 72 & 24 & 33 \% \\ \text { BP } & 72 & 12 & 17 \% \\ \text { HS } & 72 & 61 & 85 \% \\ \text { BB } & 72 & 19 & 26 \% \\ \text { LMWA } & 72 & 1 & 1 \% \\ \text { LMWN } & 72 & 24 & 33 \%\end{array}$

\subsection{HS sorption and DOC concentration}

HS is one of hydrophilic DOC fractions and HS sorption was observed to be related to the concentration of DOC found in the nature (Figure 4). HS sorption results indicated that sorbed amount of HS was observed to have a positive increase with groundwater DOC concentration (Figure 4). Adjusted $R^{2}$ of 0.7229 (Iron Oxides), 0.7727 (Calcite) and 0.8382 (Quartz) with pvalues of $9 \mathrm{E}-08,1 \mathrm{E}-08$ and $2 \mathrm{E}-10$, respectively, indicate that there is strong linear relationship fitting to the observed data shown in Figure 4 (Supplementary Table 6). Figure 4 shows that the lowest sorption was found for the BH.Golf sample and the highest sorption was found for the S2_D sample at around 1.44E-01, 7.15E-02 and 5.92E-02 mg for Iron Oxides, Calcite and Quartz, respectively.

Another point to note is that the sizes of the points in Figure 4 depicted that $88 \%$ of samples from Anna Bay contains the highest DOC concentrations while the lowest observed DOC concentrations were found in BH.Golf, BHO1 and The Well from Wellington and BH19_2, BH12_4 and EC31 from Maules Creek.

In addition to the HS sorption limits, the sorbed amount was also found to increase with groundwater DOC concentration (Figure 4). Adjusted $\mathrm{R}^{2}$ of 0.7229 (Iron Oxides), 0.7727 (Calcite) and 0.8382 (Quartz) with p-values of 9E-08, 1E-08 and 2E-10, respectively, indicate that there is strong linear relationship fitting to the observed data shown in Figure 4 (Supplementary Table 7). Figure 4 shows that the lowest sorption was found for the BH.Golf sample and the highest sorption was found for the S2_D sample at around 1.44E-01, 7.15E02 and 5.92E-02 mg for Iron Oxides, Calcite and Quartz, respectively. 


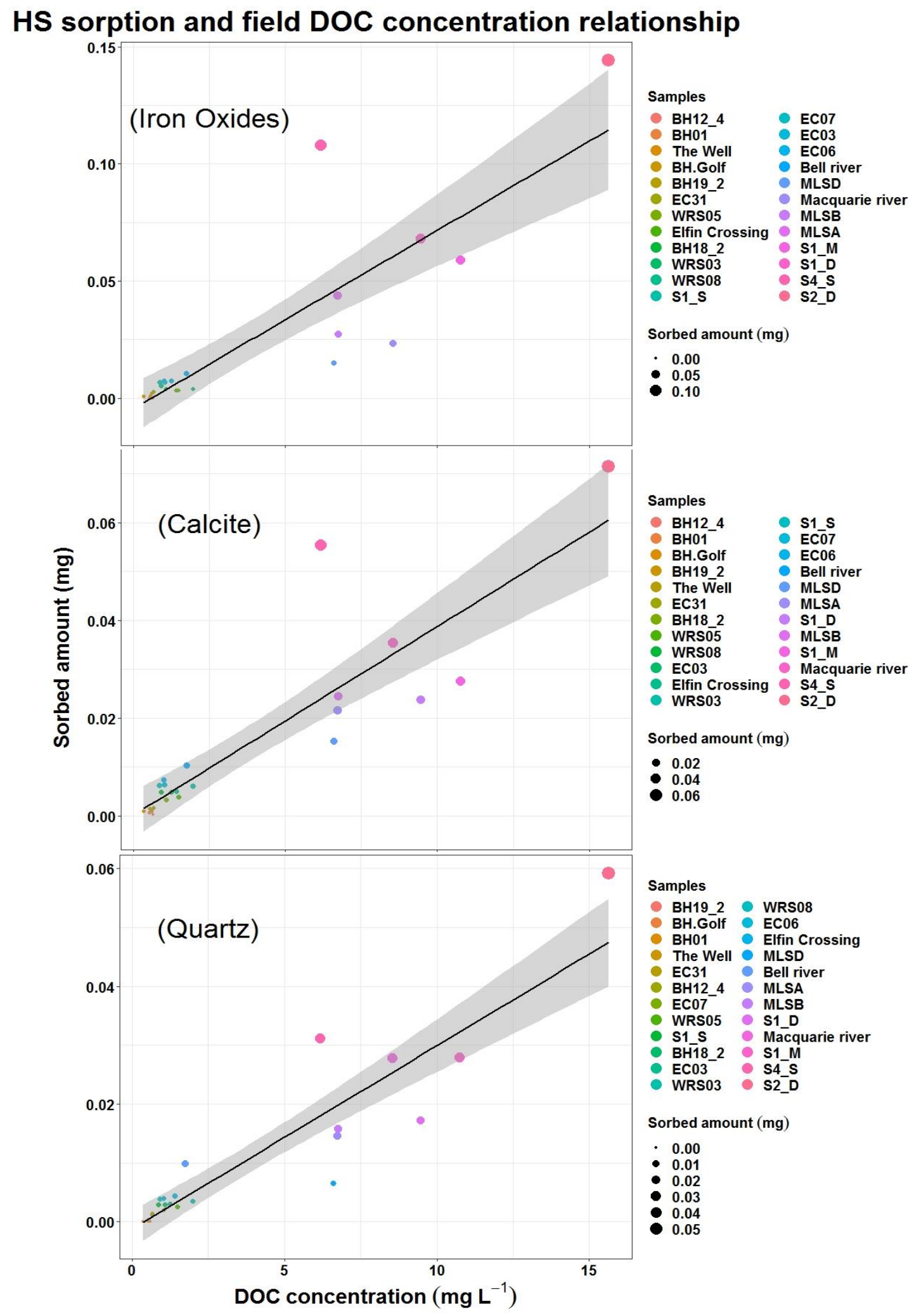

Figure 4: Linear correlation of HS sorption $(\mathrm{mg})$ and DOC concentration ( $\mathrm{mg} \mathrm{L}^{-1}$ ) of groundwater and surface water samples. The data from $10 \mathrm{~g}$ mass system was used. The linear correlation is explained by adjusted $\mathrm{R}^{2}$ of 0.7229 (Iron Oxides), 0.7727 (Calcite) and 0.8382 (Quartz) with P-values of 8.76E-08, 9.65E-09 and 2.22E-10, respectively. The legend with coloured dots refers to all samples which were ordered based on the lowest to the highest sorbed amount of HS. The black dots with different size refer to the range of sorbed amount of HS (mg) which corresponding to the size of the coloured dots in the plots (larger size means larger DOC concentration). 


\subsection{HS sorption and aromaticity and molecular weight characteristics}

In this study, field HS aromaticity and molecular weight ranged from 0.37-7.08 $\mathrm{L} \mathrm{mg}^{-1} \mathrm{~L}^{-1}$ and 100 - $904 \mathrm{~g} \mathrm{~mol}^{-1}$, respectively. Based on site, samples from Anna Bay contain higher HS aromaticity (3.69-7.08 $\left.\mathrm{L} \mathrm{mg}^{-1} \mathrm{~L}^{-1}\right)$ and molecular weight $\left(512-904 \mathrm{~g} \mathrm{~mol}^{-1}\right)$ than those found in the other groundwater and surface water samples where the aromaticity ranges around 0.37 - $3.50 \mathrm{~L} \mathrm{mg}^{-1} \mathrm{~L}^{-1}$ and molecular weight is between $110 \mathrm{~g} \mathrm{~mol}^{-1}$ and $675 \mathrm{~g} \mathrm{~mol}^{-1}$ (Supplementary Table 7)

At Wellington, HS sorption and its aromaticity and molecular weight decrease in groundwater samples with distance from surface water sources. The size of the coloured points on Figure 5 illustrated that Macquarie River has higher aromaticity and molecular weight than those found in the nearby boreholes (WRS03, WRS05 and WRS08). The difference is approximately $48 \%, 80 \%$ and $66 \%$, respectively, for aromaticity and $33 \%, 170 \%$ and $61 \%$, respectively, for molecular weight. This is also true for Bell River which has higher aromaticity and molecular weight than its nearby groundwater samples (BH.Golf, $\mathrm{BH} 01$ and The Well), which is about $14 \%, 283 \%, 119 \%$, respectively, for aromaticity and $135 \%, 475 \%$, nd $73.4 \%$, respectively for molecular weight higher.

Elfin Crossing surface water also has higher aromaticity than what was found in the adjacent bores, EC07, ECO6 and ECO3 which is approximately 14\%, 15\%, 24\% higher, respectively. Deeper samples including BH12_4 $\left(0.67 \mathrm{~L} \mathrm{mg}^{-1} \mathrm{~L}^{-1}\right), \mathrm{BH} 19 \_2\left(0.87 \mathrm{~L} \mathrm{mg}^{-1} \mathrm{~L}^{-1}\right)$ and EC31 $\left(\mathrm{L} \mathrm{mg}^{-1}\right.$ $\mathrm{L}^{-1}$ ) which are further away from surface water have low aromaticity when compared to shallow and river-adjacent samples. Other samples have similar aromaticity $\left(1.6-1.83 \mathrm{~L} \mathrm{mg}^{-1}\right.$ $\mathrm{L}^{-1}$ ). BH12_4, BH19_2 and EC31 have the lowest molecular weight, whilst the molecular weight of Elfin Crossing is more than half to 3 times lower than the molecular weight of HS in nearby bores.

When aromaticity and molecular weight are plotted against HS sorption extent, they rule out a linear correlation and show a threshold reponse (Figure 5). By assuming that the two variables are linearly correlated, segmented linear regression of HS sorption was used for fitting. The correlation rules out a positive linear correlation of HS sorption on both aromaticity molecular weight for all mineral types. When applying this statistical function, it provides a break point to this relationship. For aromaticity, it is $3.06 \mathrm{~L} \mathrm{mg}^{-1} \mathrm{~L}^{-1}$ (Iron Oxides), $2.07 \mathrm{~L} \mathrm{mg}^{-1} \mathrm{~L}^{-1}$ (Calcite) and $1.976 \mathrm{~L} \mathrm{mg}^{-1} \mathrm{~L}^{-1}$ (Quartz) and $410 \mathrm{~g} \mathrm{~mol}^{-1}$ (Iron Oxides), $389 \mathrm{~g} \mathrm{~mol}^{-1}$ (Calcite) and $364 \mathrm{~g} \mathrm{~mol}^{-1}$ (Quartz) for molecular weight.

Coastal sand and surface water samples with higher aromaticity and molecular weight showed higher HS sorption. Sorption break point and slope in iron oxide experiments are found to be higher than those found in calcite and quartz experiments (statistical summary is provided in supplementary Table 8 ). However, the overall $R^{2}$ values reveals stronger correlation for aromaticity compared to molecular weight. 


\section{HS sorption and HS aromaticity}
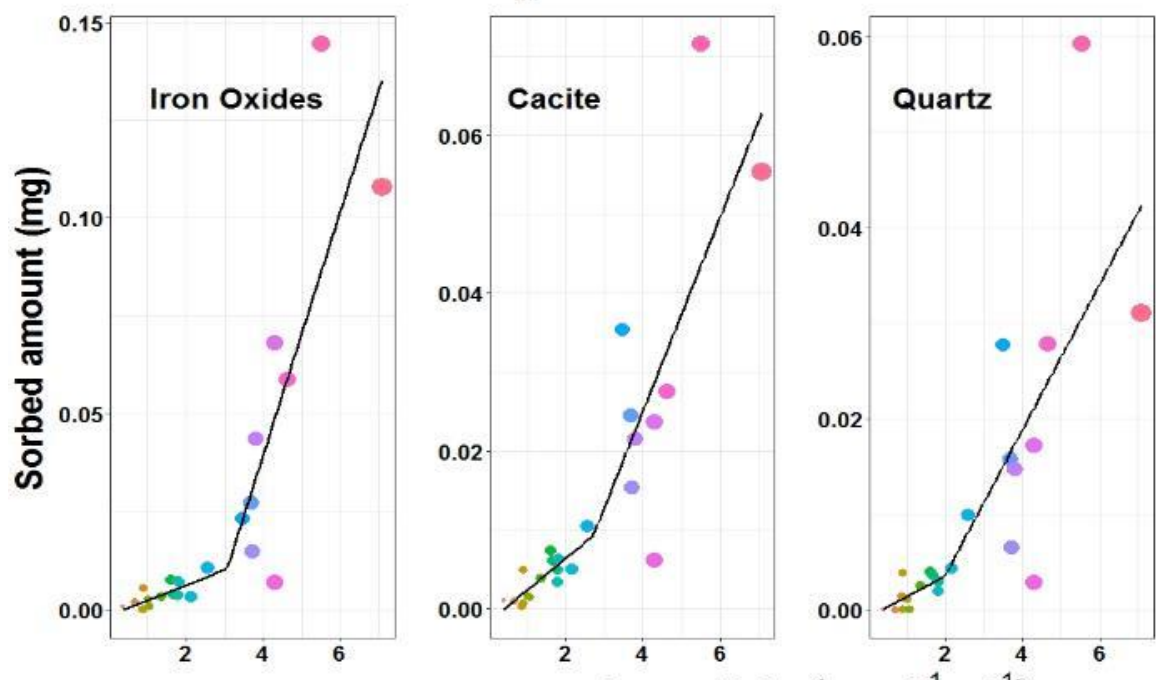

Aromaticity Range

2
$-\quad 4$
-6

Samples

BH.Golf EC07

BH19_2 Elfin Crossing

BH12_4 Bell river

WRS08 Macquarie river

BH01 MLSB

EC31 MLSD

The Well MLSA

WRS05 S1_D

EC06 S1s

WRS03 S1_M

EC03 S2_D

BH18_2 S4_S

Aromaticity $\left(\mathrm{L} \mathrm{mg}^{-1} \mathrm{~m}^{-1}\right.$ )

\section{HS sorption and HS Molecular weight}
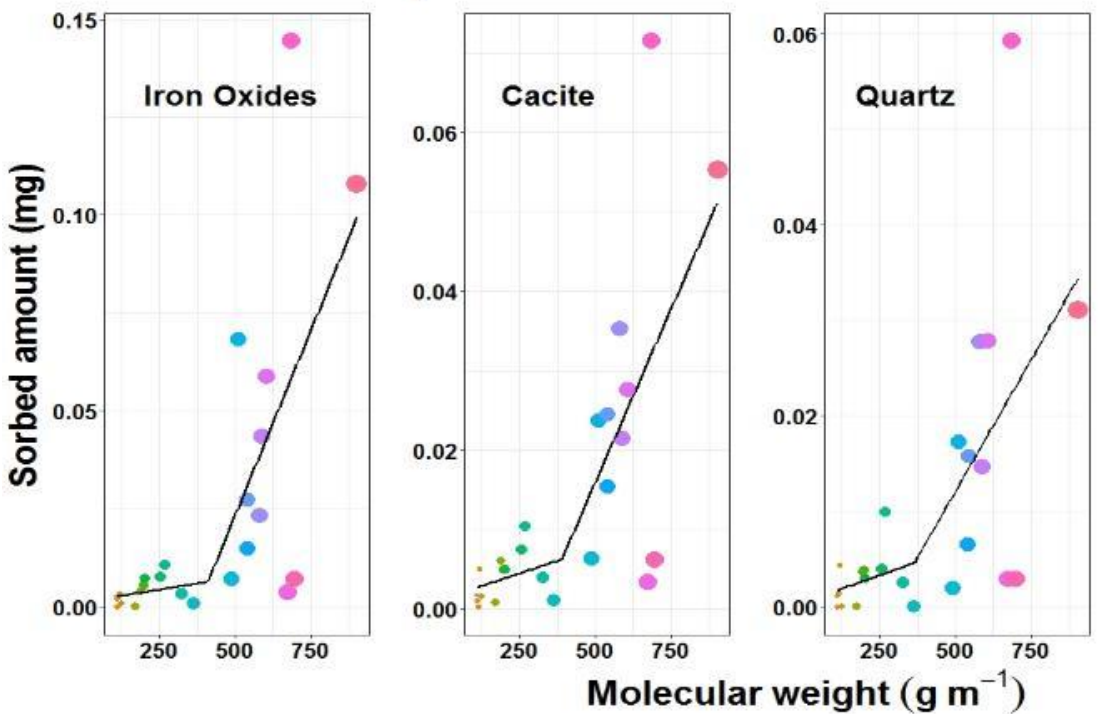

Molecular weight Range

- 250

- 500

Samples

$\begin{array}{ll}\text { EC31 } & \text { BH.Golf } \\ \text { BH19_2 } & \text { EC07 }\end{array}$

BH12_4

s1

Elfin Crossing

The Well

BH01

C WRS03

- WRS08

EC03

EC06

Bell river

WRS05

MLSD

- MLSB

Macquarie river

MLSA

S1_M

BH18_2

S2_D

s1s

s4_s

Figure 5: Comparing of HS sorption (mg) and HS characteristics in the samples from the 3 sampling sites. With degree of freedom of 20, 76 (Iron Oxides), 74 (Calcite), 60 (Quartz) and 42 (Iron Oxides), 47 (Calcite), 34\% (Quartz) explaining the relationship of sorbed HS and aromaticity and molecular weight, respectively. The samples listed in the legend were arranged in the order of how aromaticity the samples have. It starts from the lowest aromaticity at BH.Golf and increases to the highest found in S4_S. Like aromaticity legend, the molecular weight legend indicates that the molecular weight starts from the lowest at EC31 and increases to the highest found in S4_S. Black dots refer to the range of aromaticity (in aromaticity legend) and molecular weight (in molecular weight legend) which corresponding to the size of the dot in the plots.

The Ultraviolet Detector (UVD) analysis by LC-OCD provided the Spectral Absorbance Coefficients (SAC) information of HS, BB and LMWN. This information refers to the aromaticity of $B B$ and LMWN. From 24 water samples, the mean SAC of HS $(4.70 E+01)$ was found to be higher than that of BB (1.34E+01) and LMWN (2.50E+01) see Supplementary Table 9).

\subsection{Factor controlling natural HS sorption}

It has been found that HS are the dominant sorbing fraction on to the 3 minerals but the driving factors on such sorption are also important to know. By accounting how nature drives 
this sorption, multiple linear regression is used to identify how HS sorption response to natural variables. The obtained model was tested for goodness of fit by using a test called Hosmer and Lemeshow test in Rstudio (version 1.2.5001) and it was found that it fails to reject the null hypothesis as the result of $\mathrm{P}$ value $=1$. In other words, the tweedie Generalized Linear Model $(\mathrm{glm})$ used is assumed to fit well with the observed data.

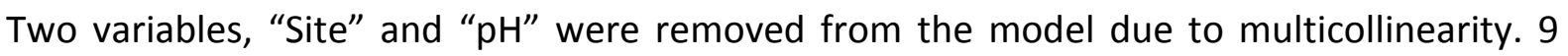
explanatory variables remained in the model (Supplementary Table 10). Mineral types (Iron Oxides, Calcite and Quartz with P-values of 4E-17, 6E-06, 7E-06, respectively), mineral mass (6E-37), sample depth (7E-15) and field HS aromaticity (category A and category B with Pvalues of $6 \mathrm{E}-0.4$ and $7 \mathrm{E}-06$ ) were found to have a statistically significant positive correlation to estimated mean $\mathrm{HS}$ sorption. Dissolved $\mathrm{Fe}^{2+}(1 \mathrm{E}-02)$ was statistically significant negatively correlated to predicted mean HS sorption. EC and field molecular weight (Category A and Category B) have positive correlations while DO has negative correlation to the predicted HS sorption. Even though they are not statistically significant with almost the same P-values (around 3E-01), they are kept in the model due to an overall model improvement.

\section{Discussion}

\subsection{HS as the dominant sorbing fraction}

Ko et al. (2005) found HS sorption increased with HS higher molecular weight and higher aromaticity. Gu et al. (1995) divided NOM into hydrophobic and hydrophilic fractions and compared their sorption extent onto iron oxide based on their molecular weights. They found that, at $\mathrm{C}$ weight basis, hydrophobic fraction sorption outweighed that of hydrophilic fraction due to higher $\mathrm{C}$ content resulting in larger size hydrophobic fraction causing higher adsorption affinity and capacity. However, at Oxygen derived organ matter weight basis, hydrophobic sorption was less than that of hydrophilic. They observed that NOM compounds are heterogenous and they are selectively preferred to sorb on minerals.

In this study, the hydrophilic fraction HS was found to be the dominant fraction of groundwater DOC, as well as the fraction showing the most sorption to mineral surfaces. The linear regression model exhibited a statistically significant positive correlation of HS sorption and DOC concentration. Similar correlation of HS sorption and HS aromaticity was also observed. Even though the model retains the variable HS molecular weight for explaining the prediction of HS sorption, HS molecular weight was not found to be statistically significant in explaining HS sorption. McKnight et al. (1992) conducted experiments of NOM sorption on hydrous aluminium and iron oxides and found that HS sorption extent did not only proportionally increased with its aromaticity but also increased with $\mathrm{O} / \mathrm{C}$ ratio content of HS. This could imply that at $C$ weight basis molecular weight could be one of the controlling factors of groundwater DOC sorption but DOC concentration and the aromaticity of DOC were found to be even more important in controlling the sorption.

Based on the LC-OCD technique of defining the molecular size of each DOC fraction, hydrophilic biopolymers (BP > 20,000 $\mathrm{g} \mathrm{mol}^{-1}$ ) is around $57-66$ times bigger in molecular size than building block $\left(300<\mathrm{BB}<350 \mathrm{~g} \mathrm{~mol}^{-1}\right)$ and about 66 times bigger than low molecular weight acids neutral (LMWN<350 $\mathrm{g} \mathrm{mol}^{-1}$ ). However, BP sorption counts (72 experimental sorption systems that DOC fraction sorption were found based on "emmeans" test earlier in Table 4) was about $35 \%$ and $62 \%$ lower than BB and LMWN, respectively. In addition, Huber et al. (2011a) claimed that in most cases BP does not display a UV signal because it does not 
have unsaturated hydrocarbon structure (no aromaticity). This indicates that BP sorption was driven by molecular weight while BB and LMWN sorption are caused by their aromaticity (as the result, the sorption of these two DOC fractions was found higher in percentage).

The Spectral Absorbance Coefficients (SAC) indicated the aromaticity coefficients of the hydrophilic fraction. Higher SAC of HS was found than that of BB and LMWN, which validated higher HS sorption than the two fractions. However, BH12_4, BH19_2 and EC31 (Maules Creek sampling site) and BH.Golf, BHO1 and The Well (Wellington sampling site) have low SAC of HS when compared to SAC of BB and LMWN. This could mean that, based on aromaticity, HS sorption might not be found in these samples, or if there is, such sorption could be a result of molecular weight effects. As previously mentioned, no HS sorption or very limited sorbed amount was observed in these samples.

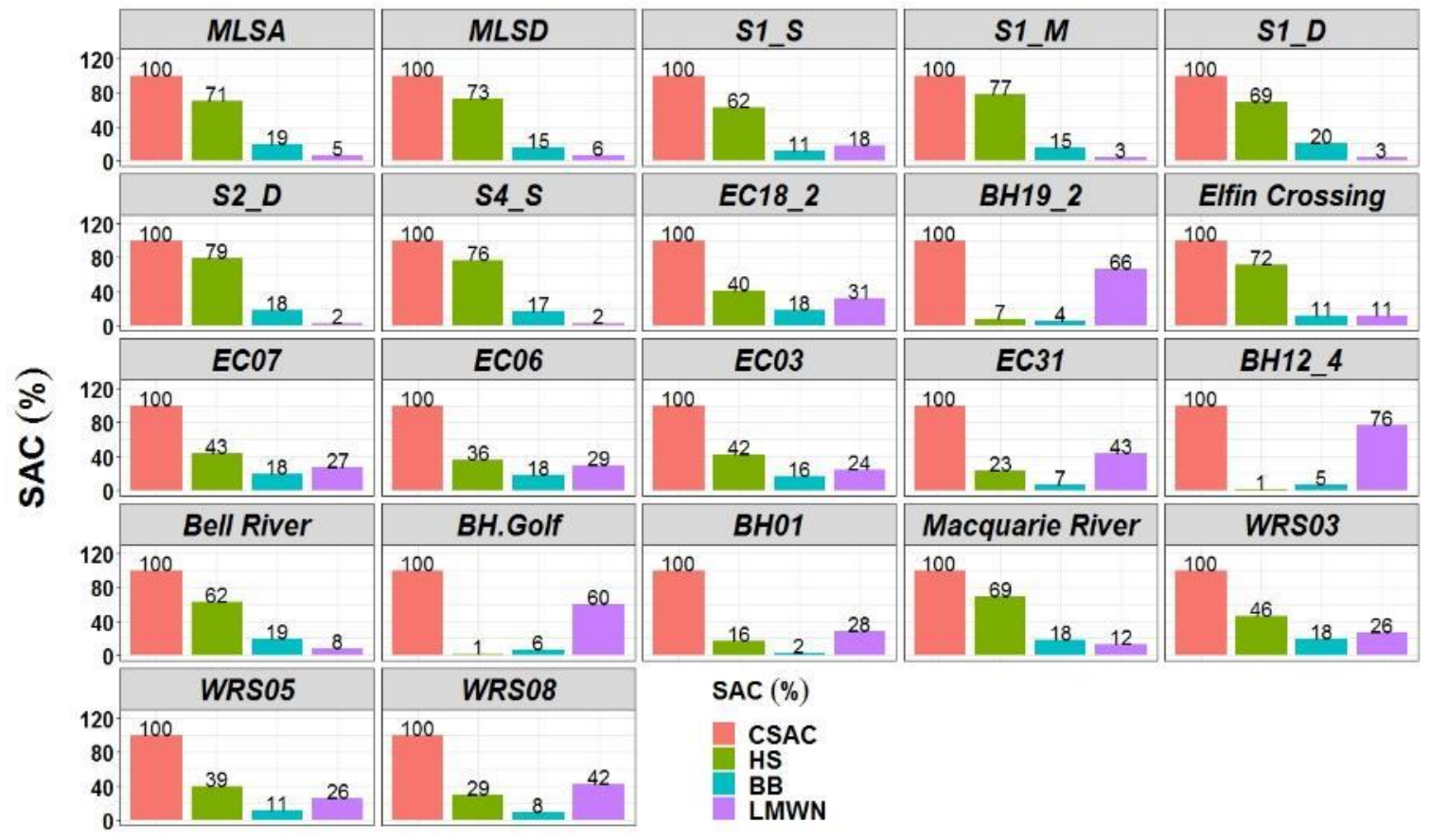

Figure 6: Showing the comparison of Spectral Absorbance Coefficients (SAC) in $\mathrm{m}^{-1}$ by UVS in percentage. SAC of $D O C=S A C$ of $H O C+S A C$ of CDOC. In addition, $S A C C D O C=S A C H S+S A C B B+S A C L M W N+S A C$ inorganic carbon. However, the plot only reported the total SAC CDOC in $100 \%$ subdivided into SAC HS, SAC BB and SAC LMWN. No SAC of inorganic carbon analysed.

In terms of LC-OCD, Huber et al. (2011a) described HOC as the composition of longer-chain aliphatic (no aromaticity) and polycyclic aromatic materials. Our model predicting that aromaticity of the DOC is more important in term of sorption than DOC molecular weight. Higher HS sorption when compared to HOC, it can be assumed that HS could have more aromaticity than HOC. It suggests that groundwater HOC is mainly composed of aliphatic molecules.

\subsection{Factors controlling natural HS sorption}

The model implies that not only the physiochemical property of HS but also the groundwater environment affects the HS sorption extent.

The model suggests that quartz sand environment could have higher HS concentration than the environment with iron coated minerals and calcium carbonate environment due to reduced HS sorption. 
The model infers that, on average, HS sorption increases by $0.00086(18 \%) \mathrm{mg}$ for every $1 \mathrm{~g}$ increase in mineral mass. The mass alone might not be directly relevant to the sorption. However, mineral mass has strong link to mineral specific surface area. Bengtsson and Picado (2008) studied on the dependence of DOC sorption on mineral grain size by making 6 fractions of quartz sand sediment ranging from $0-2000 \mu \mathrm{m}$ and found that size range mineral has negative correlation to SSA and DOC sorption. $0-63 \mu \mathrm{m}$ mass range has almost 9 times higher in SSA and almost 8 times higher in DOC sorption than what was found from $1000-$ $2000 \mu \mathrm{m}$ mass range.

The model also implies that the environment with iron coated mineral will commands 0.0017 $\mathrm{mg}(135 \%) \mathrm{HS}$ sorption and $0.001 \mathrm{mg}(44 \%)$ higher than sandy and calcium carbonate environments, respectively (comparing based on $1 \mathrm{~g}$ basis of each mineral type). Calcium carbonate environments also store HS by $0.0012 \mathrm{mg}(61 \%)$ higher than sandy environments (comparing based on $1 \mathrm{~g}$ basis of each mineral type). An explanation to higher HS sorption was found in Iron Oxides system is due to the fact that under particular $\mathrm{pH}$ range the porous Iron Oxides carries positive charge (Kim et al., 2009) attracting negatively charged HS (Fein et al., 1999), while negatively charged sand quartz (Bai and Zhang, 2001) causes repulsive effects on HS (at neutral solution pH, HS is negatively charged due to carboxyl and phenol groups on their surface). HS sorption of iron coated and quartz sand in column test by Kim et al. (2009) showed that at pH around 7.1-7.3, HS sorption on iron coated sand is 7 times higher than that on quartz sand. Available surface specific area of the minerals also play an important part in DOC sorption. Chang et al. (1997) explained that the magnitude of available surface specific area (SSA) of the sorbents indicates the magnitude of adsorptive binding capacity of NOM to the sorbents and in their study higher DOC was removed from iron coated sand than noncoated sand because the surface specific area increases from 0.04 to $2.7 \mathrm{~m}^{2} \mathrm{~g}^{-1}$ after the coating. They found that higher NOM sorption was observed than that found in silica due to more surface structure for sorption. Saidy et al. (2012) found that coated phyllosilicate with ferrihydrite increases available surface specific area (SSA) by $7 \%$ resulting in higher DOC sorption on ferrihydrite coated phyllosilicate than that of pure phyllosilicate.

The maximum organic carbon sorption on calcite with SSA of $0.714 \mathrm{~m}^{2} \mathrm{~g}^{-1}$ was up to $1.5 \mathrm{mg} C$ $\mathrm{m}^{-2}$ (Suess, 1970). Thomas et al. (1993) claimed that humic acid sorption on calcite with SSA of $0.6 \mathrm{~m}^{2} \mathrm{~g}^{-1}$ was $1.3 \mathrm{mg} \mathrm{C} \mathrm{m}^{-2}$. Moreover, calcite surfaces become positively charged when pH is below 8-9 (Thomas et al., 1993, Al-Hashim et al., 1988) and this positively charged interface exhibited strong carboxylate adsorption on carbonate (Thomas et al., 1993). The inference for this is that organic sorption onto calcite increases with SSA and with positively charged interface.

The model in this paper elucidated that even though HS sorption by calcite is higher compared to what was found in the QS system, it is about 44\% lower than observed HS sorption in ICS system. Assuming the same HS sorption mechanism, ICS might have higher SSA (by XPS analysis, $8 \%$ iron oxide coverage on QS was found) and surface charge than calcite and, thereby, higher HS sorption.

The different extent of sorption by the 3 minerals reflects on the concentration of groundwater DOC found in this study in that higher DOC concentration was found at Anna Bay site. The source of such high concentration is assumed to be from surface vegetation, mobilized particulate organic matter and in-situ peat in that sandy environment (Meredith et al.). This concentration is about 5 times higher than median global groundwater DOC 
concentration (McDonough et al., 2020a). X-ray Fluorescence spectrometry (XRF) analysis show that the major chemical composition of the soil is $\mathrm{SiO}_{2}(94 \%)$ while only $0.20 \% \mathrm{Fe}_{2} \mathrm{O}_{3}$ is present. The quartz sand environment with low attracting capacity to groundwater DOC could result in the high DOC concentration we observed, and this infers that groundwater DOC might not be processed or less processed when compared to other sites where groundwater DOC concentration was relatively low. The lower groundwater DOC concentration at Maules creek and Wellington might be the results of higher sorption. For example, at Wellington, $\mathrm{BH}$.Golf, $\mathrm{BHO1}$ and The Well with very low groundwater $\mathrm{DOC}$ are in karst environments while at Maules Creek the soil chemical composition are not only $\mathrm{SiO}_{2}(72 \%)$ but also $\mathrm{Fe}_{2} \mathrm{O}_{3}(3.04 \%)$ and $\mathrm{Al}_{2} \mathrm{O}_{3}(12.31 \%)$.

HS sorption decreases by $0.0008 \mathrm{~g}(6 \%)$ for every meter of deeper sample depth implying that HS concentration is removed along flow-paths. NOM with greater aromaticity, carboxylic acid groups and amino acid are selectively removed as groundwater flows along a pathway (McKnight et al., 1992). In the vadose zone, extensive attenuation of surface-derived DOC concentration occurs as it moves vertically to deeper water table (Pabich et al., 2001). This suggests that due to concurrent groundwater DOC sorption and flow, less sorbing DOC fractions are available for sorption along flow-paths.

The result shows that water samples with higher groundwater DOC concentrations tend to have higher aromaticity and molecular weight. For examples, samples from Anna Bay where groundwater DOC is minimally processed (McDonough et al., 2020b) showed higher groundwater DOC concentration with higher aromaticity and molecular weight. HS sorption at Anna Bay was also found to be higher than groundwater HS sorption from other sites. It is consistent with what the model predicts in that HS sorption increases with groundwater DOC and HS aromaticity. The sorption increases by $0.0009 \mathrm{mg}(22 \%)$ for $1 \mathrm{mg} / \mathrm{L}$ increase in groundwater DOC. At $1 \mathrm{~L} \mathrm{mg}^{-1} \mathrm{~m}^{-1}$ change of aromaticity, HS sorption will be about $58 \%$ higher than that found in the sample with lower aromaticity (HS aromaticity lower than $3 \mathrm{~L} \mathrm{mg}^{-1}$ $\left.\mathrm{m}^{-1}\right)$.

On the other hand, HS sorption becomes lower by $0.00008 \mathrm{~g}(13 \%)$ with every $1 \mathrm{mg} \mathrm{L}^{-1}$ change in dissolved $\mathrm{Fe}^{2+}$. A possible explanation of this is that under anoxic conditions $\mathrm{Fe}^{3+}$ is utilized as an electron acceptor during biodegradation of groundwater $\mathrm{DOC}$ and release $\mathrm{Fe}^{2+}$ as a byproduct (McMahon and Chapelle, 2008, Bastviken et al., 2004), resulting in less Fe-oxides surfaces for DOC sorption.

\section{Conclusion}

LC-OCD was used to characterize groundwater DOC and batch experiments were performed to quantify DOC sorption in groundwater. A multiple linear regression model was adopted to identify the statistically relevant factors that drive DOC sorption within various aquifers. The results showed that not all DOC fractions in groundwater sorb onto quartz, calcite or Fe-oxide minerals. HS is the largest fraction in DOC and the dominant sorbing fraction. These results suggest that HS can be used as an indicator of groundwater DOC sorption in aquifers. Nine explanatory variables were used in the multiple linear regression model to predict the control of groundwater DOC sorption. The model implies that, iron oxide coated sediments can store larger amounts of DOC from groundwater than in calcium carbonate and quartz-rich aquifer sediments. Unprocessed DOC in groundwater, especially contained within shallow aquifers that are influenced by surface water interaction and recharge are typically higher in DOC 
concentration and aromaticity. These two factors were found to play an important role in groundwater DOC sorption. Less groundwater DOC sorption occurs within deeper aquifers due to DOC removal along the flow path which results in less DOC for further sorption. However, the model also indicates that when high DOC is found in groundwater, higher dissolved $\mathrm{Fe}^{2+}$ is expected to be mobilized.

Finally, this model is not only useful for predicting the processes that regulate the storage of $\mathrm{OC}$ in aquifers, but can also be used for predicting the removal of organic contaminants from surface water and groundwater by collecting the data related the 11 explanatory into the model and the output from the model can be used for water treatment as well as for understanding more about global carbon cycle. Further research could determine whether other DOC fractions besides HS might sorb more effectively in higher DOC concentration for groundwater, such as within organic contaminated groundwater. This would confirm whether the model is universal to all ground water environments. LC-OCD allows us to identify multiple fractions of NOM and how they are impacted by sorption. Future studies could also investigate how each fraction is processed by biodegradation. 


\section{Acknowledgements:}

This research would not happen without funding by the Australian Research Council [Discovery Project number DP160101379]. Apart from this, the author would like to show appreciation to Australia Department of Foreign Affairs and Trade who grant Australia Award Scholarship to the author's Ph D at UNSW, Australia. The authors also acknowledge the Australia National Collaborative Research Infrastructure Strategy (NCRIS) who provided many access to water research and water sampling at Wellington and Maules Creek as well as a special thanks to NSW Department of Primary Industries Office of Water who allows the authors to have access to Anna Bay sampling site. The authors also would like to thank Stats Central (UNSW), in particular, Ben Maslen and Dr. Nancy Briggs for their statistic consultation. Last but not least, the authors would like to thank Mark Wainwright Analytical Centre (UNSW) in particular Khorshed Chinua, Dorothy Yu and Rabeya Akter for their kind technical support on LC-OCD and cation and anion. The authors acknowledge use of facilities in the Solid State \& Elemental Analysis Unit at Mark Wainwright Analytical Centre. 


\section{References}

ABOLLINO, O., ACETO, M., MALANDRINO, M., SARZANINI, C. \& MENTASTI, E. 2003. Adsorption of heavy metals on Na-montmorillonite. Effect of $\mathrm{pH}$ and organic substances. Water Research, 37, 1619-1627.

AL-HASHIM, H., CELIK, M., OSKAY, M. \& AL-YOUSEF, H. 1988. Adsorption and precipitation behaviour of petroleum sulfonates from Saudi Arabian limestone. Journal of Petroleum Science and Engineering, 1, 335-344.

ANDERSEN, M. S. \& ACWORTH, R. 2009. Stream-aquifer interactions in the Maules Creek catchment, Namoi Valley, New South Wales, Australia. Hydrogeology journal, 17, 2005-2021.

ANDERSEN, S. A., CASTILLA, J. C., HAMISH., S., SAM., M. \& IAN., A. 2012. Development of a Coastal Groundwater Process Investigation Site Anna Bay, New South Wales, Final Report Prepared for New South Wales Office of Water.

ARANDA, A., FERREIRA, G., MAINAR-TOLEDO, M., SCARPELLINI, S. \& SASTRESA, E. L. 2012. Multiple regression models to predict the annual energy consumption in the Spanish banking sector. Energy and Buildings, 49, 380-387.

ARNARSON, T. S. \& KEIL, R. G. 2000. Mechanisms of pore water organic matter adsorption to montmorillonite. Marine chemistry, 71, 309-320.

AYADI, I. \& ELLOUZE, A. 2015. The determinants of the Tunisian banking performance; A panel data analysis. International Journal of Economics and Finance, 7, 262-272.

BAI, R. \& ZHANG, X. 2001. Polypyrrole-coated granules for humic acid removal. Journal of Colloid and Interface Science, 243, 52-60.

BASTVIKEN, D., PERSSON, L., ODHAM, G. \& TRANVIK, L. 2004. Degradation of dissolved organic matter in oxic and anoxic lake water. Limnology and Oceanography, 49, 109-116.

BENGTSSON, G. \& PICADO, F. 2008. Mercury sorption to sediments: dependence on grain size, dissolved organic carbon, and suspended bacteria. Chemosphere, 73, 526-531.

BRODOWSKI, S., AMELUNG, W., HAUMAIER, L., ABETZ, C. \& ZECH, W. 2005. Morphological and chemical properties of black carbon in physical soil fractions as revealed by scanning electron microscopy and energy-dispersive X-ray spectroscopy. Geoderma, 128, 116-129.

BROWN, S. \& LUGO, A. E. 1982. The storage and production of organic matter in tropical forests and their role in the global carbon cycle. Biotropica, 14, 161-187.

CHANG, Y., LI, C. W. \& BENJAMIN, M. M. 1997. Iron oxide-coated media for NOM sorption and particulate filtration. Journal-American Water Works Association, 89, 100-113.

CHATTERTON, B., JOHNSON, B. \& CAMPBELL, K. 1979. Silicified Lower Devonian trilobites from New South Wales. Palaeontology, 22, 799-837.

CLÉMENT, B. 2018. Study of an Anoxic, Organic Matter Rich Groundwater System: Samurai Beach, New South Wales, Australia.

CUTHBERT, M., ACWORTH, R., ANDERSEN, M., LARSEN, J., MCCALLUM, A., RAU, G. \& TELLAM, J. 2016. Understanding and quantifying focused, indirect groundwater recharge from ephemeral streams using water table fluctuations. Water Resources Research, 52, 827-840.

DELPLA, I., JUNG, A.-V., BAURES, E., CLEMENT, M. \& THOMAS, O. 2009. Impacts of climate change on surface water quality in relation to drinking water production. Environment international, $35,1225-1233$.

DING, C., YANG, X., LIU, W., CHANG, Y. \& SHANG, C. 2010. Removal of natural organic matter using surfactant-modified iron oxide-coated sand. Journal of hazardous materials, 174, 567-572.

EDWARDS, M. \& BENJAMIN, M. M. 1989. Adsorptive filtration using coated sand: a new approach for treatment of metal-bearing wastes. Research Journal of the Water Pollution Control Federation, 1523-1533.

EVANS, C., MONTEITH, D. \& COOPER, D. 2005. Long-term increases in surface water dissolved organic carbon: observations, possible causes and environmental impacts. Environmental pollution, $137,55-71$. 
FALKOWSKI, P., SCHOLES, R., BOYLE, E., CANADELL, J., CANFIELD, D., ELSER, J., GRUBER, N., HIBBARD, K., HÖGBERG, P. \& LINDER, S. 2000. The global carbon cycle: a test of our knowledge of earth as a system. science, 290, 291-296.

FEIN, J. B., BOILY, J.-F., GÜÇLÜ, K. \& KAULBACH, E. 1999. Experimental study of humic acid adsorption onto bacteria and Al-oxide mineral surfaces. Chemical Geology, 162, 33-45.

GATES, G. 1980. The hydrology of the unconsolidated sediments in the mooki river valley, new south wales. MSc Thesis, University of New South Wales, Sydney.

GATES, G. \& ROSS, J. 1980. Cainozoic alleviation and hydrogeology of the Namoi River Basin, NSW. The Cainozoic evolution of continental Southeast Australia. BMR record, 67.

GIAMBASTIANI, B. M. S., MCCALLUM, A., ANDERSEN, M., KELLY, B. \& ACWORTH, R. 2012. Understanding groundwater processes by representing aquifer heterogeneity in the Maules creek catchment, Namoi valley (New South Wales, Australia). Hydrogeology Journal, 20, 1027-1044.

GRAHAM, P., BAKER, A. \& ANDERSEN, M. 2015a. Dissolved organic carbon mobilisation in a groundwater system stressed by pumping. Scientific reports, 5, 18487.

GRAHAM, P., BAKER, A., ANDERSEN, M. \& ACWORTH, I. 2015b. Field measurement of fluorescent dissolved organic material as a means of early detection of leachate plumes. Water, Air, \& Soil Pollution, 226, 211.

GRAHAM, P. W., ANDERSEN, M., MCCABE, M., AJAMI, H., BAKER, A. \& ACWORTH, I. 2015c. To what extent do long-duration high-volume dam releases influence river-aquifer interactions? A case study in New South Wales, Australia. Hydrogeology journal, 23, 319-334.

GRAHAM, P. W., ANDERSEN, M. S., MCCABE, M. F., AJAMI, H., BAKER, A. \& ACWORTH, I. 2015d. To what extent do long-duration high-volume dam releases influence river-aquifer interactions? A case study in New South Wales, Australia. Hydrogeology Journal, 23, 319334.

GU, B., SCHMITT, J., CHEN, Z., LIANG, L. \& MCCARTHY, J. F. 1994. Adsorption and desorption of natural organic matter on iron oxide: mechanisms and models. Environmental Science \& Technology, 28, 38-46.

GU, B., SCHMITT, J., CHEN, Z., LIANG, L. \& MCCARTHY, J. F. 1995. Adsorption and desorption of different organic matter fractions on iron oxide. Geochimica et Cosmochimica Acta, 59, 219229.

HUBER, S. A., BALZ, A., ABERT, M. \& PRONK, W. 2011a. Characterisation of aquatic humic and nonhumic matter with size-exclusion chromatography-organic carbon detection-organic nitrogen detection (LC-OCD-OND). Water research, 45, 879-885.

HUBER, S. A., BALZ, A., ABERT, M. \& PRONK, W. 2011b. Characterisation of aquatic humic and nonhumic matter with size-exclusion chromatography - organic carbon detection - organic nitrogen detection (LC-OCD-OND). Water Research, 45, 879-885.

JEX, C. N., MARIETHOZ, G., BAKER, A., GRAHAM, P., ANDERSEN, M. S., ACWORTH, I., EDWARDS, N. \& AZCURRA, C. 2012. Spatially dense drip hydrological monitoring and infiltration behaviour at the Wellington Caves, South East Australia. International Journal of Speleology, 41, 14.

KAHLE, M., KLEBER, M. \& JAHN, R. 2003. Retention of dissolved organic matter by illitic soils and clay fractions: Influence of mineral phase properties. Journal of Plant Nutrition and Soil Science, 166, 737-741.

KAŠTELAN-MACAN, M. \& PETROVIC, M. 1995. Competitive sorption of phosphate and marine humic substances on suspended particulate matter. Water Science and Technology, 32, 349-355.

KESHAVARZI, M. 2017. Biological, Earth \& Environmental Sciences, Faculty of Science, UNSW 2017, Assessing hydraulic connection and dissolved organic matter in a karst landscape: Wellington, Australia, University of New South Wales. Biological, Earth \& Environmental Sciences.

KESHAVARZI, M., BAKER, A., KELLY, B. F. \& ANDERSEN, M. S. 2017. River-groundwater connectivity in a karst system, Wellington, New South Wales, Australia. Hydrogeology journal, 25, 557-574. 
KIM, H.-C., PARK, S.-J., LEE, C.-G., HAN, Y.-U., PARK, J.-A. \& KIM, S.-B. 2009. Humic acid removal from water by iron-coated sand: a column experiment. Environmental Engineering Research, 14, 41-47.

KITIS, M., KAPLAN, S., KARAKAYA, E., YIGIT, N. \& CIVELEKOGLU, G. 2007. Adsorption of natural organic matter from waters by iron coated pumice. Chemosphere, 66, 130-138.

KO, I., KIM, J.-Y. \& KIM, K.-W. 2005. Adsorption properties of soil humic and fulvic acids by hematite. Chemical Speciation \& Bioavailability, 17, 41-48.

KRAUSE, S., BRONSTERT, A. \& ZEHE, E. 2007. Groundwater-surface water interactions in a North German lowland floodplain-implications for the river discharge dynamics and riparian water balance. Journal of hydrology, 347, 404-417.

KUMAR, M., RAMANATHAN, A. \& KESHARI, A. 2009. Understanding the extent of interactions between groundwater and surface water through major ion chemistry and multivariate statistical techniques. Hydrological Processes: An International Journal, 23, 297-310.

LAI, C. \& CHEN, C.-Y. 2001. Removal of metal ions and humic acid from water by iron-coated filter media. Chemosphere, 44, 1177-1184.

LENTH, R. 2018. Emmeans: Estimated Marginal Means, aka Least-Squares Means. 2018.

LI, T., TAO, Q., LIANG, C., SHOHAG, M., YANG, X. \& SPARKS, D. L. 2013. Complexation with dissolved organic matter and mobility control of heavy metals in the rhizosphere of hyperaccumulator Sedum alfredii. Environmental Pollution, 182, 248-255.

MCCALLUM, A. M., ANDERSEN, M. S. \& ACWORTH, R. I. 2014. A new method for estimating recharge to unconfined aquifers using differential river gauging. Groundwater, 52, 291-297.

MCCALLUM, A. M., ANDERSEN, M. S., KELLY, B. F., GIAMBASTIANI, B. \& ACWORTH, R. I. 2009. Hydrological investigations of surface water-groundwater interactions in a sub-catchment in the Namoi Valley, NSW, Australia. IAHS publication, 20, 157.

MCDONOUGH, L., SANTOS, I., ANDERSEN, M., O'CARROLL, D., RUTLIDGE, H., MEREDITH, K., OUDONE, P. \& BAKER, A. 2020a. Changes in global groundwater organic carbon driven by climate change and urbanization.

MCDONOUGH, L. K., O'CARROLL, D. M., MEREDITH, K., ANDERSEN, M. S., BRÜGGER, C., HUANG, H., RUTLIDGE, H., BEHNKE, M. I., SPENCER, R. G. \& MCKENNA, A. 2020b. Changes in groundwater dissolved organic matter character in a coastal sand aquifer due to rainfall recharge. Water research, 115201.

MCKNIGHT, D. M., BENCALA, K. E., ZELLWEGER, G. W., AIKEN, G. R., FEDER, G. L. \& THORN, K. A. 1992. Sorption of dissolved organic carbon by hydrous aluminum and iron oxides occurring at the confluence of Deer Creek with the Snake River, Summit County, Colorado. Environmental science \& technology, 26, 1388-1396.

MCMAHON, P. \& CHAPELLE, F. 2008. Redox processes and water quality of selected principal aquifer systems. Groundwater, 46, 259-271.

MEREDITH, K. T., BAKER, A., ANDERSEN, M. S., O'CARROLL, D. M., RUTLIDGE, H., MCDONOUGH, L. K., OUDONE, P., BRYAN, E. \& ZAINUDDIN, N. S. 2020. Isotopic and chromatographic fingerprinting of the sources of dissolved organic carbon in a shallow coastal aquifer.

MIDDELBURG, J. J. \& HERMAN, P. M. 2007. Organic matter processing in tidal estuaries. Marine Chemistry, 106, 127-147.

NCRIS 2014. National Research Infrastructure of Australia. http://groundwater.anu.edu.au/fieldsite/maules-creek.

NEIL, C. W., RAY, J. R., LEE, B. \& JUN, Y.-S. 2016. Fractal aggregation and disaggregation of newly formed iron (III)(hydr) oxide nanoparticles in the presence of natural organic matter and arsenic. Environmental Science: Nano, 3, 647-656.

OCHS, M., ĆOSOVIĆ, B. \& STUMM, W. 1994. Coordinative and hydrophobic interaction of humic substances with hydrophilic Al2O3 and hydrophobic mercury surfaces. Geochimica et Cosmochimica Acta, 58, 639-650. 
PABICH, W. J., VALIELA, I. \& HEMOND, H. F. 2001. Relationship between DOC concentration and vadose zone thickness and depth below water table in groundwater of Cape Cod, USA. Biogeochemistry, 55, 247-268.

PARIA, S. 2008. Surfactant-enhanced remediation of organic contaminated soil and water. Advances in colloid and interface science, 138, 24-58.

RAU, G. C., HALLORAN, L. J., CUTHBERT, M. O., ANDERSEN, M. S., ACWORTH, R. I. \& TELLAM, J. H. 2017. Characterising the dynamics of surface water-groundwater interactions in intermittent and ephemeral streams using streambed thermal signatures. Advances in water resources, 107, 354-369.

ROSENBERGER, S., LAABS, C., LESJEAN, B., GNIRSS, R., AMY, G., JEKEL, M. \& SCHROTTER, J.-C. 2006. Impact of colloidal and soluble organic material on membrane performance in membrane bioreactors for municipal wastewater treatment. Water research, 40, 710-720.

RUBINSTEIN, M. L., SHIFFMAN, S., MOSCICKI, A. B., RAIT, M. A., SEN, S. \& BENOWITZ, N. L. 2013. Nicotine metabolism and addiction among adolescent smokers. Addiction, 108, 406-412.

SAIDY, A., SMERNIK, R., BALDOCK, J., KAISER, K. \& SANDERMAN, J. 2015. Microbial degradation of organic carbon sorbed to phyllosilicate clays with and without hydrous iron oxide coating. European Journal of Soil Science, 66, 83-94.

SAIDY, A., SMERNIK, R., BALDOCK, J., KAISER, K., SANDERMAN, J. \& MACDONALD, L. 2012. Effects of clay mineralogy and hydrous iron oxides on labile organic carbon stabilisation. Geoderma, 173, 104-110.

SANTÍN, C., DOERR, S. H., PRESTON, C. M. \& GONZÁLEZ-RODRÍGUEZ, G. 2015. Pyrogenic organic matter production from wildfires: a missing sink in the global carbon cycle. Global Change Biology, 21, 1621-1633.

SHACKLEY, M. S. 2010. X-ray fluorescence spectrometry (XRF) in geoarchaeology, Springer.

SHACKLEY, M. S. 2011. An introduction to X-ray fluorescence (XRF) analysis in archaeology. X-ray fluorescence spectrometry (XRF) in geoarchaeology. Springer.

SINGH, M., SARKAR, B., BISWAS, B., CHURCHMAN, J. \& BOLAN, N. S. 2016. Adsorption-desorption behavior of dissolved organic carbon by soil clay fractions of varying mineralogy. Geoderma, 280, 47-56.

SOPHOCLEOUS, M. 2002. Interactions between groundwater and surface water: the state of the science. Hydrogeology journal, 10, 52-67.

SUESS, E. 1970. Interaction of organic compounds with calcium carbonate-I. Association phenomena and geochemical implications. Geochimica et Cosmochimica Acta, 34, 157-168.

SUESS, E. 1973. Interaction of organic compounds with calcium carbonate-II. Organo-carbonate association in recent sediments. Geochimica et Cosmochimica Acta, 37, 2435-2447.

THIRUNAVUKKARASU, O., VIRARAGHAVAN, T. \& SUBRAMANIAN, K. 2001. Removal of arsenic in drinking water by iron oxide-coated sand and ferrihydrite-batch studies. Water Quality Research Journal, 36, 55-70.

THOMAS, M. M., CLOUSE, J. A. \& LONGO, J. M. 1993. Adsorption of organic compounds on carbonate minerals: 1 . Model compounds and their influence on mineral wettability. Chemical geology, 109, 201-213.

UNSW 2019. Mark Wainwright Analytical Centre, X-ray Fluorescence Laboratory. URL: https://www.analytical.unsw.edu.au/facilities/sseau/xrflab.

USSIRI, D. A. \& JOHNSON, C. E. 2004. Sorption of organic carbon fractions by Spodosol mineral horizons. Soil Science Society of America Journal, 68, 253-262.

VERMEER, A., VAN RIEMSDIJK, W. \& KOOPAL, L. 1998. Adsorption of humic acid to mineral particles. 1. Specific and electrostatic interactions. Langmuir, 14, 2810-2819.

WANG, L.-S., HU, H.-Y. \& WANG, C. 2007. Effect of ammonia nitrogen and dissolved organic matter fractions on the genotoxicity of wastewater effluent during chlorine disinfection. Environmental science \& technology, 41, 160-165. 
Supplementary Information

The Supplemental Information comprises 10 tables and 2 figures 
Supplementary Table 1: 3. Sampling sites locating in New South Wales, Australia. Sample GPS coordinates (easting and northing) are based on WGS 1984 UTM Zone 56S zoning system in which Maules Creek and Anna Bay sample site is in Zone 56S and Wellington Research Station and Wellington Caves are in Zone 55S in Southern Hemisphere. The depth where the samples were taken were based on screen depth below ground surface taken from NCRIS (2014) except for that The Well, $\mathrm{BH} . G o l f$ and $\mathrm{BHO1}$ were the groundwater depth and taken from Keshavarzi (2017).

\begin{tabular}{|c|c|c|c|c|}
\hline Samples & Easting & Northing & $\begin{array}{l}\text { Depth of screen below } \\
\text { ground surface }\end{array}$ & $\begin{array}{l}\text { Distance from } \\
\text { Surface water }\end{array}$ \\
\hline \multicolumn{5}{|c|}{ Anna Bay sampling site } \\
\hline Wetlands & No sample & No sample & Not applicable & Not applicable \\
\hline MLSA & 417595.37 & 6374461.24 & 0.62 & 0 \\
\hline MLSB & 417596.84 & 6374461.23 & 1.04 & 1.03 \\
\hline MLSD & 417597.48 & 6374461.23 & 1.19 & 2.11 \\
\hline S1_S & 417608.39 & 6374462.72 & 3.50 & 13.02 \\
\hline S1_M & 417607.22 & 6374462.51 & 12.50 & 11.85 \\
\hline S1_D & 417609.72 & 6374462.56 & 16.90 & 14.35 \\
\hline S2_D & 417688.66 & 6374441.93 & 17.30 & 93.29 \\
\hline S4_S & 417907.13 & 6374305.2 & 4.64 & 311.76 \\
\hline \multicolumn{5}{|c|}{ Maules Creek sampling site } \\
\hline Middle Creek & No sample & No sample & Not applicable & Not applicable \\
\hline BH 18_2 & 227599.17 & 6626170.27 & 10.45 & 23.37 \\
\hline BH 19_2 & 227555.28 & 6626196.06 & 21.93 & 72.91 \\
\hline Elfin Crossing & 220009.56 & 6622666.4 & Not applicable & Not applicable \\
\hline EC07 & 219998.83 & 6622667.16 & 1.51 & 8.68 \\
\hline EC06 & 220000.11 & 6622668.67 & 4.24 & 9.16 \\
\hline EC03 & 219995.88 & 6622672.71 & 2.83 & 14.4 \\
\hline EC31 & 219996.85 & 6622688.86 & 11.68 & 28.66 \\
\hline BH12_4 & 219987.99 & 6622697.93 & 39.57 & 51.55 \\
\hline \multicolumn{5}{|c|}{ Wellington Caves } \\
\hline Bell River & 681035.05 & 6389078.09 & Not applicable & Not applicable \\
\hline The Well & 681984.36 & 6389045.46 & 27.00 & 820.01 \\
\hline $\mathrm{BH} 01$ & 681775.08 & 6388903.42 & 10.70 & 710.03 \\
\hline BH.Golf & 681152.21 & 6388383.14 & $17-19$ & 350.24 \\
\hline \multicolumn{5}{|c|}{ Wellington Research Station } \\
\hline \multicolumn{5}{|l|}{ Macquarie } \\
\hline River & 686892.5 & 6394261.03 & Not applicable & Not applicable \\
\hline WRSO2 & 686864.23 & 6394255.75 & $9.5-11$ & 41.13 \\
\hline WRS03 & 686883.92 & 6394221.01 & $6.5-8$ & 23.73 \\
\hline WRS05 & 686770.42 & 6394214.61 & $15-18$ & 131.71 \\
\hline WRS08 & 686574.88 & 6394215.81 & $18.5-21.5$ & 326.39 \\
\hline
\end{tabular}


Supplementary Table 2: By sampling sites, Field data $D O C(D O C=H O C+C D O C)$ and its fraction concentrations $(C D O C=B P+H S+B B+L M W A+$ LMWN). bld means below detection limits. The ordering of samples is based on the distance of the bore away from surface river.

\begin{tabular}{|c|c|c|c|c|c|c|c|c|c|c|c|}
\hline No & Samples & $\begin{array}{l}\mathrm{DOC} \\
\mathrm{mg} \mathrm{L}^{-1}\end{array}$ & $\begin{array}{l}\mathrm{HOC} \\
\mathrm{mg} \mathrm{L}^{-1}\end{array}$ & $\begin{array}{l}\text { CDOC } \\
\mathrm{mg} \mathrm{L}^{-1}\end{array}$ & $\begin{array}{c}B P \\
\mathrm{mg} \mathrm{L}^{-1}\end{array}$ & $\begin{array}{c}\mathrm{HS} \\
\mathrm{mg} \mathrm{L}^{-1}\end{array}$ & $\begin{array}{c}\text { BB } \\
\mathrm{mg} \mathrm{L}^{-1}\end{array}$ & $\begin{array}{l}\text { LMWA } \\
\mathrm{mg} \mathrm{L}^{-1}\end{array}$ & $\begin{array}{l}\text { LMWN } \\
\mathrm{mg} \mathrm{L}^{-1}\end{array}$ & $\begin{array}{c}\mathrm{HS} \\
\text { Aromaticity } \\
\mathrm{L} \mathrm{mg}^{-1} \mathrm{~m}^{-1}\end{array}$ & $\begin{array}{l}\text { HS Molecular } \\
\text { weight } \\
\mathrm{g} \mathrm{mol}^{-1}\end{array}$ \\
\hline \multicolumn{12}{|c|}{ Anna Bay sampling site } \\
\hline 1 & MLSA & 6.73 & 0.92 & 5.80 & 0.01 & 3.93 & 1.09 & bld & 0.77 & 3.81 & 588 \\
\hline 2 & MLSB & 6.76 & 0.88 & 5.88 & 0.01 & 4.06 & 0.94 & bld & 0.87 & 3.69 & 544 \\
\hline 3 & MLSD & 6.61 & 1.07 & 5.54 & 0.00 & 4.00 & 0.83 & bld & 0.70 & 3.72 & 542 \\
\hline 4 & S1_S & 0.86 & 0.24 & 0.62 & 0.00 & 0.42 & 0.11 & bld & 0.09 & 4.29 & 699 \\
\hline 5 & S1_M & 10.76 & 1.20 & 9.56 & 0.09 & 6.76 & 1.58 & bld & 1.13 & 4.63 & 605 \\
\hline 6 & S1_D & 9.46 & 2.41 & 7.05 & 0.07 & 5.37 & 0.88 & bld & 0.74 & 4.28 & 512 \\
\hline 7 & S2_D & 15.64 & 2.25 & 13.39 & 0.01 & 10.34 & 1.95 & bld & 1.10 & 5.52 & 686 \\
\hline 8 & S4_S & 6.18 & 0.67 & 5.51 & 0.00 & 4.30 & 0.75 & bld & 0.46 & 7.08 & 904 \\
\hline Min & & 0.86 & 0.24 & 0.62 & 0.00 & 0.42 & 0.11 & & 0.09 & 3.69 & 512 \\
\hline Max & & 15.64 & 2.41 & 13.39 & 0.09 & 10.34 & 1.95 & & 1.13 & 7.08 & 904 \\
\hline Mea & & 7.87 & 1.21 & 6.67 & 0.02 & 4.90 & 1.02 & & 0.73 & 4.63 & 635 \\
\hline $\mathrm{Mec}$ & dian & 6.74 & 1.00 & 5.84 & 0.01 & 4.18 & 0.91 & & 0.76 & 4.29 & 597 \\
\hline SE & & 4.26 & 0.75 & 3.67 & 0.03 & 2.83 & 0.55 & & 0.34 & 1.16 & 128 \\
\hline \multicolumn{12}{|c|}{ Maules Creek sampling site } \\
\hline \multicolumn{12}{|c|}{ Middle Cree } \\
\hline 1 & BH18_2 & 1.08 & 0.23 & 0.85 & 0.01 & 0.47 & 0.19 & bld & 0.18 & 1.80 & 675 \\
\hline 2 & BH19_2 & 0.61 & 0.23 & 0.38 & 0.00 & 0.09 & 0.07 & bld & 0.22 & 0.67 & 112 \\
\hline \multicolumn{12}{|c|}{ Elfin Crossing } \\
\hline 3 & Elfin Crossing & 1.42 & 0.22 & 1.20 & 0.10 & 0.64 & 0.10 & bld & 0.36 & 2.13 & 119 \\
\hline 4 & $\mathrm{ECO} 7$ & 1.04 & 0.19 & 0.85 & 0.00 & 0.40 & 0.21 & bld & 0.24 & 1.83 & 491 \\
\hline 5 & EC06 & 1.02 & 0.22 & 0.80 & 0.00 & 0.47 & 0.14 & bld & 0.19 & 1.61 & 257 \\
\hline
\end{tabular}




\begin{tabular}{|c|c|c|c|c|c|c|c|c|c|c|c|}
\hline 6 & ECO3 & 1.24 & 0.31 & 0.93 & 0.01 & 0.55 & 0.13 & bld & 0.23 & 1.80 & 201 \\
\hline 7 & EC31 & 0.68 & 0.18 & 0.49 & 0.00 & 0.16 & 0.07 & bld & 0.25 & 1.00 & 110 \\
\hline 8 & BH12_4 & 0.66 & 0.21 & 0.45 & 0.01 & 0.09 & 0.17 & bld & 0.19 & 0.87 & 113 \\
\hline \multicolumn{2}{|c|}{ Min } & 0.61 & 0.18 & 0.38 & 0.00 & 0.09 & 0.07 & & 0.18 & 0.67 & 110 \\
\hline \multicolumn{2}{|c|}{ Max } & 1.42 & 0.31 & 1.20 & 0.10 & 0.64 & 0.21 & & 0.36 & 2.13 & 675 \\
\hline \multicolumn{2}{|c|}{ Mean } & 0.97 & 0.22 & 0.74 & 0.02 & 0.36 & 0.13 & & 0.23 & 1.46 & 260 \\
\hline \multicolumn{2}{|c|}{ Median } & 1.03 & 0.22 & 0.83 & 0.00 & 0.43 & 0.13 & & 0.22 & 1.71 & 160 \\
\hline \multicolumn{2}{|c|}{ SE } & 0.29 & 0.04 & 0.28 & 0.04 & 0.22 & 0.05 & & 0.06 & 0.54 & 212 \\
\hline \multicolumn{12}{|c|}{ Wellington Caves } \\
\hline 1 & Bell River & 1.74 & 0.05 & 1.70 & 0.10 & 1.05 & 0.27 & bld & 0.28 & 2.57 & 269 \\
\hline 2 & Golf Bore & 0.35 & 0.09 & 0.26 & 0.00 & 0.12 & 0.06 & bld & 0.07 & 0.37 & 364 \\
\hline 3 & $\mathrm{BH} 01$ & 0.52 & 0.14 & 0.37 & 0.00 & 0.22 & 0.03 & bld & 0.12 & 0.89 & 173 \\
\hline 4 & The Well & 0.54 & 0.12 & 0.43 & 0.01 & 0.23 & 0.07 & bld & 0.12 & 1.06 & 127 \\
\hline \multicolumn{12}{|c|}{ Wellington Research Station } \\
\hline 5 & Macquarie River & 8.54 & 0.25 & 8.29 & 0.18 & 5.51 & 1.62 & bld & 0.98 & 3.47 & 581 \\
\hline 6 & WRS03 & 1.98 & 0.07 & 1.90 & 0.00 & 1.32 & 0.16 & bld & 0.42 & 1.66 & 192 \\
\hline 7 & WRS05 & 1.48 & 0.18 & 1.30 & 0.01 & 0.78 & 0.28 & bld & 0.23 & 1.33 & 325 \\
\hline 8 & WRS08 & 0.91 & 0.05 & 0.87 & 0.01 & 0.61 & 0.08 & bld & 0.16 & 0.89 & 199 \\
\hline \multicolumn{2}{|c|}{ Min } & 0.35 & 0.05 & 0.26 & 0.00 & 0.12 & 0.03 & & 0.07 & 0.37 & 127 \\
\hline \multicolumn{2}{|c|}{ Max } & 8.54 & 0.25 & 8.29 & 0.18 & 5.51 & 1.62 & & 0.98 & 3.47 & 581 \\
\hline \multicolumn{2}{|c|}{ Mean } & 2.01 & 0.12 & 1.89 & 0.04 & 1.23 & 0.32 & & 0.30 & 1.53 & 279 \\
\hline \multicolumn{2}{|c|}{ Median } & 1.20 & 0.10 & 1.08 & 0.01 & 0.70 & 0.12 & & 0.20 & 1.20 & 234 \\
\hline \multicolumn{2}{|c|}{ SE } & 2.71 & 0.07 & 2.66 & 0.07 & 1.78 & 0.53 & & 0.30 & 1.02 & 146 \\
\hline
\end{tabular}


Supplementary Table 3: Sorbed amount of 6 DOC fractions ( $\mathrm{mg}$ ) found in $10 \mathrm{~g}$ Iron Oxides system. bld means below detection limits. The ordering of samples is based on the distance of the bore away from surface river.

\begin{tabular}{|c|c|c|c|c|c|c|c|}
\hline No & Samples & HOC & BP & HS & BB & LMWA & LMWN \\
\hline 1 & MLSA & 4.93E-03 & bld & 4.37E-02 & $1.21 \mathrm{E}-02$ & bld & bld \\
\hline 2 & MLSB & bld & $1.03 \mathrm{E}-03$ & $2.72 \mathrm{E}-02$ & $3.86 \mathrm{E}-03$ & $9.41 \mathrm{E}-03$ & bld \\
\hline 3 & MLSD & bld & $7.46 \mathrm{E}-05$ & $1.48 \mathrm{E}-02$ & $1.29 \mathrm{E}-02$ & bld & bld \\
\hline 4 & S1_S & bld & $2.38 \mathrm{E}-04$ & $6.90 \mathrm{E}-03$ & $1.13 \mathrm{E}-03$ & bld & bld \\
\hline 5 & S1_M & 4.87E-03 & $1.29 \mathrm{E}-03$ & $5.90 \mathrm{E}-02$ & $2.34 \mathrm{E}-02$ & $4.31 \mathrm{E}-03$ & bld \\
\hline 6 & S1_D & $9.45 \mathrm{E}-03$ & $6.15 \mathrm{E}-03$ & $6.82 \mathrm{E}-02$ & $2.98 \mathrm{E}-02$ & $4.50 \mathrm{E}-03$ & bld \\
\hline 7 & S2_D & $3.88 \mathrm{E}-03$ & bld & $1.44 \mathrm{E}-01$ & $1.58 \mathrm{E}-02$ & bld & bld \\
\hline 8 & S4_S & $6.35 \mathrm{E}-03$ & bld & $1.08 \mathrm{E}-01$ & $1.29 \mathrm{E}-02$ & $2.33 \mathrm{E}-03$ & bld \\
\hline 9 & BH18_2 & $2.11 \mathrm{E}-03$ & $8.78 \mathrm{E}-05$ & $3.74 \mathrm{E}-03$ & $2.55 \mathrm{E}-03$ & $2.25 \mathrm{E}-03$ & bld \\
\hline 10 & BH19_2 & $8.96 \mathrm{E}-03$ & bld & $2.03 E-03$ & bld & bld & bld \\
\hline 11 & Elfin Crossing & bld & $5.07 \mathrm{E}-03$ & $3.30 \mathrm{E}-03$ & $4.96 \mathrm{E}-04$ & $9.98 \mathrm{E}-04$ & bld \\
\hline 12 & ECO7 & $8.30 \mathrm{E}-04$ & $1.76 \mathrm{E}-04$ & $6.91 \mathrm{E}-03$ & bld & $1.01 \mathrm{E}-03$ & bld \\
\hline 13 & EC06 & $4.53 \mathrm{E}-03$ & bld & $7.45 E-03$ & bld & $2.23 \mathrm{E}-04$ & bld \\
\hline 14 & ECO3 & $0.00 E+00$ & $2.80 \mathrm{E}-04$ & 7.39E-03 & bld & bld & bld \\
\hline 15 & EC31 & $2.40 \mathrm{E}-03$ & bld & $2.59 \mathrm{E}-03$ & bld & bld & bld \\
\hline 16 & BH12_4 & $0.00 E+00$ & $1.30 \mathrm{E}-04$ & bld & bld & $2.25 \mathrm{E}-04$ & 4.67E-04 \\
\hline 17 & Bell river & bld & $1.72 \mathrm{E}-03$ & $1.05 E-02$ & bld & bld & bld \\
\hline 18 & BH.Golf & 1.19E-03 & $3.45 E-04$ & $8.68 \mathrm{E}-04$ & bld & bld & $1.04 \mathrm{E}-04$ \\
\hline 19 & $\mathrm{BH} 01$ & bld & $6.78 \mathrm{E}-05$ & bld & bld & bld & bld \\
\hline 20 & The Well & $1.01 \mathrm{E}-03$ & $1.91 \mathrm{E}-05$ & $6.78 \mathrm{E}-04$ & bld & $7.50 \mathrm{E}-04$ & bld \\
\hline 21 & Macquarie river & bld & $9.61 \mathrm{E}-04$ & $2.34 \mathrm{E}-02$ & bld & $4.11 \mathrm{E}-03$ & 2.17E-04 \\
\hline 22 & WRSO3 & $1.29 \mathrm{E}-03$ & bld & $3.88 \mathrm{E}-03$ & bld & $1.31 \mathrm{E}-04$ & bld \\
\hline 23 & WRS05 & $1.37 \mathrm{E}-03$ & $1.02 \mathrm{E}-03$ & 3.30E-03 & bld & $1.44 \mathrm{E}-03$ & bld \\
\hline \multirow[t]{2}{*}{24} & WRS08 & $8.54 \mathrm{E}-03$ & $3.83 E-05$ & $5.40 \mathrm{E}-03$ & bld & 2.77E-03 & bld \\
\hline & Min & $0.00 E+00$ & 1.91E-05 & $6.78 \mathrm{E}-04$ & $1.13 E-03$ & $1.31 \mathrm{E}-04$ & 1.04E-04 \\
\hline
\end{tabular}




$\begin{array}{lllllll}\text { Max } & 9.45 \mathrm{E}-03 & 6.15 \mathrm{E}-03 & 1.44 \mathrm{E}-01 & 2.98 \mathrm{E}-02 & 9.41 \mathrm{E}-03 & 2.17 \mathrm{E}-04 \\ \text { Mean } & 3.86 \mathrm{E}-03 & 1.01 \mathrm{E}-03 & 2.62 \mathrm{E}-02 & 1.40 \mathrm{E}-02 & 2.93 \mathrm{E}-03 & 1.61 \mathrm{E}-04 \\ \text { Median } & 3.14 \mathrm{E}-03 & 2.92 \mathrm{E}-04 & 7.39 \mathrm{E}-03 & 1.29 \mathrm{E}-02 & 2.33 \mathrm{E}-03 & 1.61 \mathrm{E}-04 \\ \text { SD } & 3.11 \mathrm{E}-03 & 1.72 \mathrm{E}-03 & 3.87 \mathrm{E}-02 & 9.39 \mathrm{E}-03 & 2.66 \mathrm{E}-03 & 8.01 \mathrm{E}-05\end{array}$


Supplementary Table 4: A summary of Emmeans test to identify if specific DOC fractions sorbs on specific minerals (a range of Lower and Upper $\mathrm{CL}$ indicates $\mathrm{HS}$ sorption in the systems or confidence interval). If the range of Lower and upper $\mathrm{CL}$ include zero, it means no DOC fraction sorption in the model. 432 systems were analysed for any sorption ( 1 system means 1 DOC fraction sorption versus 6 mineral mass ( 0 - $10 \mathrm{~g}$ ) of 1 mineral type). " $N$ " and " $Y$ " under "Sorb" heading in the table below refers to no DOC fraction sorption or there is DOC fraction sorption, respectively. The samples were listed in order of field DOC concentration $\left(\mathrm{mg} \mathrm{L}^{-1}\right)$. The samples with lower DOC concentration are listed at the top.

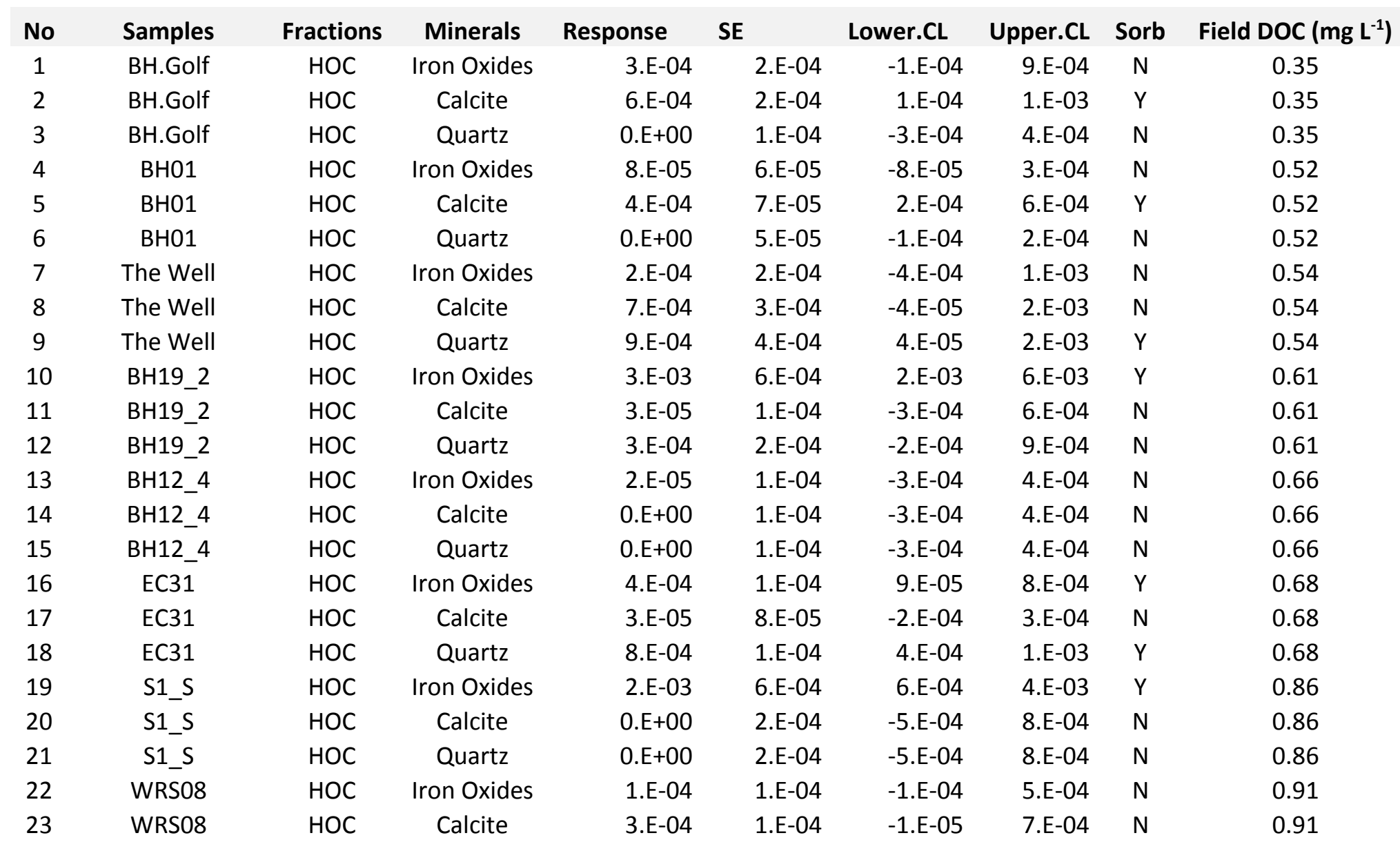




\begin{tabular}{|c|c|c|c|c|c|c|c|c|c|}
\hline 24 & WRS08 & $\mathrm{HOC}$ & Quartz & 8.E-07 & 9.E-05 & $-2 . E-04$ & 3.E-04 & $\mathrm{N}$ & 0.91 \\
\hline 25 & EC06 & $\mathrm{HOC}$ & Iron Oxides & 1.E-03 & 3.E-04 & 4.E-04 & 2.E-03 & $\mathrm{Y}$ & 1.02 \\
\hline 26 & EC06 & $\mathrm{HOC}$ & Calcite & 2.E-03 & 4.E-04 & 1.E-03 & 4.E-03 & $Y$ & 1.02 \\
\hline 27 & EC06 & $\mathrm{HOC}$ & Quartz & 2.E-04 & 2.E-04 & $-2 . E-04$ & 8.E-04 & $\mathrm{N}$ & 1.02 \\
\hline 28 & $\mathrm{ECO7}$ & $\mathrm{HOC}$ & Iron Oxides & 5.E-04 & 2.E-04 & 7.E-05 & 1.E-03 & $Y$ & 1.04 \\
\hline 29 & EC07 & $\mathrm{HOC}$ & Calcite & 1.E-03 & 2.E-04 & 5.E-04 & 2.E-03 & $\mathrm{Y}$ & 1.04 \\
\hline 30 & EC07 & $\mathrm{HOC}$ & Quartz & 3.E-04 & 1.E-04 & $-4 . E-05$ & 8.E-04 & $\mathrm{N}$ & 1.04 \\
\hline 31 & BH18_2 & $\mathrm{HOC}$ & Iron Oxides & 3.E-03 & 4.E-04 & 2.E-03 & 4.E-03 & $Y$ & 1.08 \\
\hline 32 & BH18_2 & $\mathrm{HOC}$ & Calcite & 4.E-05 & 1.E-04 & $-3 . E-04$ & 5.E-04 & $\mathrm{N}$ & 1.08 \\
\hline 33 & BH18_2 & $\mathrm{HOC}$ & Quartz & $0 . E+00$ & 1.E-04 & $-3 . E-04$ & 4.E-04 & $\mathrm{N}$ & 1.08 \\
\hline 34 & EC03 & $\mathrm{HOC}$ & Iron Oxides & 5.E-05 & 1.E-04 & $-2 . E-04$ & 5.E-04 & $\mathrm{N}$ & 1.24 \\
\hline 35 & ECO3 & $\mathrm{HOC}$ & Calcite & 2.E-03 & 3.E-04 & 1.E-03 & 3.E-03 & $Y$ & 1.24 \\
\hline 36 & ECO3 & $\mathrm{HOC}$ & Quartz & 6.E-04 & 2.E-04 & 1.E-04 & 1.E-03 & $Y$ & 1.24 \\
\hline 37 & Elfin Crossing & $\mathrm{HOC}$ & Iron Oxides & $0 . E+00$ & 1.E-04 & $-3 . E-04$ & 5.E-04 & $\mathrm{N}$ & 1.42 \\
\hline 38 & Elfin Crossing & $\mathrm{HOC}$ & Calcite & 2.E-04 & 2.E-04 & $-2 . E-04$ & 8.E-04 & $\mathrm{N}$ & 1.42 \\
\hline 39 & Elfin Crossing & $\mathrm{HOC}$ & Quartz & $0 . E+00$ & 1.E-04 & $-3 . E-04$ & 5.E-04 & $\mathrm{N}$ & 1.42 \\
\hline 40 & WRS05 & $\mathrm{HOC}$ & Iron Oxides & 1.E-04 & 1.E-04 & $-1 . E-04$ & 5.E-04 & $\mathrm{N}$ & 1.48 \\
\hline 41 & WRS05 & $\mathrm{HOC}$ & Calcite & 3.E-04 & 1.E-04 & $-1 . E-05$ & 7.E-04 & $\mathrm{N}$ & 1.48 \\
\hline 42 & WRS05 & $\mathrm{HOC}$ & Quartz & 8.E-07 & 9.E-05 & $-2 . E-04$ & 3.E-04 & $\mathrm{N}$ & 1.48 \\
\hline 43 & Bell river & $\mathrm{HOC}$ & Iron Oxides & $0 . E+00$ & 1.E-04 & $-4 . E-04$ & 6.E-04 & $\mathrm{N}$ & 1.74 \\
\hline 44 & Bell river & $\mathrm{HOC}$ & Calcite & 6.E-04 & 2.E-04 & 2.E-05 & 1.E-03 & $\mathrm{Y}$ & 1.74 \\
\hline 45 & Bell river & $\mathrm{HOC}$ & Quartz & 2.E-03 & 4.E-04 & 8.E-04 & 3.E-03 & $\mathrm{Y}$ & 1.74 \\
\hline 46 & WRS03 & $\mathrm{HOC}$ & Iron Oxides & 1.E-04 & 1.E-04 & $-1 . E-04$ & 5.E-04 & $\mathrm{N}$ & 1.98 \\
\hline 47 & WRSO3 & $\mathrm{HOC}$ & Calcite & 3.E-04 & 1.E-04 & $-1 . E-05$ & 7.E-04 & $\mathrm{N}$ & 1.98 \\
\hline 48 & WRS03 & $\mathrm{HOC}$ & Quartz & 8.E-07 & 9.E-05 & $-2 . E-04$ & 3.E-04 & $\mathrm{N}$ & 1.98 \\
\hline 49 & S4_S & $\mathrm{HOC}$ & Iron Oxides & 4.E-04 & 3.E-04 & $-3 . E-04$ & 2.E-03 & $\mathrm{N}$ & 6.18 \\
\hline 50 & S4_S & $\mathrm{HOC}$ & Calcite & 4.E-04 & 3.E-04 & $-3 . E-04$ & 2.E-03 & $\mathrm{N}$ & 6.18 \\
\hline 51 & S4_S & $\mathrm{HOC}$ & Quartz & 6.E-04 & 4.E-04 & $-2 . E-04$ & 2.E-03 & $\mathrm{N}$ & 6.18 \\
\hline 52 & MLSD & $\mathrm{HOC}$ & Iron Oxides & 3.E-03 & 8.E-04 & 1.E-03 & 6.E-03 & $\mathrm{Y}$ & 6.61 \\
\hline 53 & MLSD & $\mathrm{HOC}$ & Calcite & $0 . E+00$ & 2.E-04 & $-5 . E-04$ & 8.E-04 & $\mathrm{N}$ & 6.61 \\
\hline 54 & MLSD & $\mathrm{HOC}$ & Quartz & $0 . E+00$ & 2.E-04 & $-5 . E-04$ & 8.E-04 & $\mathrm{N}$ & 6.61 \\
\hline
\end{tabular}




\begin{tabular}{|c|c|c|c|c|c|c|c|c|c|}
\hline 55 & MLSA & $\mathrm{HOC}$ & Iron Oxides & 2.E-03 & 5.E-04 & 4.E-04 & 4.E-03 & $Y$ & 6.73 \\
\hline 56 & MLSA & $\mathrm{HOC}$ & Calcite & $0 . E+00$ & 2.E-04 & $-5 . E-04$ & 9.E-04 & $\mathrm{N}$ & 6.73 \\
\hline 57 & MLSA & $\mathrm{HOC}$ & Quartz & $0 . E+00$ & 2.E-04 & $-5 . E-04$ & 9.E-04 & $\mathrm{N}$ & 6.73 \\
\hline 59 & MLSB & $\mathrm{HOC}$ & Calcite & 3.E-04 & 3.E-04 & $-4 . E-04$ & 2.E-03 & $\mathrm{N}$ & 6.76 \\
\hline 60 & MLSB & $\mathrm{HOC}$ & Quartz & $0 . E+00$ & 2.E-04 & $-5 . E-04$ & 1.E-03 & $\mathrm{N}$ & 6.76 \\
\hline 61 & Macquarie river & $\mathrm{HOC}$ & Iron Oxides & 2.E-04 & 2.E-04 & $-3 . E-04$ & 1.E-03 & $\mathrm{N}$ & 8.54 \\
\hline 63 & Macquarie river & $\mathrm{HOC}$ & Quartz & $0 . E+00$ & 2.E-04 & $-4 . E-04$ & 7.E-04 & $\mathrm{N}$ & 8.54 \\
\hline 64 & S1_D & $\mathrm{HOC}$ & Iron Oxides & 9.E-03 & 3.E-03 & 3.E-03 & 2.E-02 & $Y$ & 9.46 \\
\hline 65 & S1_D & $\mathrm{HOC}$ & Calcite & 2.E-03 & 9.E-04 & 5.E-04 & 7.E-03 & $Y$ & 9.46 \\
\hline 66 & S1_D & $\mathrm{HOC}$ & Quartz & 2.E-04 & 3.E-04 & $-5 . E-04$ & 2.E-03 & $\mathrm{N}$ & 9.46 \\
\hline 67 & S1_M & $\mathrm{HOC}$ & Iron Oxides & 2.E-03 & 6.E-04 & 6.E-04 & 4.E-03 & $Y$ & 10.76 \\
\hline 71 & S2_D & $\mathrm{HOC}$ & Calcite & 4.E-03 & 2.E-03 & 9.E-04 & 1.E-02 & $Y$ & 15.64 \\
\hline 72 & S2_D & $\mathrm{HOC}$ & Quartz & $0 . E+00$ & 3.E-04 & $-6 . E-04$ & 2.E-03 & $\mathrm{N}$ & 15.64 \\
\hline No & ID & Fractions & Minerals & Response & SE & Lower.CL & Upper.CL & Sorb & Field DOC $\left(\mathrm{mg} \mathrm{L}^{-1}\right)$ \\
\hline 1 & BH.Golf & BP & Iron Oxides & 2.E-04 & 1.E-04 & $-2 . E-04$ & 7.E-04 & $\mathrm{N}$ & 0.35 \\
\hline 2 & BH.Golf & $\mathrm{BP}$ & Calcite & 2.E-04 & 1.E-04 & $-2 . E-04$ & 7.E-04 & $\mathrm{N}$ & 0.35 \\
\hline 3 & BH.Golf & $\mathrm{BP}$ & Quartz & 2.E-04 & 1.E-04 & $-2 . E-04$ & 7.E-04 & $\mathrm{N}$ & 0.35 \\
\hline 4 & $\mathrm{BH} 01$ & $\mathrm{BP}$ & Iron Oxides & 6.E-05 & 5.E-05 & $-1 . E-04$ & 2.E-04 & $\mathrm{N}$ & 0.52 \\
\hline 5 & $\mathrm{BHO1}$ & $\mathrm{BP}$ & Calcite & 2.E-05 & 5.E-05 & $-1 . E-04$ & 2.E-04 & $\mathrm{N}$ & 0.52 \\
\hline
\end{tabular}




\begin{tabular}{|c|c|c|c|c|c|c|c|c|c|}
\hline 12 & BH19_2 & BP & Quartz & 2.E-05 & 1.E-04 & $-3 . E-04$ & 6.E-04 & $\mathrm{N}$ & 0.61 \\
\hline 13 & BH12_4 & $\mathrm{BP}$ & Iron Oxides & 1.E-04 & 1.E-04 & $-2 . E-04$ & 5.E-04 & $\mathrm{N}$ & 0.66 \\
\hline 14 & BH12_4 & BP & Calcite & 5.E-05 & 1.E-04 & $-2 . E-04$ & 5.E-04 & $\mathrm{N}$ & 0.66 \\
\hline 15 & BH12_4 & $\mathrm{BP}$ & Quartz & 6.E-04 & 2.E-04 & 1.E-04 & 1.E-03 & $Y$ & 0.66 \\
\hline 16 & EC31 & BP & Iron Oxides & $0 . E+00$ & 8.E-05 & $-2 . E-04$ & 3.E-04 & $\mathrm{N}$ & 0.68 \\
\hline 17 & EC31 & $\mathrm{BP}$ & Calcite & $0 . E+00$ & 8.E-05 & $-2 . E-04$ & 3.E-04 & $\mathrm{N}$ & 0.68 \\
\hline 18 & EC31 & BP & Quartz & $0 . E+00$ & 8.E-05 & $-2 . E-04$ & 3.E-04 & $\mathrm{N}$ & 0.68 \\
\hline 19 & S1_S & $\mathrm{BP}$ & Iron Oxides & 4.E-04 & 3.E-04 & $-2 . E-04$ & 2.E-03 & $\mathrm{N}$ & 0.86 \\
\hline 20 & S1_S & $\mathrm{BP}$ & Calcite & 1.E-03 & 4.E-04 & 2.E-04 & 3.E-03 & $Y$ & 0.86 \\
\hline 21 & S1_S & BP & Quartz & $0 . E+00$ & 2.E-04 & $-5 . E-04$ & 8.E-04 & $\mathrm{N}$ & 0.86 \\
\hline 22 & WRS08 & BP & Iron Oxides & $0 . E+00$ & 9.E-05 & $-2 . E-04$ & 3.E-04 & $\mathrm{N}$ & 0.91 \\
\hline 23 & WRS08 & $\mathrm{BP}$ & Calcite & 2.E-05 & 9.E-05 & $-2 . E-04$ & 3.E-04 & $\mathrm{N}$ & 0.91 \\
\hline 24 & WRS08 & BP & Quartz & $0 . E+00$ & 9.E-05 & $-2 . E-04$ & 3.E-04 & $\mathrm{N}$ & 0.91 \\
\hline 25 & EC06 & $\mathrm{BP}$ & Iron Oxides & 2.E-05 & 1.E-04 & $-3 . E-04$ & 6.E-04 & $\mathrm{N}$ & 1.02 \\
\hline 26 & EC06 & $\mathrm{BP}$ & Calcite & 1.E-04 & 2.E-04 & $-3 . E-04$ & 7.E-04 & $\mathrm{N}$ & 1.02 \\
\hline 27 & EC06 & $\mathrm{BP}$ & Quartz & 1.E-04 & 2.E-04 & $-3 . E-04$ & 7.E-04 & $\mathrm{N}$ & 1.02 \\
\hline 28 & $\mathrm{ECO7}$ & $\mathrm{BP}$ & Iron Oxides & 1.E-04 & 1.E-04 & $-2 . E-04$ & 5.E-04 & $\mathrm{N}$ & 1.04 \\
\hline 29 & $\mathrm{ECO7}$ & $\mathrm{BP}$ & Calcite & $0 . E+00$ & 1.E-04 & $-3 . E-04$ & 4.E-04 & $\mathrm{N}$ & 1.04 \\
\hline 30 & EC07 & $\mathrm{BP}$ & Quartz & 6.E-05 & 1.E-04 & $-2 . E-04$ & 5.E-04 & $\mathrm{N}$ & 1.04 \\
\hline 31 & BH18_2 & $\mathrm{BP}$ & Iron Oxides & 8.E-05 & 1.E-04 & $-2 . E-04$ & 5.E-04 & $\mathrm{N}$ & 1.08 \\
\hline 32 & BH18_2 & $\mathrm{BP}$ & Calcite & 1.E-04 & 1.E-04 & $-2 . E-04$ & 6.E-04 & $\mathrm{N}$ & 1.08 \\
\hline 33 & BH18_2 & $\mathrm{BP}$ & Quartz & 7.E-05 & 1.E-04 & $-2 . E-04$ & 5.E-04 & $\mathrm{N}$ & 1.08 \\
\hline 34 & ECO3 & $\mathrm{BP}$ & Iron Oxides & 2.E-04 & 1.E-04 & $-1 . E-04$ & 7.E-04 & $\mathrm{N}$ & 1.24 \\
\hline 35 & $\mathrm{ECO3}$ & $\mathrm{BP}$ & Calcite & $0 . E+00$ & 1.E-04 & $-3 . E-04$ & 4.E-04 & $\mathrm{N}$ & 1.24 \\
\hline 36 & EC03 & $\mathrm{BP}$ & Quartz & 1.E-04 & 1.E-04 & $-2 . E-04$ & 6.E-04 & $\mathrm{N}$ & 1.24 \\
\hline 37 & Elfin Crossing & $\mathrm{BP}$ & Iron Oxides & 3.E-03 & 5.E-04 & 2.E-03 & 4.E-03 & $\mathrm{Y}$ & 1.42 \\
\hline 38 & Elfin Crossing & $\mathrm{BP}$ & Calcite & 2.E-03 & 4.E-04 & 1.E-03 & 4.E-03 & $\mathrm{Y}$ & 1.42 \\
\hline 39 & Elfin Crossing & $\mathrm{BP}$ & Quartz & 1.E-03 & 3.E-04 & 4.E-04 & 2.E-03 & $\mathrm{Y}$ & 1.42 \\
\hline 40 & WRS05 & $\mathrm{BP}$ & Iron Oxides & $0 . E+00$ & 9.E-05 & $-2 . E-04$ & 3.E-04 & $\mathrm{N}$ & 1.48 \\
\hline 41 & WRS05 & $\mathrm{BP}$ & Calcite & 2.E-05 & 9.E-05 & $-2 . E-04$ & 3.E-04 & $\mathrm{N}$ & 1.48 \\
\hline 42 & WRS05 & $\mathrm{BP}$ & Quartz & $0 . E+00$ & 9.E-05 & $-2 . E-04$ & 3.E-04 & $\mathrm{N}$ & 1.48 \\
\hline
\end{tabular}




\begin{tabular}{|c|c|c|c|c|c|c|c|c|c|}
\hline 43 & Bell river & BP & Iron Oxides & 1.E-03 & 3.E-04 & 3.E-04 & 2.E-03 & $Y$ & 1.74 \\
\hline 44 & Bell river & BP & Calcite & 2.E-03 & 4.E-04 & 7.E-04 & 3.E-03 & $Y$ & 1.74 \\
\hline 45 & Bell river & $\mathrm{BP}$ & Quartz & 5.E-04 & 2.E-04 & $-4 . E-05$ & 1.E-03 & $\mathrm{N}$ & 1.74 \\
\hline 46 & WRS03 & $\mathrm{BP}$ & Iron Oxides & $0 . E+00$ & 9.E-05 & $-2 . E-04$ & 3.E-04 & $\mathrm{N}$ & 1.98 \\
\hline 47 & WRSO3 & $\mathrm{BP}$ & Calcite & 2.E-05 & 9.E-05 & $-2 . E-04$ & 3.E-04 & $\mathrm{N}$ & 1.98 \\
\hline 48 & WRSO3 & $\mathrm{BP}$ & Quartz & $0 . E+00$ & 9.E-05 & $-2 . E-04$ & 3.E-04 & $\mathrm{N}$ & 1.98 \\
\hline 49 & S4_S & $\mathrm{BP}$ & Iron Oxides & 3.E-06 & 2.E-04 & $-5 . E-04$ & 9.E-04 & $\mathrm{N}$ & 6.18 \\
\hline 50 & S4_S & $\mathrm{BP}$ & Calcite & $0 . E+00$ & 2.E-04 & $-5 . E-04$ & 9.E-04 & $\mathrm{N}$ & 6.18 \\
\hline 51 & S4_S & BP & Quartz & 9.E-06 & 2.E-04 & $-5 . E-04$ & 1.E-03 & $N$ & 6.18 \\
\hline 52 & MLSD & $\mathrm{BP}$ & Iron Oxides & 3.E-05 & 2.E-04 & $-4 . E-04$ & 9.E-04 & $\mathrm{N}$ & 6.61 \\
\hline 53 & MLSD & $\mathrm{BP}$ & Calcite & 4.E-04 & 3.E-04 & $-2 . E-04$ & 2.E-03 & $\mathrm{N}$ & 6.61 \\
\hline 54 & MLSD & $\mathrm{BP}$ & Quartz & 3.E-04 & 3.E-04 & $-3 . E-04$ & 1.E-03 & $\mathrm{N}$ & 6.61 \\
\hline 55 & MLSA & BP & Iron Oxides & $0 . E+00$ & 2.E-04 & $-5 . E-04$ & 9.E-04 & $N$ & 6.73 \\
\hline 56 & MLSA & $\mathrm{BP}$ & Calcite & 2.E-04 & 2.E-04 & $-4 . E-04$ & 1.E-03 & $\mathrm{N}$ & 6.73 \\
\hline 57 & MLSA & BP & Quartz & 2.E-03 & 6.E-04 & 6.E-04 & 5.E-03 & $Y$ & 6.73 \\
\hline 58 & MLSB & BP & Iron Oxides & 4.E-04 & 3.E-04 & $-4 . E-04$ & 2.E-03 & $\mathrm{N}$ & 6.76 \\
\hline 59 & MLSB & BP & Calcite & 4.E-04 & 3.E-04 & $-3 . E-04$ & 2.E-03 & $\mathrm{N}$ & 6.76 \\
\hline 60 & MLSB & BP & Quartz & 9.E-04 & 4.E-04 & $-1 . E-04$ & 3.E-03 & $\mathrm{N}$ & 6.76 \\
\hline 61 & Macquarie river & BP & Iron Oxides & 5.E-04 & 3.E-04 & $-1 . E-04$ & 1.E-03 & $\mathrm{N}$ & 8.54 \\
\hline 62 & Macquarie river & BP & Calcite & 1.E-03 & 4.E-04 & 3.E-04 & 3.E-03 & Y & 8.54 \\
\hline 63 & Macquarie river & $\mathrm{BP}$ & Quartz & 9.E-06 & 2.E-04 & $-4 . E-04$ & 7.E-04 & $\mathrm{N}$ & 8.54 \\
\hline 64 & S1_D & BP & Iron Oxides & 3.E-03 & 1.E-03 & 8.E-04 & 9.E-03 & Y & 9.46 \\
\hline 65 & S1_D & $\mathrm{BP}$ & Calcite & 2.E-03 & 8.E-04 & 3.E-04 & 6.E-03 & Y & 9.46 \\
\hline 66 & S1_D & BP & Quartz & $0 . E+00$ & 3.E-04 & $-6 . E-04$ & 1.E-03 & $\mathrm{N}$ & 9.46 \\
\hline 67 & S1_M & $\mathrm{BP}$ & Iron Oxides & 4.E-04 & 3.E-04 & $-2 . E-04$ & 2.E-03 & $\mathrm{N}$ & 10.76 \\
\hline 68 & S1_M & BP & Calcite & 1.E-03 & 4.E-04 & 2.E-04 & 3.E-03 & Y & 10.76 \\
\hline 69 & S1_M & $\mathrm{BP}$ & Quartz & $0 . E+00$ & 2.E-04 & $-5 . E-04$ & 8.E-04 & $\mathrm{N}$ & 10.76 \\
\hline 70 & S2_D & BP & Iron Oxides & 1.E-04 & 4.E-04 & $-6 . E-04$ & 2.E-03 & $\mathrm{N}$ & 15.64 \\
\hline 71 & S2_D & BP & Calcite & 3.E-04 & 4.E-04 & $-5 . E-04$ & 3.E-03 & $\mathrm{N}$ & 15.64 \\
\hline 72 & S2_D & BP & Quartz & $0 . E+00$ & 3.E-04 & $-6 . E-04$ & 2.E-03 & $\mathrm{N}$ & 15.64 \\
\hline
\end{tabular}




\begin{tabular}{|c|c|c|c|c|c|c|c|c|c|}
\hline No & ID & Fractions & Minerals & Response & SE & Lower.CL & Upper.CL & Sorb & Field DOC $\left(\mathrm{mg} \mathrm{L}^{-1}\right)$ \\
\hline 1 & BH.Golf & HS & Iron Oxides & 3.E-04 & 1.E-04 & -1.E-04 & 8.E-04 & $N$ & 0.35 \\
\hline 2 & BH.Golf & HS & Calcite & 2.E-04 & 1.E-04 & $-2 . E-04$ & 7.E-04 & $\mathrm{N}$ & 0.35 \\
\hline 3 & BH.Golf & HS & Quartz & $0 . E+00$ & 1.E-04 & $-3 . E-04$ & 4.E-04 & $\mathrm{N}$ & 0.35 \\
\hline 4 & BH01 & HS & Iron Oxides & 6.E-06 & 5.E-05 & $-1 . E-04$ & 2.E-04 & $\mathrm{N}$ & 0.52 \\
\hline 5 & $\mathrm{BH} 01$ & HS & Calcite & 4.E-04 & 7.E-05 & 2.E-04 & 6.E-04 & $Y$ & 0.52 \\
\hline 6 & $\mathrm{BH} 01$ & HS & Quartz & $0 . E+00$ & 5.E-05 & $-1 . E-04$ & 2.E-04 & $\mathrm{N}$ & 0.52 \\
\hline 7 & The Well & HS & Iron Oxides & 4.E-04 & 3.E-04 & $-2 . E-04$ & 1.E-03 & $\mathrm{N}$ & 0.54 \\
\hline 8 & The Well & HS & Calcite & 1.E-03 & 4.E-04 & 2.E-04 & 3.E-03 & $Y$ & 0.54 \\
\hline 9 & The Well & HS & Quartz & $0 . E+00$ & 2.E-04 & $-4 . E-04$ & 8.E-04 & $\mathrm{N}$ & 0.54 \\
\hline 10 & BH19_2 & HS & Iron Oxides & 6.E-04 & 2.E-04 & 8.E-05 & 2.E-03 & Y & 0.61 \\
\hline 11 & BH19_2 & HS & Calcite & 2.E-04 & 2.E-04 & $-2 . E-04$ & 8.E-04 & $\mathrm{N}$ & 0.61 \\
\hline 12 & BH19_2 & HS & Quartz & $0 . E+00$ & 1.E-04 & $-3 . E-04$ & 5.E-04 & $\mathrm{N}$ & 0.61 \\
\hline 13 & BH12_4 & HS & Iron Oxides & 2.E-04 & 1.E-04 & $-1 . E-04$ & 7.E-04 & $\mathrm{N}$ & 0.66 \\
\hline 14 & BH12_4 & HS & Calcite & 1.E-04 & 1.E-04 & $-2 . E-04$ & 6.E-04 & $\mathrm{N}$ & 0.66 \\
\hline 15 & BH12_4 & HS & Quartz & 9.E-04 & 2.E-04 & 3.E-04 & 2.E-03 & $Y$ & 0.66 \\
\hline 16 & EC31 & HS & Iron Oxides & 8.E-04 & 1.E-04 & 4.E-04 & 1.E-03 & $Y$ & 0.68 \\
\hline 17 & EC31 & HS & Calcite & 5.E-04 & 1.E-04 & 2.E-04 & 9.E-04 & $Y$ & 0.68 \\
\hline 18 & EC31 & HS & Quartz & 3.E-04 & 1.E-04 & 4.E-05 & 7.E-04 & $Y$ & 0.68 \\
\hline 19 & S1_S & HS & Iron Oxides & 1.E-02 & 3.E-03 & 6.E-03 & 2.E-02 & $Y$ & 0.86 \\
\hline 20 & S1_S & HS & Calcite & 8.E-03 & 2.E-03 & 4.E-03 & 2.E-02 & $Y$ & 0.86 \\
\hline 21 & S1_S & HS & Quartz & 7.E-03 & 2.E-03 & 3.E-03 & 1.E-02 & $Y$ & 0.86 \\
\hline 22 & WRS08 & HS & Iron Oxides & 2.E-03 & 2.E-04 & 9.E-04 & 2.E-03 & $Y$ & 0.91 \\
\hline 23 & WRS08 & HS & Calcite & 2.E-03 & 3.E-04 & 2.E-03 & 3.E-03 & $Y$ & 0.91 \\
\hline 24 & WRS08 & HS & Quartz & 1.E-03 & 2.E-04 & 8.E-04 & 2.E-03 & $Y$ & 0.91 \\
\hline 25 & EC06 & HS & Iron Oxides & 3.E-03 & 6.E-04 & 2.E-03 & 5.E-03 & $Y$ & 1.02 \\
\hline 26 & EC06 & HS & Calcite & 3.E-03 & 5.E-04 & 1.E-03 & 5.E-03 & $Y$ & 1.02 \\
\hline 27 & EC06 & HS & Quartz & 2.E-03 & 4.E-04 & 7.E-04 & 3.E-03 & $Y$ & 1.02 \\
\hline 28 & $\mathrm{ECO} 7$ & HS & Iron Oxides & 3.E-03 & 4.E-04 & 2.E-03 & 4.E-03 & $Y$ & 1.04 \\
\hline 29 & EC07 & HS & Calcite & 3.E-03 & 4.E-04 & 2.E-03 & 4.E-03 & $Y$ & 1.04 \\
\hline
\end{tabular}




\begin{tabular}{|c|c|c|c|c|c|c|c|c|c|}
\hline 30 & ECO7 & HS & Quartz & 8.E-04 & 2.E-04 & 3.E-04 & 1.E-03 & $Y$ & 1.04 \\
\hline 31 & BH18_2 & HS & Iron Oxides & 2.E-03 & 3.E-04 & 8.E-04 & 3.E-03 & $Y$ & 1.08 \\
\hline 32 & BH18_2 & HS & Calcite & 1.E-03 & 2.E-04 & 5.E-04 & 2.E-03 & $Y$ & 1.08 \\
\hline 33 & BH18_2 & HS & Quartz & 1.E-03 & 2.E-04 & 4.E-04 & 2.E-03 & $Y$ & 1.08 \\
\hline 34 & ECO3 & HS & Iron Oxides & 3.E-03 & 4.E-04 & 2.E-03 & 4.E-03 & $Y$ & 1.24 \\
\hline 35 & $\mathrm{ECO3}$ & HS & Calcite & 2.E-03 & 3.E-04 & 1.E-03 & 3.E-03 & $Y$ & 1.24 \\
\hline 36 & ECO3 & HS & Quartz & 1.E-03 & 2.E-04 & 6.E-04 & 2.E-03 & $Y$ & 1.24 \\
\hline 37 & Elfin Crossing & HS & Iron Oxides & 1.E-03 & 3.E-04 & 6.E-04 & 2.E-03 & $Y$ & 1.42 \\
\hline 38 & Elfin Crossing & HS & Calcite & 2.E-03 & 4.E-04 & 1.E-03 & 4.E-03 & $Y$ & 1.42 \\
\hline 39 & Elfin Crossing & HS & Quartz & 2.E-03 & 3.E-04 & 8.E-04 & 3.E-03 & $Y$ & 1.42 \\
\hline 40 & WRS05 & HS & Iron Oxides & 2.E-03 & 2.E-04 & 9.E-04 & 2.E-03 & $Y$ & 1.48 \\
\hline 41 & WRS05 & HS & Calcite & 2.E-03 & 3.E-04 & 2.E-03 & 3.E-03 & $Y$ & 1.48 \\
\hline 42 & WRS05 & HS & Quartz & 1.E-03 & 2.E-04 & 8.E-04 & 2.E-03 & $Y$ & 1.48 \\
\hline 43 & Bell river & HS & Iron Oxides & 4.E-03 & 8.E-04 & 2.E-03 & 7.E-03 & $Y$ & 1.74 \\
\hline 44 & Bell river & HS & Calcite & 4.E-03 & 8.E-04 & 2.E-03 & 8.E-03 & $\mathrm{Y}$ & 1.74 \\
\hline 45 & Bell river & HS & Quartz & 4.E-03 & 7.E-04 & 2.E-03 & 6.E-03 & $Y$ & 1.74 \\
\hline 46 & WRS03 & HS & Iron Oxides & 2.E-03 & 2.E-04 & 9.E-04 & 2.E-03 & $Y$ & 1.98 \\
\hline 47 & WRS03 & HS & Calcite & 2.E-03 & 3.E-04 & 2.E-03 & 3.E-03 & $Y$ & 1.98 \\
\hline 48 & WRS03 & HS & Quartz & 1.E-03 & 2.E-04 & 8.E-04 & 2.E-03 & $Y$ & 1.98 \\
\hline 49 & S4_S & HS & Iron Oxides & 3.E-02 & 6.E-03 & 1.E-02 & 6.E-02 & $Y$ & 6.18 \\
\hline 50 & S4_S & HS & Calcite & 1.E-02 & 3.E-03 & 7.E-03 & 3.E-02 & $Y$ & 6.18 \\
\hline 51 & S4_S & HS & Quartz & 8.E-03 & 2.E-03 & 4.E-03 & 2.E-02 & $Y$ & 6.18 \\
\hline 52 & MLSD & HS & Iron Oxides & 7.E-03 & 1.E-03 & 3.E-03 & 1.E-02 & $Y$ & 6.61 \\
\hline 53 & MLSD & HS & Calcite & 4.E-03 & 1.E-03 & 2.E-03 & 8.E-03 & $Y$ & 6.61 \\
\hline 54 & MLSD & HS & Quartz & 2.E-03 & 6.E-04 & 6.E-04 & 4.E-03 & $Y$ & 6.61 \\
\hline 55 & MLSA & HS & Iron Oxides & 1.E-02 & 3.E-03 & 6.E-03 & 2.E-02 & $Y$ & 6.73 \\
\hline 56 & MLSA & HS & Calcite & 7.E-03 & 2.E-03 & 3.E-03 & 1.E-02 & $Y$ & 6.73 \\
\hline 57 & MLSA & HS & Quartz & 4.E-03 & 1.E-03 & 2.E-03 & 9.E-03 & $Y$ & 6.73 \\
\hline 58 & MLSB & HS & Iron Oxides & 9.E-03 & 2.E-03 & 4.E-03 & 2.E-02 & $Y$ & 6.76 \\
\hline 59 & MLSB & HS & Calcite & 8.E-03 & 2.E-03 & 3.E-03 & 2.E-02 & $Y$ & 6.76 \\
\hline 60 & MLSB & HS & Quartz & 5.E-03 & 1.E-03 & 2.E-03 & 1.E-02 & $\mathrm{Y}$ & 6.76 \\
\hline
\end{tabular}




\begin{tabular}{|c|c|c|c|c|c|c|c|c|c|}
\hline 61 & Macquarie river & $\mathrm{HS}$ & Iron Oxides & 8.E-03 & 2.E-03 & 4.E-03 & 1.E-02 & $Y$ & 8.54 \\
\hline 62 & Macquarie river & HS & Calcite & 1.E-02 & 2.E-03 & 6.E-03 & 2.E-02 & $Y$ & 8.54 \\
\hline 63 & Macquarie river & HS & Quartz & 8.E-03 & 1.E-03 & 4.E-03 & 1.E-02 & $Y$ & 8.54 \\
\hline 65 & S1_D & HS & Calcite & 7.E-03 & 2.E-03 & 3.E-03 & 2.E-02 & $Y$ & 9.46 \\
\hline 66 & S1_D & $\mathrm{HS}$ & Quartz & 6.E-03 & 2.E-03 & 2.E-03 & 2.E-02 & Y & 9.46 \\
\hline 67 & S1_M & $\mathrm{HS}$ & Iron Oxides & 1.E-02 & 3.E-03 & $6 . \mathrm{E}-03$ & 2.E-02 & $Y$ & 10.76 \\
\hline 69 & S1_M & $\mathrm{HS}$ & Quartz & 7.E-03 & 2.E-03 & 3.E-03 & 1.E-02 & $Y$ & 10.76 \\
\hline 70 & S2_D & $\mathrm{HS}$ & Iron Oxides & 3.E-02 & 1.E-02 & 1.E-02 & 8.E-02 & $Y$ & 15.64 \\
\hline 71 & S2_D & $\mathrm{HS}$ & Calcite & 2.E-02 & 7.E-03 & 8.E-03 & 6.E-02 & $Y$ & 15.64 \\
\hline 72 & S2_D & $\mathrm{HS}$ & Quartz & 1.E-02 & 5.E-03 & 5.E-03 & 4.E-02 & $Y$ & 15.64 \\
\hline 3 & BH.Golf & BB & Quartz & $0 . E+00$ & 1.E-04 & $-3 . E-04$ & 4.E-04 & $\mathrm{N}$ & 0.35 \\
\hline 4 & BH01 & BB & Iron Oxides & 2.E-05 & 5.E-05 & $-1 . E-04$ & 2.E-04 & $\mathrm{N}$ & 0.52 \\
\hline 5 & $\mathrm{BH} 01$ & BB & Calcite & $0 . E+00$ & 5.E-05 & $-1 . E-04$ & 2.E-04 & $\mathrm{N}$ & 0.52 \\
\hline 6 & BH01 & BB & Quartz & $0 . E+00$ & 5.E-05 & $-1 . E-04$ & 2.E-04 & $\mathrm{N}$ & 0.52 \\
\hline 7 & The Well & BB & Iron Oxides & 5.E-05 & 2.E-04 & $-4 . E-04$ & 9.E-04 & $\mathrm{N}$ & 0.54 \\
\hline 8 & The Well & $\mathrm{BB}$ & Calcite & 9.E-04 & 4.E-04 & 7.E-05 & 2.E-03 & $Y$ & 0.54 \\
\hline 9 & The Well & $\mathrm{BB}$ & Quartz & 4.E-04 & 3.E-04 & $-2 . E-04$ & 2.E-03 & $\mathrm{N}$ & 0.54 \\
\hline 10 & BH19_2 & $\mathrm{BB}$ & Iron Oxides & $0 . E+00$ & 1.E-04 & $-3 . E-04$ & 5.E-04 & $\mathrm{N}$ & 0.61 \\
\hline 11 & BH19_2 & $\mathrm{BB}$ & Calcite & 7.E-06 & 1.E-04 & $-3 . E-04$ & 5.E-04 & $\mathrm{N}$ & 0.61 \\
\hline
\end{tabular}




\begin{tabular}{|c|c|c|c|c|c|c|c|c|c|}
\hline 18 & EC31 & BB & Quartz & 8.E-06 & 8.E-05 & $-2 . E-04$ & 3.E-04 & $\mathrm{N}$ & 0.68 \\
\hline 19 & S1_S & BB & Iron Oxides & 5.E-03 & 1.E-03 & 2.E-03 & 1.E-02 & $Y$ & 0.86 \\
\hline 20 & S1_S & BB & Calcite & 5.E-03 & 1.E-03 & 2.E-03 & 1.E-02 & $Y$ & 0.86 \\
\hline 21 & S1_S & BB & Quartz & 4.E-03 & 1.E-03 & 2.E-03 & 9.E-03 & $Y$ & 0.86 \\
\hline 22 & WRS08 & BB & Iron Oxides & $0 . E+00$ & 9.E-05 & $-2 . E-04$ & 3.E-04 & $\mathrm{N}$ & 0.91 \\
\hline 23 & WRS08 & BB & Calcite & $0 . E+00$ & 9.E-05 & $-2 . E-04$ & 3.E-04 & $\mathrm{N}$ & 0.91 \\
\hline 24 & WRS08 & BB & Quartz & $0 . E+00$ & 9.E-05 & $-2 . E-04$ & 3.E-04 & $\mathrm{N}$ & 0.91 \\
\hline 25 & EC06 & BB & Iron Oxides & 2.E-04 & 2.E-04 & $-2 . E-04$ & 9.E-04 & $\mathrm{N}$ & 1.02 \\
\hline 26 & EC06 & BB & Calcite & 5.E-04 & 2.E-04 & $-4 . E-05$ & 1.E-03 & $\mathrm{N}$ & 1.02 \\
\hline 27 & EC06 & BB & Quartz & $0 . E+00$ & 1.E-04 & $-3 . E-04$ & 5.E-04 & $\mathrm{N}$ & 1.02 \\
\hline 28 & EC07 & BB & Iron Oxides & $0 . E+00$ & 1.E-04 & $-3 . E-04$ & 4.E-04 & $\mathrm{N}$ & 1.04 \\
\hline 29 & ECO7 & BB & Calcite & 3.E-05 & 1.E-04 & $-3 . E-04$ & 4.E-04 & $\mathrm{N}$ & 1.04 \\
\hline 30 & EC07 & BB & Quartz & $0 . E+00$ & 1.E-04 & $-3 . E-04$ & 4.E-04 & $\mathrm{N}$ & 1.04 \\
\hline 31 & BH18_2 & BB & Iron Oxides & 1.E-03 & 3.E-04 & 6.E-04 & 2.E-03 & $\mathrm{Y}$ & 1.08 \\
\hline 32 & BH18_2 & BB & Calcite & 1.E-03 & 3.E-04 & 6.E-04 & 2.E-03 & $Y$ & 1.08 \\
\hline 33 & BH18_2 & BB & Quartz & $0 . E+00$ & 1.E-04 & $-3 . E-04$ & 4.E-04 & $\mathrm{N}$ & 1.08 \\
\hline 34 & EC03 & BB & Iron Oxides & 8.E-05 & 1.E-04 & $-2 . E-04$ & 5.E-04 & $\mathrm{N}$ & 1.24 \\
\hline 35 & ECO3 & BB & Calcite & 2.E-04 & 1.E-04 & $-1 . E-04$ & 7.E-04 & $\mathrm{N}$ & 1.24 \\
\hline 36 & ECO3 & BB & Quartz & $0 . E+00$ & 1.E-04 & $-3 . E-04$ & 4.E-04 & $\mathrm{N}$ & 1.24 \\
\hline 37 & Elfin Crossing & BB & Iron Oxides & 3.E-04 & 2.E-04 & $-1 . E-04$ & 9.E-04 & $\mathrm{N}$ & 1.42 \\
\hline 38 & Elfin Crossing & BB & Calcite & $0 . E+00$ & 1.E-04 & $-3 . E-04$ & 5.E-04 & $\mathrm{N}$ & 1.42 \\
\hline 39 & Elfin Crossing & BB & Quartz & $0 . E+00$ & 1.E-04 & $-3 . E-04$ & 5.E-04 & $\mathrm{N}$ & 1.42 \\
\hline 40 & WRS05 & BB & Iron Oxides & $0 . E+00$ & 9.E-05 & $-2 . E-04$ & 3.E-04 & $\mathrm{N}$ & 1.48 \\
\hline 41 & WRS05 & BB & Calcite & $0 . E+00$ & 9.E-05 & $-2 . E-04$ & 3.E-04 & $\mathrm{N}$ & 1.48 \\
\hline 42 & WRS05 & BB & Quartz & $0 . E+00$ & 9.E-05 & $-2 . E-04$ & 3.E-04 & $\mathrm{N}$ & 1.48 \\
\hline 43 & Bell river & BB & Iron Oxides & $0 . E+00$ & 1.E-04 & $-4 . E-04$ & 6.E-04 & $\mathrm{N}$ & 1.74 \\
\hline 44 & Bell river & BB & Calcite & 7.E-05 & 2.E-04 & $-3 . E-04$ & 7.E-04 & $\mathrm{N}$ & 1.74 \\
\hline 45 & Bell river & BB & Quartz & $0 . E+00$ & 1.E-04 & $-4 . E-04$ & 6.E-04 & $\mathrm{N}$ & 1.74 \\
\hline 46 & WRS03 & BB & Iron Oxides & $0 . E+00$ & 9.E-05 & $-2 . E-04$ & 3.E-04 & $\mathrm{N}$ & 1.98 \\
\hline 47 & WRSO3 & BB & Calcite & $0 . E+00$ & 9.E-05 & $-2 . E-04$ & 3.E-04 & $\mathrm{N}$ & 1.98 \\
\hline 48 & WRSO3 & BB & Quartz & $0 . E+00$ & 9.E-05 & $-2 . E-04$ & 3.E-04 & $\mathrm{N}$ & 1.98 \\
\hline
\end{tabular}




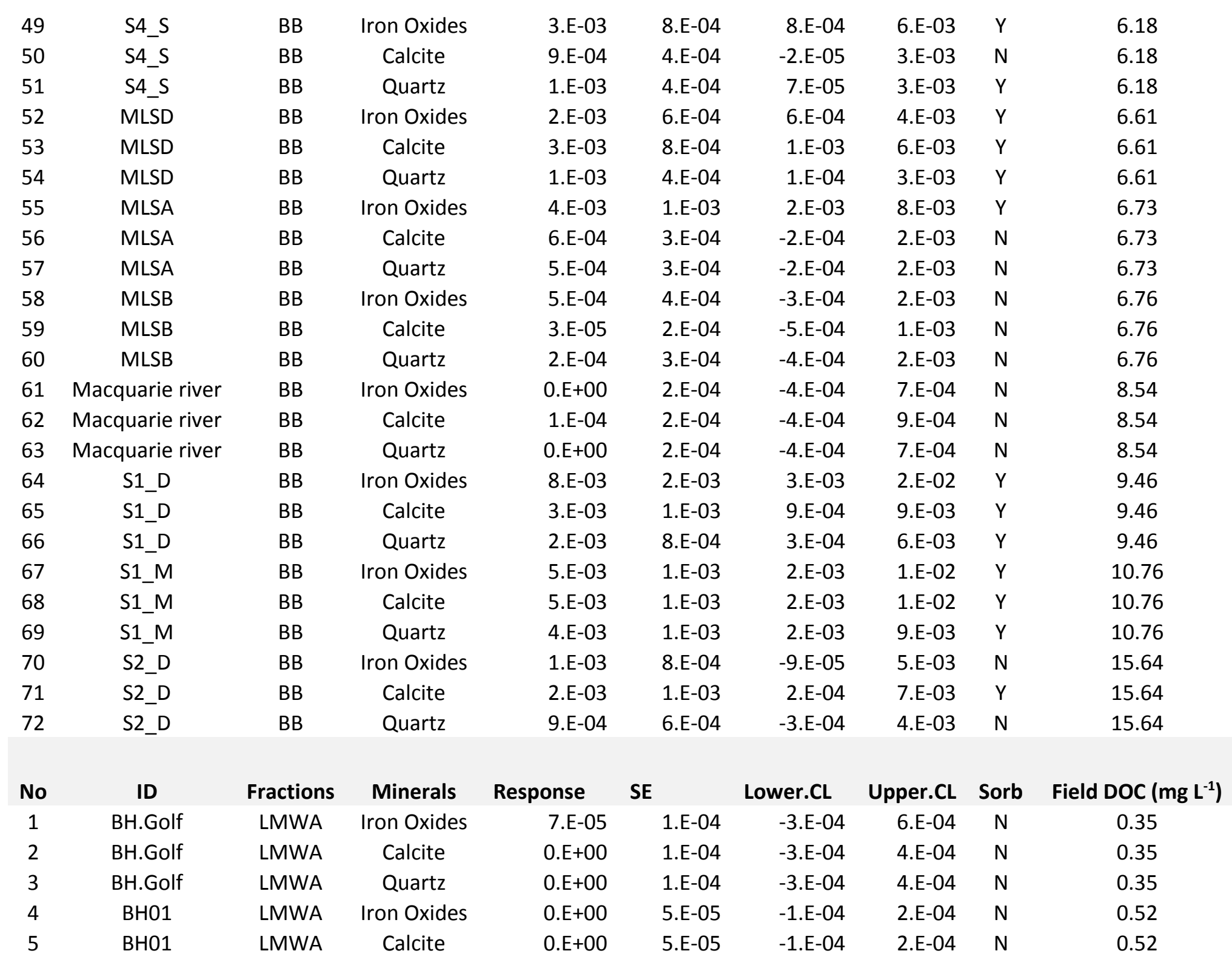




\begin{tabular}{|c|c|c|c|c|c|c|c|c|c|}
\hline 6 & BHO1 & LMWA & Quartz & $0 . E+00$ & 5.E-05 & $-1 . E-04$ & 2.E-04 & $\mathrm{N}$ & 0.52 \\
\hline 7 & The Well & LMWA & Iron Oxides & $0 . E+00$ & 2.E-04 & $-4 . E-04$ & 8.E-04 & $\mathrm{N}$ & 0.54 \\
\hline 8 & The Well & LMWA & Calcite & $0 . E+00$ & 2.E-04 & $-4 . E-04$ & 8.E-04 & $\mathrm{N}$ & 0.54 \\
\hline 9 & The Well & LMWA & Quartz & $0 . E+00$ & 2.E-04 & $-4 . E-04$ & 8.E-04 & $\mathrm{N}$ & 0.54 \\
\hline 10 & BH19_2 & LMWA & Iron Oxides & $0 . E+00$ & 1.E-04 & $-3 . E-04$ & 5.E-04 & $\mathrm{N}$ & 0.61 \\
\hline 11 & BH19_2 & LMWA & Calcite & $0 . E+00$ & 1.E-04 & $-3 . E-04$ & 5.E-04 & $\mathrm{N}$ & 0.61 \\
\hline 12 & BH19_2 & LMWA & Quartz & $0 . E+00$ & 1.E-04 & $-3 . E-04$ & 5.E-04 & $\mathrm{N}$ & 0.61 \\
\hline 13 & BH12_4 & LMWA & Iron Oxides & 4.E-04 & 2.E-04 & 9.E-06 & 1.E-03 & $Y$ & 0.66 \\
\hline 14 & BH12_4 & LMWA & Calcite & $0 . E+00$ & 1.E-04 & $-3 . E-04$ & 4.E-04 & $\mathrm{N}$ & 0.66 \\
\hline 15 & BH12_4 & LMWA & Quartz & $0 . E+00$ & 1.E-04 & $-3 . E-04$ & 4.E-04 & $\mathrm{N}$ & 0.66 \\
\hline 16 & EC31 & LMWA & Iron Oxides & $0 . E+00$ & 8.E-05 & $-2 . E-04$ & 3.E-04 & $\mathrm{N}$ & 0.68 \\
\hline 17 & EC31 & LMWA & Calcite & $0 . E+00$ & 8.E-05 & $-2 . E-04$ & 3.E-04 & $\mathrm{N}$ & 0.68 \\
\hline 18 & EC31 & LMWA & Quartz & $0 . E+00$ & 8.E-05 & $-2 . E-04$ & 3.E-04 & $\mathrm{N}$ & 0.68 \\
\hline 19 & S1_S & LMWA & Iron Oxides & $0 . E+00$ & 2.E-04 & $-5 . E-04$ & 8.E-04 & $\mathrm{N}$ & 0.86 \\
\hline 20 & S1_S & LMWA & Calcite & $0 . E+00$ & 2.E-04 & $-5 . E-04$ & 8.E-04 & $\mathrm{N}$ & 0.86 \\
\hline 21 & S1_S & LMWA & Quartz & $0 . E+00$ & 2.E-04 & $-5 . E-04$ & 8.E-04 & $\mathrm{N}$ & 0.86 \\
\hline 22 & WRS08 & LMWA & Iron Oxides & $0 . E+00$ & 9.E-05 & $-2 . E-04$ & 3.E-04 & $\mathrm{N}$ & 0.91 \\
\hline 23 & WRS08 & LMWA & Calcite & $0 . E+00$ & 9.E-05 & $-2 . E-04$ & 3.E-04 & $\mathrm{N}$ & 0.91 \\
\hline 24 & WRS08 & LMWA & Quartz & $0 . E+00$ & 9.E-05 & $-2 . E-04$ & 3.E-04 & $\mathrm{N}$ & 0.91 \\
\hline 25 & EC06 & LMWA & Iron Oxides & $0 . E+00$ & 1.E-04 & $-3 . E-04$ & 5.E-04 & $\mathrm{N}$ & 1.02 \\
\hline 26 & ECO6 & LMWA & Calcite & $0 . E+00$ & 1.E-04 & $-3 . E-04$ & 5.E-04 & $\mathrm{N}$ & 1.02 \\
\hline 27 & EC06 & LMWA & Quartz & $0 . E+00$ & 1.E-04 & $-3 . E-04$ & 5.E-04 & $\mathrm{N}$ & 1.02 \\
\hline 28 & $\mathrm{ECO7}$ & LMWA & Iron Oxides & $0 . E+00$ & 1.E-04 & $-3 . E-04$ & 4.E-04 & $\mathrm{N}$ & 1.04 \\
\hline 29 & ECO7 & LMWA & Calcite & $0 . E+00$ & 1.E-04 & $-3 . E-04$ & 4.E-04 & $\mathrm{N}$ & 1.04 \\
\hline 30 & EC07 & LMWA & Quartz & $0 . E+00$ & 1.E-04 & $-3 . E-04$ & 4.E-04 & $\mathrm{N}$ & 1.04 \\
\hline 31 & BH18_2 & LMWA & Iron Oxides & $0 . E+00$ & 1.E-04 & $-3 . E-04$ & 4.E-04 & $\mathrm{N}$ & 1.08 \\
\hline 32 & BH18_2 & LMWA & Calcite & $0 . E+00$ & 1.E-04 & $-3 . E-04$ & 4.E-04 & $\mathrm{N}$ & 1.08 \\
\hline 33 & BH18_2 & LMWA & Quartz & $0 . E+00$ & 1.E-04 & $-3 . E-04$ & 4.E-04 & $\mathrm{N}$ & 1.08 \\
\hline 34 & EC03 & LMWA & Iron Oxides & $0 . E+00$ & 1.E-04 & $-3 . E-04$ & 4.E-04 & $\mathrm{N}$ & 1.24 \\
\hline 35 & $\mathrm{ECO3}$ & LMWA & Calcite & $0 . E+00$ & 1.E-04 & $-3 . E-04$ & 4.E-04 & $\mathrm{N}$ & 1.24 \\
\hline 36 & ECO3 & LMWA & Quartz & $0 . E+00$ & 1.E-04 & $-3 . E-04$ & 4.E-04 & $\mathrm{N}$ & 1.24 \\
\hline
\end{tabular}




\begin{tabular}{|c|c|c|c|c|c|c|c|c|c|}
\hline 37 & Elfin Crossing & LMWA & Iron Oxides & $0 . E+00$ & 1.E-04 & $-3 . E-04$ & 5.E-04 & $\mathrm{N}$ & 1.42 \\
\hline 38 & Elfin Crossing & LMWA & Calcite & $0 . E+00$ & 1.E-04 & $-3 . E-04$ & 5.E-04 & $\mathrm{N}$ & 1.42 \\
\hline 39 & Elfin Crossing & LMWA & Quartz & $0 . E+00$ & 1.E-04 & $-3 . E-04$ & 5.E-04 & $\mathrm{N}$ & 1.42 \\
\hline 40 & WRS05 & LMWA & Iron Oxides & $0 . E+00$ & 9.E-05 & $-2 . E-04$ & 3.E-04 & $\mathrm{N}$ & 1.48 \\
\hline 41 & WRS05 & LMWA & Calcite & $0 . E+00$ & 9.E-05 & $-2 . E-04$ & 3.E-04 & $\mathrm{N}$ & 1.48 \\
\hline 42 & WRS05 & LMWA & Quartz & $0 . E+00$ & 9.E-05 & $-2 . E-04$ & 3.E-04 & $\mathrm{N}$ & 1.48 \\
\hline 43 & Bell river & LMWA & Iron Oxides & $0 . E+00$ & 1.E-04 & $-4 . E-04$ & 6.E-04 & $\mathrm{N}$ & 1.74 \\
\hline 44 & Bell river & LMWA & Calcite & $0 . E+00$ & 1.E-04 & $-4 . E-04$ & 6.E-04 & $\mathrm{N}$ & 1.74 \\
\hline 45 & Bell river & LMWA & Quartz & $0 . E+00$ & 1.E-04 & $-4 . E-04$ & 6.E-04 & $\mathrm{N}$ & 1.74 \\
\hline 46 & WRSO3 & LMWA & Iron Oxides & $0 . E+00$ & 9.E-05 & $-2 . E-04$ & 3.E-04 & $\mathrm{N}$ & 1.98 \\
\hline 47 & WRSO3 & LMWA & Calcite & $0 . E+00$ & 9.E-05 & $-2 . E-04$ & 3.E-04 & $\mathrm{N}$ & 1.98 \\
\hline 48 & WRSO3 & LMWA & Quartz & $0 . E+00$ & 9.E-05 & $-2 . E-04$ & 3.E-04 & $\mathrm{N}$ & 1.98 \\
\hline 49 & S4_S & LMWA & Iron Oxides & $0 . E+00$ & 2.E-04 & $-5 . E-04$ & 9.E-04 & $\mathrm{N}$ & 6.18 \\
\hline 50 & S4_S & LMWA & Calcite & $0 . E+00$ & 2.E-04 & $-5 . E-04$ & 9.E-04 & $\mathrm{N}$ & 6.18 \\
\hline 51 & S4_S & LMWA & Quartz & $0 . E+00$ & 2.E-04 & $-5 . E-04$ & 9.E-04 & $\mathrm{N}$ & 6.18 \\
\hline 52 & MLSD & LMWA & Iron Oxides & $0 . E+00$ & 2.E-04 & $-5 . E-04$ & 8.E-04 & $\mathrm{N}$ & 6.61 \\
\hline 53 & MLSD & LMWA & Calcite & $0 . E+00$ & 2.E-04 & $-5 . E-04$ & 8.E-04 & $\mathrm{N}$ & 6.61 \\
\hline 54 & MLSD & LMWA & Quartz & $0 . E+00$ & 2.E-04 & $-5 . E-04$ & 8.E-04 & $\mathrm{N}$ & 6.61 \\
\hline 55 & MLSA & LMWA & Iron Oxides & $0 . E+00$ & 2.E-04 & $-5 . E-04$ & 9.E-04 & $\mathrm{N}$ & 6.73 \\
\hline 56 & MLSA & LMWA & Calcite & $0 . E+00$ & 2.E-04 & $-5 . E-04$ & 9.E-04 & $\mathrm{N}$ & 6.73 \\
\hline 57 & MLSA & LMWA & Quartz & $0 . E+00$ & 2.E-04 & $-5 . E-04$ & 9.E-04 & $\mathrm{N}$ & 6.73 \\
\hline 58 & MLSB & LMWA & Iron Oxides & $0 . E+00$ & 2.E-04 & $-5 . E-04$ & 1.E-03 & $\mathrm{N}$ & 6.76 \\
\hline 59 & MLSB & LMWA & Calcite & $0 . E+00$ & 2.E-04 & $-5 . E-04$ & 1.E-03 & $\mathrm{N}$ & 6.76 \\
\hline 60 & MLSB & LMWA & Quartz & $0 . E+00$ & 2.E-04 & $-5 . E-04$ & 1.E-03 & $\mathrm{N}$ & 6.76 \\
\hline 61 & Macquarie river & LMWA & Iron Oxides & 1.E-04 & 2.E-04 & $-3 . E-04$ & 9.E-04 & $\mathrm{N}$ & 8.54 \\
\hline 62 & Macquarie river & LMWA & Calcite & $0 . E+00$ & 2.E-04 & $-4 . E-04$ & 7.E-04 & $\mathrm{N}$ & 8.54 \\
\hline 63 & Macquarie river & LMWA & Quartz & $0 . E+00$ & 2.E-04 & $-4 . E-04$ & 7.E-04 & $\mathrm{N}$ & 8.54 \\
\hline 64 & S1_D & LMWA & Iron Oxides & $0 . E+00$ & 3.E-04 & $-6 . E-04$ & 1.E-03 & $\mathrm{N}$ & 9.46 \\
\hline 65 & S1_D & LMWA & Calcite & $0 . E+00$ & 3.E-04 & $-6 . E-04$ & 1.E-03 & $\mathrm{N}$ & 9.46 \\
\hline 66 & S1_D & LMWA & Quartz & $0 . E+00$ & 3.E-04 & $-6 . E-04$ & 1.E-03 & $\mathrm{N}$ & 9.46 \\
\hline 67 & S1_M & LMWA & Iron Oxides & $0 . E+00$ & 2.E-04 & $-5 . E-04$ & 8.E-04 & $\mathrm{N}$ & 10.76 \\
\hline
\end{tabular}




\begin{tabular}{|c|c|c|c|c|c|c|c|c|c|}
\hline 68 & S1_M & LMWA & Calcite & $0 . E+00$ & 2.E-04 & $-5 . E-04$ & 8.E-04 & $\mathrm{N}$ & 10.76 \\
\hline 69 & S1_M & LMWA & Quartz & $0 . E+00$ & 2.E-04 & $-5 . E-04$ & 8.E-04 & $\mathrm{N}$ & 10.76 \\
\hline 70 & S2_D & LMWA & Iron Oxides & $0 . E+00$ & 3.E-04 & $-6 . E-04$ & 2.E-03 & $\mathrm{N}$ & 15.64 \\
\hline 72 & S2_D & LMWA & Quartz & $0 . E+00$ & 3.E-04 & $-6 . E-04$ & 2.E-03 & $\mathrm{N}$ & 15.64 \\
\hline 2 & BH.Golf & LMWN & Calcite & $0 . E+00$ & 1.E-04 & $-3 . E-04$ & 4.E-04 & $\mathrm{N}$ & 0.35 \\
\hline 3 & BH.Golf & LMWN & Quartz & $0 . E+00$ & 1.E-04 & $-3 . E-04$ & 4.E-04 & $\mathrm{N}$ & 0.35 \\
\hline 4 & BH01 & LMWN & Iron Oxides & $0 . E+00$ & 5.E-05 & $-1 . E-04$ & 2.E-04 & $\mathrm{N}$ & 0.52 \\
\hline 5 & $\mathrm{BHO1}$ & LMWN & Calcite & 1.E-04 & 6.E-05 & $-3 . E-05$ & 3.E-04 & $\mathrm{N}$ & 0.52 \\
\hline 10 & BH19_2 & LMWN & Iron Oxides & 3.E-04 & 2.E-04 & $-2 . E-04$ & 1.E-03 & $\mathrm{N}$ & 0.61 \\
\hline 11 & BH19_2 & LMWN & Calcite & $0 . E+00$ & 1.E-04 & $-3 . E-04$ & 5.E-04 & $\mathrm{N}$ & 0.61 \\
\hline 12 & BH19_2 & LMWN & Quartz & 2.E-04 & 2.E-04 & $-2 . E-04$ & 8.E-04 & $\mathrm{N}$ & 0.61 \\
\hline 13 & BH12_4 & LMWN & Iron Oxides & 2.E-04 & 1.E-04 & $-1 . E-04$ & 7.E-04 & $\mathrm{N}$ & 0.66 \\
\hline 14 & BH12_4 & LMWN & Calcite & 3.E-04 & 1.E-04 & $-4 . E-05$ & 9.E-04 & $\mathrm{N}$ & 0.66 \\
\hline 15 & BH12_4 & LMWN & Quartz & 1.E-03 & 2.E-04 & 7.E-04 & 2.E-03 & $Y$ & 0.66 \\
\hline 16 & EC31 & LMWN & Iron Oxides & 4.E-04 & 1.E-04 & 8.E-05 & 8.E-04 & $Y$ & 0.68 \\
\hline 17 & EC31 & LMWN & Calcite & $0 . E+00$ & 8.E-05 & $-2 . E-04$ & 3.E-04 & $\mathrm{N}$ & 0.68 \\
\hline 18 & EC31 & LMWN & Quartz & 2.E-05 & 8.E-05 & $-2 . E-04$ & 3.E-04 & $\mathrm{N}$ & 0.68 \\
\hline
\end{tabular}




\begin{tabular}{|c|c|c|c|c|c|c|c|c|c|}
\hline 25 & EC06 & LMWN & Iron Oxides & 9.E-04 & 3.E-04 & 2.E-04 & 2.E-03 & $Y$ & 1.02 \\
\hline 26 & EC06 & LMWN & Calcite & 2.E-03 & 4.E-04 & 1.E-03 & 4.E-03 & $Y$ & 1.02 \\
\hline 27 & EC06 & LMWN & Quartz & 1.E-04 & 2.E-04 & $-3 . E-04$ & 7.E-04 & $\mathrm{N}$ & 1.02 \\
\hline 28 & $\mathrm{ECO7}$ & LMWN & Iron Oxides & 1.E-03 & 2.E-04 & 5.E-04 & 2.E-03 & $Y$ & 1.04 \\
\hline 29 & $\mathrm{ECO7}$ & LMWN & Calcite & $0 . E+00$ & 1.E-04 & $-3 . E-04$ & 4.E-04 & $\mathrm{N}$ & 1.04 \\
\hline 30 & ECO7 & LMWN & Quartz & 4.E-05 & 1.E-04 & $-2 . E-04$ & 4.E-04 & $\mathrm{N}$ & 1.04 \\
\hline 31 & BH18_2 & LMWN & Iron Oxides & 1.E-03 & 2.E-04 & 5.E-04 & 2.E-03 & $Y$ & 1.08 \\
\hline 32 & BH18_2 & LMWN & Calcite & 4.E-04 & 2.E-04 & 1.E-05 & 1.E-03 & $Y$ & 1.08 \\
\hline 33 & BH18_2 & LMWN & Quartz & 8.E-04 & 2.E-04 & 3.E-04 & 2.E-03 & $Y$ & 1.08 \\
\hline 34 & ECO3 & LMWN & Iron Oxides & $0 . E+00$ & 1.E-04 & $-3 . E-04$ & 4.E-04 & $\mathrm{N}$ & 1.24 \\
\hline 35 & ECO3 & LMWN & Calcite & 1.E-03 & 2.E-04 & 5.E-04 & 2.E-03 & $Y$ & 1.24 \\
\hline 36 & $\mathrm{ECO3}$ & LMWN & Quartz & 1.E-04 & 1.E-04 & $-2 . E-04$ & 5.E-04 & $\mathrm{N}$ & 1.24 \\
\hline 37 & Elfin Crossing & LMWN & Iron Oxides & 1.E-03 & 3.E-04 & 6.E-04 & 2.E-03 & $Y$ & 1.42 \\
\hline 38 & Elfin Crossing & LMWN & Calcite & 1.E-03 & 3.E-04 & 6.E-04 & 2.E-03 & $\mathrm{Y}$ & 1.42 \\
\hline 39 & Elfin Crossing & LMWN & Quartz & 2.E-03 & 4.E-04 & 1.E-03 & 3.E-03 & $\mathrm{Y}$ & 1.42 \\
\hline 40 & WRS05 & LMWN & Iron Oxides & 2.E-05 & $9 . E-05$ & $-2 . E-04$ & 3.E-04 & $\mathrm{N}$ & 1.48 \\
\hline 41 & WRS05 & LMWN & Calcite & 1.E-04 & 1.E-04 & $-1 . E-04$ & 5.E-04 & $\mathrm{N}$ & 1.48 \\
\hline 42 & WRS05 & LMWN & Quartz & 8.E-05 & 1.E-04 & $-2 . E-04$ & 4.E-04 & $\mathrm{N}$ & 1.48 \\
\hline 43 & Bell river & LMWN & Iron Oxides & $0 . E+00$ & 1.E-04 & $-4 . E-04$ & 6.E-04 & $\mathrm{N}$ & 1.74 \\
\hline 44 & Bell river & LMWN & Calcite & $0 . E+00$ & 1.E-04 & $-4 . E-04$ & 6.E-04 & $\mathrm{N}$ & 1.74 \\
\hline 45 & Bell river & LMWN & Quartz & 1.E-04 & 2.E-04 & $-3 . E-04$ & 8.E-04 & $\mathrm{N}$ & 1.74 \\
\hline 46 & WRS03 & LMWN & Iron Oxides & 2.E-05 & 9.E-05 & $-2 . E-04$ & 3.E-04 & $\mathrm{N}$ & 1.98 \\
\hline 47 & WRSO3 & LMWN & Calcite & 1.E-04 & 1.E-04 & $-1 . E-04$ & 5.E-04 & $\mathrm{N}$ & 1.98 \\
\hline 48 & WRS03 & LMWN & Quartz & 8.E-05 & 1.E-04 & $-2 . E-04$ & 4.E-04 & $\mathrm{N}$ & 1.98 \\
\hline 49 & S4_S & LMWN & Iron Oxides & 1.E-03 & 4.E-04 & 8.E-05 & 3.E-03 & $\mathrm{Y}$ & 6.18 \\
\hline 50 & S4_S & LMWN & Calcite & $0 . E+00$ & 2.E-04 & $-5 . E-04$ & 9.E-04 & $\mathrm{N}$ & 6.18 \\
\hline 51 & S4_S & LMWN & Quartz & $0 . E+00$ & 2.E-04 & $-5 . E-04$ & 9.E-04 & $\mathrm{N}$ & 6.18 \\
\hline 52 & MLSD & LMWN & Iron Oxides & $0 . E+00$ & 2.E-04 & $-5 . E-04$ & 8.E-04 & $\mathrm{N}$ & 6.61 \\
\hline 53 & MLSD & LMWN & Calcite & 1.E-03 & 4.E-04 & 2.E-04 & 3.E-03 & $\mathrm{Y}$ & 6.61 \\
\hline 54 & MLSD & LMWN & Quartz & 5.E-05 & 2.E-04 & $-4 . E-04$ & 9.E-04 & $\mathrm{N}$ & 6.61 \\
\hline 55 & MLSA & LMWN & Iron Oxides & 7.E-04 & 4.E-04 & -1.E-04 & 2.E-03 & $\mathrm{N}$ & 6.73 \\
\hline
\end{tabular}




\begin{tabular}{|c|c|c|c|c|c|c|c|c|c|}
\hline 56 & MLSA & LMWN & Calcite & $0 . E+00$ & 2.E-04 & $-5 . E-04$ & 9.E-04 & $\mathrm{N}$ & 6.73 \\
\hline 57 & MLSA & LMWN & Quartz & 6.E-04 & 3.E-04 & $-2 . E-04$ & 2.E-03 & $\mathrm{N}$ & 6.73 \\
\hline 58 & MLSB & LMWN & Iron Oxides & 3.E-03 & 1.E-03 & 1.E-03 & 8.E-03 & $\mathrm{Y}$ & 6.76 \\
\hline 59 & MLSB & LMWN & Calcite & 4.E-04 & 3.E-04 & $-3 . E-04$ & 2.E-03 & $\mathrm{N}$ & 6.76 \\
\hline 60 & MLSB & LMWN & Quartz & 1.E-03 & 5.E-04 & $-5 . E-05$ & 3.E-03 & $\mathrm{N}$ & 6.76 \\
\hline 61 & Macquarie river & LMWN & Iron Oxides & 1.E-03 & 4.E-04 & 3.E-04 & 3.E-03 & $Y$ & 8.54 \\
\hline 62 & Macquarie river & LMWN & Calcite & 6.E-04 & 3.E-04 & $-3 . E-05$ & 2.E-03 & $\mathrm{N}$ & 8.54 \\
\hline 63 & Macquarie river & LMWN & Quartz & 3.E-04 & 2.E-04 & $-3 . E-04$ & 1.E-03 & $\mathrm{N}$ & 8.54 \\
\hline 64 & S1_D & LMWN & Iron Oxides & 3.E-03 & 1.E-03 & 8.E-04 & 8.E-03 & $\mathrm{Y}$ & 9.46 \\
\hline 65 & S1_D & LMWN & Calcite & 2.E-04 & 3.E-04 & $-5 . E-04$ & 2.E-03 & $\mathrm{N}$ & 9.46 \\
\hline 66 & S1_D & LMWN & Quartz & 2.E-03 & 9.E-04 & 5.E-04 & 7.E-03 & $\mathrm{Y}$ & 9.46 \\
\hline 67 & S1_M & LMWN & Iron Oxides & 7.E-04 & 3.E-04 & $-6 . E-05$ & 2.E-03 & $\mathrm{N}$ & 10.76 \\
\hline 68 & S1_M & LMWN & Calcite & 1.E-03 & 4.E-04 & 1.E-04 & 3.E-03 & $\mathrm{Y}$ & 10.76 \\
\hline 69 & S1_M & LMWN & Quartz & 2.E-04 & 2.E-04 & $-4 . E-04$ & 1.E-03 & $\mathrm{N}$ & 10.76 \\
\hline 70 & S2_D & LMWN & Iron Oxides & $0 . E+00$ & 3.E-04 & $-6 . E-04$ & 2.E-03 & $\mathrm{N}$ & 15.64 \\
\hline 71 & S2_D & LMWN & Calcite & 2.E-03 & 1.E-03 & 2.E-04 & 8.E-03 & $Y$ & 15.64 \\
\hline 72 & S2_D & LMWN & Quartz & 4.E-04 & 5.E-04 & $-5 . E-04$ & 3.E-03 & $\mathrm{N}$ & 15.64 \\
\hline
\end{tabular}


Supplementary Table 5: Showing HS sorption as a percentage of the total sample DOC amount (at $10 \mathrm{~g}$ mass system). \% refers to sorbed HS in percentage to total DOC mass (mg) in water sample. Samples are listed with the lowest \% sorption (e.g. BH12_4) of HS to DOC mass to the highest \% sorption (e.g. S4_S) of HS to DOC mass to the DOC. The samples listed based on the \% HS sorption (lower \% HS sorption is on the top).

\begin{tabular}{rll}
\multicolumn{2}{c}{ No } & \multicolumn{2}{c}{ Samples } & Minerals \\
Iron Oxides & \\
1 & BH12_4 & Iron Oxides \\
2 & BH01 & Iron Oxides \\
4 & The Well & Iron Oxides \\
8 & BH.Golf & Iron Oxides \\
3 & WRSO3 & Iron Oxides \\
5 & WRSO5 & Iron Oxides \\
7 & MLSD & Iron Oxides \\
6 & Macquarie river & Iron Oxides \\
9 & Elfin Crossing & Iron Oxides \\
11 & BH18_2 & Iron Oxides \\
12 & WRSO8 & Iron Oxides \\
22 & BH19_2 & Iron Oxides \\
14 & EC31 & Iron Oxides \\
10 & MLSB & Iron Oxides \\
13 & S1_M & Iron Oxides \\
15 & Bell river & Iron Oxides \\
18 & EC06 & Iron Oxides \\
17 & EC07 & Iron Oxides \\
16 & MLSA & Iron Oxides \\
20 & EC03 & Iron Oxides \\
19 & S1_D & Iron Oxides \\
23 & S1_S & Iron Oxides \\
21 & S2_D & Iron Oxides \\
24 & S4_S & Iron Oxides \\
& Min & \\
& Max & \\
& Mean & \\
& Median & SE \\
\end{tabular}

\section{$\operatorname{DOC}\left(\mathrm{mg} \mathrm{L}^{-1}\right)$}

4.30E-01

$5.81 \mathrm{E}-01$

$9.40 \mathrm{E}-01$

$1.07 \mathrm{E}+00$

$2.14 \mathrm{E}+00$

$1.76 \mathrm{E}+00$

$5.89 \mathrm{E}+00$

$8.86 \mathrm{E}+00$

$1.19 \mathrm{E}+00$

$1.11 \mathrm{E}+00$

$1.44 \mathrm{E}+00$

5.21E-01

6.46E-01

$6.39 \mathrm{E}+00$

$1.10 \mathrm{E}+01$

$1.85 \mathrm{E}+00$

$1.22 \mathrm{E}+00$

$1.02 \mathrm{E}+00$

$6.38 \mathrm{E}+00$

$1.01 \mathrm{E}+00$

$9.13 \mathrm{E}+00$

8.60E-01

$1.55 \mathrm{E}+01$

$6.13 \mathrm{E}+00$

4.30E-01

$1.55 \mathrm{E}+01$

$3.63 \mathrm{E}+00$

$1.33 \mathrm{E}+00$

$4.09 \mathrm{E}+00$

\section{Sorbed HS} (mg L-1)

\% Sorption

(total DOC)$$
0
$$

0

1.70E-02

2.17E-02

9.69E-02

8.25E-02

3.70E-01

5.85E-01

8.26E-02

9.34E-02

1.35E-01

5.09E-02

6.46E-02

6.80E-01

$1.47 \mathrm{E}+00$

2.63E-01

1.86E-01

1.73E-01

$1.09 \mathrm{E}+00$

1.85E-01

$1.70 \mathrm{E}+00$

1.72E-01

$3.61 \mathrm{E}+00$

$2.70 \mathrm{E}+00$

$$
0
$$

3. $61 \mathrm{E}+00$

5.76E-01

1.73E-01

9.28E-01
0

0

$1.80 \mathrm{E}+00$

$2.03 \mathrm{E}+00$

$4.53 \mathrm{E}+00$

$4.69 \mathrm{E}+00$

$6.29 \mathrm{E}+00$

$6.61 \mathrm{E}+00$

$6.97 \mathrm{E}+00$

$8.38 \mathrm{E}+00$

$9.37 \mathrm{E}+00$

$9.76 \mathrm{E}+00$

$1.00 \mathrm{E}+01$

1.07E+01

$1.34 \mathrm{E}+01$

1.43E+01

$1.53 \mathrm{E}+01$

$1.69 \mathrm{E}+01$

$1.71 \mathrm{E}+01$

$1.84 \mathrm{E}+01$

$1.87 \mathrm{E}+01$

$2.00 \mathrm{E}+01$

2.33E+01

4.40E+01

0

4. $40 \mathrm{E}+01$

$1.18 \mathrm{E}+01$

$9.88 \mathrm{E}+00$

$9.53 \mathrm{E}+00$

\section{Calcite}

25 BH12_4

$26 \mathrm{BHO1}$

32 BH.Golf

Calcite

4.24E-01

4.97E-03

$1.17 \mathrm{E}+00$

36 The Well

Calcite

6.84E-01

1.67E-02

$2.45 \mathrm{E}+00$

9.92E-01

2.45E-02

$2.47 \mathrm{E}+00$

1.13E+00

3.62E-02

$3.20 \mathrm{E}+00$ 


$\begin{array}{llllll}28 & \text { MLSD } & \text { Calcite } & 6.35 \mathrm{E}+00 & 3.82 \mathrm{E}-01 & 6.02 \mathrm{E}+00 \\ 29 & \text { WRSO5 } & \text { Calcite } & 1.61 \mathrm{E}+00 & 9.76 \mathrm{E}-02 & 6.05 \mathrm{E}+00 \\ 30 & \text { S1_D } & \text { Calcite } & 9.69 \mathrm{E}+00 & 5.93 \mathrm{E}-01 & 6.12 \mathrm{E}+00 \\ 27 & \text { S1_M } & \text { Calcite } & 1.10 \mathrm{E}+01 & 6.90 \mathrm{E}-01 & 6.24 \mathrm{E}+00 \\ 41 & \text { BH19_2 } & \text { Calcite } & 3.89 \mathrm{E}-01 & 2.48 \mathrm{E}-02 & 6.38 \mathrm{E}+00 \\ 31 & \text { WRS03 } & \text { Calcite } & 2.19 \mathrm{E}+00 & 1.50 \mathrm{E}-01 & 6.84 \mathrm{E}+00 \\ 35 & \text { BH18_2 } & \text { Calcite } & 1.04 \mathrm{E}+00 & 8.34 \mathrm{E}-02 & 8.02 \mathrm{E}+00 \\ 38 & \text { EC31 } & \text { Calcite } & 4.68 \mathrm{E}-01 & 3.90 \mathrm{E}-02 & 8.33 \mathrm{E}+00 \\ 34 & \text { MLSA } & \text { Calcite } & 6.36 \mathrm{E}+00 & 5.38 \mathrm{E}-01 & 8.46 \mathrm{E}+00 \\ 37 & \text { MLSB } & \text { Calcite } & 6.48 \mathrm{E}+00 & 6.11 \mathrm{E}-01 & 9.43 \mathrm{E}+00 \\ 42 & \text { Elfin Crossing } & \text { Calcite } & 1.31 \mathrm{E}+00 & 1.25 \mathrm{E}-01 & 9.58 \mathrm{E}+00 \\ 33 & \text { Macquarie river } & \text { Calcite } & 8.96 \mathrm{E}+00 & 8.84 \mathrm{E}-01 & 9.87 \mathrm{E}+00 \\ 44 & \text { EC03 } & \text { Calcite } & 1.17 \mathrm{E}+00 & 1.23 \mathrm{E}-01 & 1.05 \mathrm{E}+01 \\ 39 & \text { S2_D } & \text { Calcite } & 1.60 \mathrm{E}+01 & 1.79 \mathrm{E}+00 & 1.12 \mathrm{E}+01 \\ 40 & \text { WRS08 } & \text { Calcite } & 1.10 \mathrm{E}+00 & 1.23 \mathrm{E}-01 & 1.12 \mathrm{E}+01 \\ 43 & \text { Bell river } & \text { Calcite } & 1.99 \mathrm{E}+00 & 2.60 \mathrm{E}-01 & 1.31 \mathrm{E}+01 \\ 48 & \text { S1_S } & \text { Calcite } & 1.07 \mathrm{E}+00 & 1.54 \mathrm{E}-01 & 1.44 \mathrm{E}+01 \\ 47 & \text { EC06 } & \text { Calcite } & 1.22 \mathrm{E}+00 & 1.83 \mathrm{E}-01 & 1.51 \mathrm{E}+01 \\ 45 & \text { EC07 } & \text { Calcite } & 9.37 \mathrm{E}-01 & 1.56 \mathrm{E}-01 & 1.67 \mathrm{E}+01 \\ 46 & \text { S4_S } & \text { Calcite } & 6.32 \mathrm{E}+00 & 1.38 \mathrm{E}+00 & 2.19 \mathrm{E}+01 \\ & \text { Min } & & 3.89 \mathrm{E}-01 & 4.97 \mathrm{E}-03 & 1.17 \mathrm{E}+00 \\ & \text { Max } & & 1.60 \mathrm{E}+01 & 1.79 \mathrm{E}+00 & 2.19 \mathrm{E}+01 \\ \text { Mean } & & 3.70 \mathrm{E}+00 & 3.53 \mathrm{E}-01 & 8.94 \mathrm{E}+00 \\ & \text { Median } & & 1.26 \mathrm{E}+00 & 1.52 \mathrm{E}-01 & 8.40 \mathrm{E}+00 \\ & \text { SE } & 4.22 \mathrm{E}+00 & 4.56 \mathrm{E}-01 & 4.88 \mathrm{E}+00\end{array}$

\section{Quartz}

$\begin{array}{lllccc}49 & \text { BH19_2 } & \text { Quartz } & 4.11 \mathrm{E}-01 & 0 & 0 \\ 50 & \text { BH.Golf } & \text { Quartz } & 6.74 \mathrm{E}-01 & 0 & 0 \\ 51 & \text { BH01 } & \text { Quartz } & 6.14 \mathrm{E}-01 & 0 & 0 \\ 52 & \text { The Well } & \text { Quartz } & 9.80 \mathrm{E}-01 & 0 & 0 \\ 53 & \text { MLSD } & \text { Quartz } & 6.11 \mathrm{E}+00 & 1.62 \mathrm{E}-01 & 2.65 \mathrm{E}+00 \\ 54 & \text { WRS05 } & \text { Quartz } & 1.63 \mathrm{E}+00 & 6.51 \mathrm{E}-02 & 4.00 \mathrm{E}+00 \\ 55 & \text { WRS03 } & \text { Quartz } & 2.10 \mathrm{E}+00 & 8.95 \mathrm{E}-02 & 4.26 \mathrm{E}+00 \\ 56 & \text { S1_D } & \text { Quartz } & 9.25 \mathrm{E}+00 & 4.32 \mathrm{E}-01 & 4.67 \mathrm{E}+00 \\ 57 & \text { EC31 } & \text { Quartz } & 5.21 \mathrm{E}-01 & 2.74 \mathrm{E}-02 & 5.25 \mathrm{E}+00 \\ 58 & \text { EC07 } & \text { Quartz } & 8.85 \mathrm{E}-01 & 4.87 \mathrm{E}-02 & 5.50 \mathrm{E}+00 \\ 59 & \text { MLSA } & \text { Quartz } & 6.49 \mathrm{E}+00 & 3.66 \mathrm{E}-01 & 5.64 \mathrm{E}+00 \\ 60 & \text { BH12_4 } & \text { Quartz } & 5.74 \mathrm{E}-01 & 3.38 \mathrm{E}-02 & 5.88 \mathrm{E}+00 \\ 61 & \text { MLSB } & \text { Quartz } & 6.39 \mathrm{E}+00 & 3.95 \mathrm{E}-01 & 6.18 \mathrm{E}+00 \\ 62 & \text { S1_M } & \text { Quartz } & 1.11 \mathrm{E}+01 & 6.97 \mathrm{E}-01 & 6.29 \mathrm{E}+00 \\ 63 & \text { S1_S } & \text { Quartz } & 1.13 \mathrm{E}+00 & 7.21 \mathrm{E}-02 & 6.41 \mathrm{E}+00 \\ 64 & \text { EC03 } & \text { Quartz } & 1.13 \mathrm{E}+00 & 7.48 \mathrm{E}-02 & 6.62 \mathrm{E}+00 \\ 65 & \text { WRS08 } & \text { Quartz } & 1.32 \mathrm{E}+00 & 9.65 \mathrm{E}-02 & 7.31 \mathrm{E}+00\end{array}$




$\begin{array}{llllll}66 & \text { BH18_2 } & \text { Quartz } & 9.64 \mathrm{E}-01 & 7.23 \mathrm{E}-02 & 7.50 \mathrm{E}+00 \\ 67 & \text { Macquarie river } & \text { Quartz } & 8.77 \mathrm{E}+00 & 6.94 \mathrm{E}-01 & 7.92 \mathrm{E}+00 \\ 68 & \text { Elfin Crossing } & \text { Quartz } & 1.28 \mathrm{E}+00 & 1.09 \mathrm{E}-01 & 8.52 \mathrm{E}+00 \\ 69 & \text { EC06 } & \text { Quartz } & 1.09 \mathrm{E}+00 & 9.90 \mathrm{E}-02 & 9.10 \mathrm{E}+00 \\ 70 & \text { S2_D } & \text { Quartz } & 1.56 \mathrm{E}+01 & 1.48 \mathrm{E}+00 & 9.50 \mathrm{E}+00 \\ 71 & \text { Bell river } & \text { Quartz } & 2.00 \mathrm{E}+00 & 2.47 \mathrm{E}-01 & 1.24 \mathrm{E}+01 \\ 72 & \text { S4_S } & \text { Quartz } & 6.13 \mathrm{E}+00 & 7.78 \mathrm{E}-01 & 1.27 \mathrm{E}+01 \\ & \text { Min } & & 4.11 \mathrm{E}-01 & 0.00 \mathrm{E}+00 & 0.00 \mathrm{E}+00 \\ & & 1.56 \mathrm{E}+01 & 1.48 \mathrm{E}+00 & 1.27 \mathrm{E}+01 \\ \text { Max } & & 3.63 \mathrm{E}+00 & 2.52 \mathrm{E}-01 & 5.76 \mathrm{E}+00 \\ \text { Mean } & & 1.30 \mathrm{E}+00 & 9.30 \mathrm{E}-02 & 6.03 \mathrm{E}+00 \\ \text { Median } & & 4.13 \mathrm{E}+00 & 3.53 \mathrm{E}-01 & 3.52 \mathrm{E}+00 \\ \text { SE } & & & & \end{array}$


Supplementary Table 6: Summary of Linear model fitting on estimated mean HS sorption and field DOC (DOC concentration in $\mathrm{mg} \mathrm{L}^{-1}$ ).

$\begin{array}{rcccc} & \text { Estimate } & \text { SE } & \text { P_value } & \text { Adj R }^{\mathbf{2}} \\ \text { (Intercept) } & -4 . \mathrm{E}-03 & 5 . \mathrm{E}-03 & 4 . \mathrm{E}-01 & \\ \text { Iron Oxides } & 8 . \mathrm{E}-03 & 1 . \mathrm{E}-03 & 9 . \mathrm{E}-08 & 0.7229 \\ \text { (Intercept) } & 2 . \mathrm{E}-04 & 2 . \mathrm{E}-03 & 9 . \mathrm{E}-01 & \\ \text { Calcite } & 4 . \mathrm{E}-03 & 4 . \mathrm{E}-04 & 1 . \mathrm{E}-08 & 0.7727 \\ \text { (Intercept) } & -1 . \mathrm{E}-03 & 2 . \mathrm{E}-03 & 5 . \mathrm{E}-01 & \\ \text { Quartz } & 3 . \mathrm{E}-03 & 3 . \mathrm{E}-04 & 2 . \mathrm{E}-10 & 0.8382\end{array}$


Supplementary Table 7: Sorbed HS and field HS aromaticity and molecular weight. Sorbed HS (mg) obtained from 3 systems (Iron Oxides, Calcite and Quartz) and field HS aromaticity (L $\mathrm{mg}^{-1} \mathrm{~m}^{-1}$ ) and molecular weight $\left(\mathrm{g} \mathrm{mol}^{-1}\right.$ ) from 24 samples. The samples listed based on their location away from the adjacent river.

\begin{tabular}{|c|c|c|c|c|c|c|}
\hline No & Samples & $\begin{array}{l}\text { HS } \\
\text { aromaticity }\end{array}$ & $\begin{array}{c}\text { HS } \\
\text { molecular } \\
\text { weight }\end{array}$ & $\begin{array}{c}\text { Sorbed HS } \\
\text { on Iron } \\
\text { Oxides }\end{array}$ & $\begin{array}{l}\text { Sorbed } \\
\text { HS on } \\
\text { Calcite }\end{array}$ & $\begin{array}{c}\text { Sorbed } \\
\text { HS on } \\
\text { Quartz }\end{array}$ \\
\hline \multicolumn{7}{|c|}{ Anna Bay sampling sites } \\
\hline 1 & MLSA & 3.81 & 588 & 4.37E-02 & $2.15 \mathrm{E}-02$ & 1.47E-02 \\
\hline 2 & MLSB & 3.69 & 544 & $2.72 \mathrm{E}-02$ & $2.44 \mathrm{E}-02$ & $1.58 \mathrm{E}-02$ \\
\hline 3 & MLSD & 3.72 & 542 & $1.48 \mathrm{E}-02$ & $1.53 \mathrm{E}-02$ & $6.49 \mathrm{E}-03$ \\
\hline 4 & S1_S & 4.29 & 699 & $6.90 \mathrm{E}-03$ & $6.15 \mathrm{E}-03$ & $2.88 \mathrm{E}-03$ \\
\hline 5 & S1_M & 4.63 & 605 & $5.90 \mathrm{E}-02$ & $2.76 \mathrm{E}-02$ & 2.79E-02 \\
\hline 6 & S1_D & 4.28 & 512 & $6.82 \mathrm{E}-02$ & $2.37 \mathrm{E}-02$ & $1.73 \mathrm{E}-02$ \\
\hline 7 & $S 2 \_D$ & 5.52 & 686 & $1.44 \mathrm{E}-01$ & 7.15E-02 & $5.92 \mathrm{E}-02$ \\
\hline 8 & S4_S & 7.08 & 904 & $1.08 \mathrm{E}-01$ & $5.53 \mathrm{E}-02$ & $3.11 E-02$ \\
\hline \multicolumn{7}{|c|}{ Maules Creek sampling sites } \\
\hline 9 & BH18_2 & 1.8 & 675 & $3.74 \mathrm{E}-03$ & $3.34 \mathrm{E}-03$ & $2.89 \mathrm{E}-03$ \\
\hline 10 & BH19_2 & 0.67 & 112 & $2.03 E-03$ & $9.93 \mathrm{E}-04$ & $0.00 \mathrm{E}+00$ \\
\hline 11 & Elfin Crossing & 2.13 & 119 & $3.30 \mathrm{E}-03$ & $5.00 \mathrm{E}-03$ & 4.35E-03 \\
\hline 12 & EC07 & 1.83 & 491 & $6.91 \mathrm{E}-03$ & $6.26 \mathrm{E}-03$ & $1.95 \mathrm{E}-03$ \\
\hline 13 & EC06 & 1.61 & 257 & 7.45E-03 & $7.34 \mathrm{E}-03$ & $3.96 \mathrm{E}-03$ \\
\hline 14 & ECO3 & 1.8 & 201 & 7.39E-03 & $4.91 \mathrm{E}-03$ & 2.99E-03 \\
\hline 15 & EC31 & 1 & 110 & 2.59E-03 & $1.56 \mathrm{E}-03$ & 1.09E-03 \\
\hline 16 & BH12_4 & 0.87 & 113 & $0.00 E+00$ & $1.99 \mathrm{E}-04$ & $1.35 \mathrm{E}-03$ \\
\hline \multicolumn{7}{|c|}{ Wellington sampling sites } \\
\hline 17 & Bell River & 2.57 & 269 & $1.05 \mathrm{E}-02$ & $1.04 \mathrm{E}-02$ & $9.90 \mathrm{E}-03$ \\
\hline 18 & BH.Golf & 0.37 & 364 & $8.68 \mathrm{E}-04$ & $9.79 E-04$ & $0.00 E+00$ \\
\hline 19 & $\mathrm{BH} 01$ & 0.89 & 173 & $0.00 E+00$ & $6.69 \mathrm{E}-04$ & $0.00 \mathrm{E}+00$ \\
\hline 20 & The Well & 1.06 & 127 & $2.34 \mathrm{E}-02$ & $3.54 \mathrm{E}-02$ & $2.78 \mathrm{E}-02$ \\
\hline 21 & Macquarie River & 3.47 & 581 & $6.78 \mathrm{E}-04$ & $1.45 \mathrm{E}-03$ & $0.00 E+00$ \\
\hline 22 & WRS03 & 1.66 & 192 & $3.88 \mathrm{E}-03$ & $6.00 \mathrm{E}-03$ & $3.58 \mathrm{E}-03$ \\
\hline 23 & WRS05 & 1.33 & 325 & $3.30 \mathrm{E}-03$ & $3.90 \mathrm{E}-03$ & $2.61 \mathrm{E}-03$ \\
\hline 24 & WRS08 & 0.89 & 199 & $5.40 \mathrm{E}-03$ & $4.91 \mathrm{E}-03$ & $3.86 \mathrm{E}-03$ \\
\hline
\end{tabular}


Supplementary Table 8: Summary of linear model of sorbed HS and HS aromaticity and molecular weight

\begin{tabular}{|c|c|c|c|c|c|c|c|}
\hline \multicolumn{8}{|c|}{ Aromaticity } \\
\hline \multicolumn{2}{|c|}{ Confident Interval } & Est. & SE & Lower $\mathrm{Cl}$ & Upper Cl & Df & Adj $R^{2}$ \\
\hline & Break point & $3.1 E+00$ & $6.5 \mathrm{E}-01$ & $1.7 E+00$ & $4.4 \mathrm{E}+00$ & & \\
\hline \multirow[t]{3}{*}{ Iron Oxides } & slope1 & $3.9 \mathrm{E}-03$ & 8.0E-03 & $-1.3 E-02$ & $2.1 \mathrm{E}-02$ & 20 & 0.7598 \\
\hline & slope2 & 2.7E-02 & $9.8 \mathrm{E}-03$ & $1.9 \mathrm{E}-02$ & 4.3E-02 & & \\
\hline & Break point & 2.7E+00 & $1.0 \mathrm{E}+00$ & $5.4 \mathrm{E}-01$ & $4.9 \mathrm{E}+00$ & & \\
\hline \multirow[t]{3}{*}{ Calcite } & slope1 & 4.0E-03 & 4.1E-03 & $-4.6 \mathrm{E}-03$ & $1.3 \mathrm{E}-02$ & 20 & 0.7357 \\
\hline & slope2 & $8.2 \mathrm{E}-03$ & $5.0 \mathrm{E}-03$ & $6.3 \mathrm{E}-03$ & $1.8 \mathrm{E}-02$ & & \\
\hline & Break point & $2.0 \mathrm{E}+00$ & $1.3 E+00$ & $-7.4 \mathrm{E}-01$ & $4.7 E+00$ & & \\
\hline \multirow[t]{2}{*}{ Quartz } & slope1 & $2.2 \mathrm{E}-03$ & $5.3 \mathrm{E}-03$ & $-9.0 E-03$ & $1.3 \mathrm{E}-02$ & 20 & 0.5952 \\
\hline & slope2 & $5.4 \mathrm{E}-03$ & 5.7E-03 & $3.2 \mathrm{E}-03$ & $1.2 \mathrm{E}-02$ & & \\
\hline \multicolumn{8}{|c|}{ Molecular Weight } \\
\hline \multicolumn{2}{|c|}{ Confident Interval } & Est. & SE & Lower $\mathrm{Cl}$ & Upper $\mathrm{Cl}$ & Df & Adj $R^{2}$ \\
\hline & Break point & $4.1 \mathrm{E}+02$ & $1.6 \mathrm{E}+02$ & $7.3 E+01$ & $7.5 E+02$ & & \\
\hline \multirow[t]{3}{*}{ Iron Oxides } & slope1 & $1.3 \mathrm{E}-05$ & $9.6 \mathrm{E}-05$ & $-1.9 \mathrm{E}-04$ & $2.1 \mathrm{E}-04$ & 20 & 0.4168 \\
\hline & slope2 & $1.8 \mathrm{E}-04$ & $1.2 \mathrm{E}-04$ & $2.9 \mathrm{E}-05$ & $3.5 \mathrm{E}-04$ & & \\
\hline & Break point & $3.9 E+02$ & $1.8 \mathrm{E}+02$ & $2.3 E+01$ & $7.6 E+02$ & & \\
\hline \multirow[t]{3}{*}{ Calcite } & slope1 & $1.3 \mathrm{E}-05$ & $4.5 \mathrm{E}-05$ & $-8.1 E-05$ & $1.1 \mathrm{E}-04$ & 20 & 0.4722 \\
\hline & slope2 & $7.5 \mathrm{E}-05$ & 5.7E-05 & 1.3E-05 & $1.6 \mathrm{E}-04$ & & \\
\hline & Break point & $3.6 \mathrm{E}+02$ & $2.6 \mathrm{E}+02$ & $-1.7 E+02$ & $9.0 \mathrm{E}+02$ & & \\
\hline \multirow[t]{2}{*}{ Quartz } & slope1 & $1.1 \mathrm{E}-05$ & $3.9 E-05$ & $-7.0 \mathrm{E}-05$ & 9.3E-05 & 20 & 0.3422 \\
\hline & slope2 & 4.4E-05 & 5.0E-05 & $-9.3 E-06$ & $1.2 \mathrm{E}-04$ & & \\
\hline
\end{tabular}


Supplementary Table 9: Showing the comparison of Spectral Absorbance Coefficients (SAC) in $\mathrm{m}^{-1}$ by UVS in percentage. SAC of DOC = SAC of HOC + SAC of CDOC. In addition, SAC CDOC $=\mathrm{SAC} H \mathrm{HS}+\mathrm{SAC} B \mathrm{BB}+\mathrm{SAC} L \mathrm{SMWN}+\mathrm{SAC}$ inorganic carbon. However, the plot only reported the total SAC CDOC in $100 \%$ subdivided into SAC HS, SAC BB and SAC LMWN. No SAC of inorganic carbon analysed. The samples listed based on their location away from the adjacent river.

$\begin{array}{lcccc}\text { Samples } & \text { CSAC } & \text { HS } & \text { BB } & \text { LMWN } \\ \text { MLSA } & 100 & 7.1 \mathrm{E}+01 & 1.9 \mathrm{E}+01 & 5.4 \mathrm{E}+00 \\ \text { MLSD } & 100 & 7.3 \mathrm{E}+01 & 1.5 \mathrm{E}+01 & 6.2 \mathrm{E}+00 \\ \text { S1_S } & 100 & 6.2 \mathrm{E}+01 & 1.1 \mathrm{E}+01 & 1.8 \mathrm{E}+01 \\ \text { S1_M } & 100 & 7.7 \mathrm{E}+01 & 1.5 \mathrm{E}+01 & 3.2 \mathrm{E}+00 \\ \text { S1_D } & 100 & 6.9 \mathrm{E}+01 & 2.0 \mathrm{E}+01 & 2.8 \mathrm{E}+00 \\ \text { S2_D } & 100 & 7.9 \mathrm{E}+01 & 1.8 \mathrm{E}+01 & 2.0 \mathrm{E}+00 \\ \text { S4_S } & 100 & 7.6 \mathrm{E}+01 & 1.7 \mathrm{E}+01 & 2.1 \mathrm{E}+00 \\ \text { EC18_2 } & 100 & 4.0 \mathrm{E}+01 & 1.8 \mathrm{E}+01 & 3.1 \mathrm{E}+01 \\ \text { BH19_2 } & 100 & 6.7 \mathrm{E}+00 & 4.3 \mathrm{E}+00 & 6.6 \mathrm{E}+01 \\ \text { Elfin Crossing } & 100 & 7.2 \mathrm{E}+01 & 1.1 \mathrm{E}+01 & 1.1 \mathrm{E}+01 \\ \text { EC07 } & 100 & 4.3 \mathrm{E}+01 & 1.8 \mathrm{E}+01 & 2.7 \mathrm{E}+01 \\ \text { EC06 } & 100 & 3.6 \mathrm{E}+01 & 1.8 \mathrm{E}+01 & 2.9 \mathrm{E}+01 \\ \text { EC03 } & 100 & 4.2 \mathrm{E}+01 & 1.6 \mathrm{E}+01 & 2.4 \mathrm{E}+01 \\ \text { EC31 } & 100 & 2.3 \mathrm{E}+01 & 6.5 \mathrm{E}+00 & 4.3 \mathrm{E}+01 \\ \text { BH12_4 } & 100 & 1.3 \mathrm{E}+00 & 5.4 \mathrm{E}+00 & 7.6 \mathrm{E}+01 \\ \text { Bell River } & 100 & 6.2 \mathrm{E}+01 & 1.9 \mathrm{E}+01 & 7.8 \mathrm{E}+00 \\ \text { BH.Golf } & 100 & 1.1 \mathrm{E}+00 & 5.9 \mathrm{E}+00 & 6.0 \mathrm{E}+01 \\ \text { BH01 } & 100 & 1.6 \mathrm{E}+01 & 2.3 \mathrm{E}+00 & 2.8 \mathrm{E}+01 \\ \text { Macquarie River } & 100 & 6.9 \mathrm{E}+01 & 1.8 \mathrm{E}+01 & 1.2 \mathrm{E}+01 \\ \text { WRS03 } & 100 & 4.6 \mathrm{E}+01 & 1.8 \mathrm{E}+01 & 2.6 \mathrm{E}+01 \\ \text { WRS05 } & 100 & 3.9 \mathrm{E}+01 & 1.1 \mathrm{E}+01 & 2.6 \mathrm{E}+01 \\ \text { WRS08 } & 100 & 2.9 \mathrm{E}+01 & 8.0 \mathrm{E}+00 & 4.2 \mathrm{E}+01 \\ & & & & \\ \text { Min } & \mathbf{1 . 0 0 E + 0 2} & \mathbf{1 . 1 1 E}+00 & \mathbf{2 . 2 6 E + 0 0} & \mathbf{2 . 0 1 E + 0 0} \\ \text { Max } & \mathbf{1 . 0 0 E + 0 2} & \mathbf{7 . 9 5 E + 0 1} & \mathbf{2 . 0 4 E + 0 1} & \mathbf{7 . 6 3 E + 0 1} \\ \text { Mean } & \mathbf{1 . 0 0 E + 0 2} & \mathbf{4 . 7 0 E + 0 1} & \mathbf{1 . 3 4 E + 0 1} & \mathbf{2 . 5 0 E + 0 1} \\ \text { Median } & \mathbf{0 . 0 0 E + 0 0} & \mathbf{2 . 5 9 E + 0 1} & \mathbf{5 . 7 2 E}+00 & \mathbf{2 . 1 5 E + 0 1} \\ \text { SD } & & & & \end{array}$


Supplementary Table 10: Statistical summary of "tweedie glm" model for identifying controlling natural HS sorption fractions

$\begin{array}{ll}\text { No } & \text { Explanatory variables } \\ 1 & \text { Calcite - Quartz } \\ 2 & \text { Iron Oxides - Quartz } \\ 3 & \text { Iron Oxides - Calcite } \\ 4 & \text { Mass } \\ 5 & \text { Depth } \\ 6 & \text { Dissolved oxygen (DO) } \\ 7 & \text { EC } \\ 8 & \text { DOC Concentration } \\ 9 & \text { Dissolved Fe } \\ 10 & \text { HS aromaticity (B-A) } \\ 11 & \text { HS molecular weight (B-A) }\end{array}$

Coefficient

0.0011722

0.0016828

0.001

0.0008556

$-0.0007746$

$-0.0007473$

0.0007264

0.0008887

$-0.000833$

0.0012526

0.0009253

$\begin{array}{cc}\text { Coefficient (\%) } & \text { P_value } \\ 61 & 5 \mathrm{E}-128 \\ 132 & 6 \mathrm{E}-06 \\ 44 & 4 \mathrm{E}-17 \\ 18 & 6 \mathrm{E}-37 \\ -6 & 7 \mathrm{E}-15 \\ -3 & 3 \mathrm{E}-01 \\ 0.027 & 3 \mathrm{E}-01 \\ 22 & 1 \mathrm{E}-36 \\ -13 & 1 \mathrm{E}-02 \\ 72 & 6 \mathrm{E}-04 \\ 27 & 3 \mathrm{E}-01\end{array}$


Supplementary Figure 1: Linear relationship between field DOC concentration and HS aromaticity and molecular weight. In aromaticity legend, sample list starts from the sample (BH.Golf) with the lowest aromaticity to the sample (S4_S) with the highest aromaticity. In molecular legend, the sample list starts from the sample (EC31) with lowest molecular weight to the sample (S4_S) with the highest molecular weight. The black dots show the range of field DOC concentration ( $\mathrm{mg} \mathrm{L}^{-1}$ ).
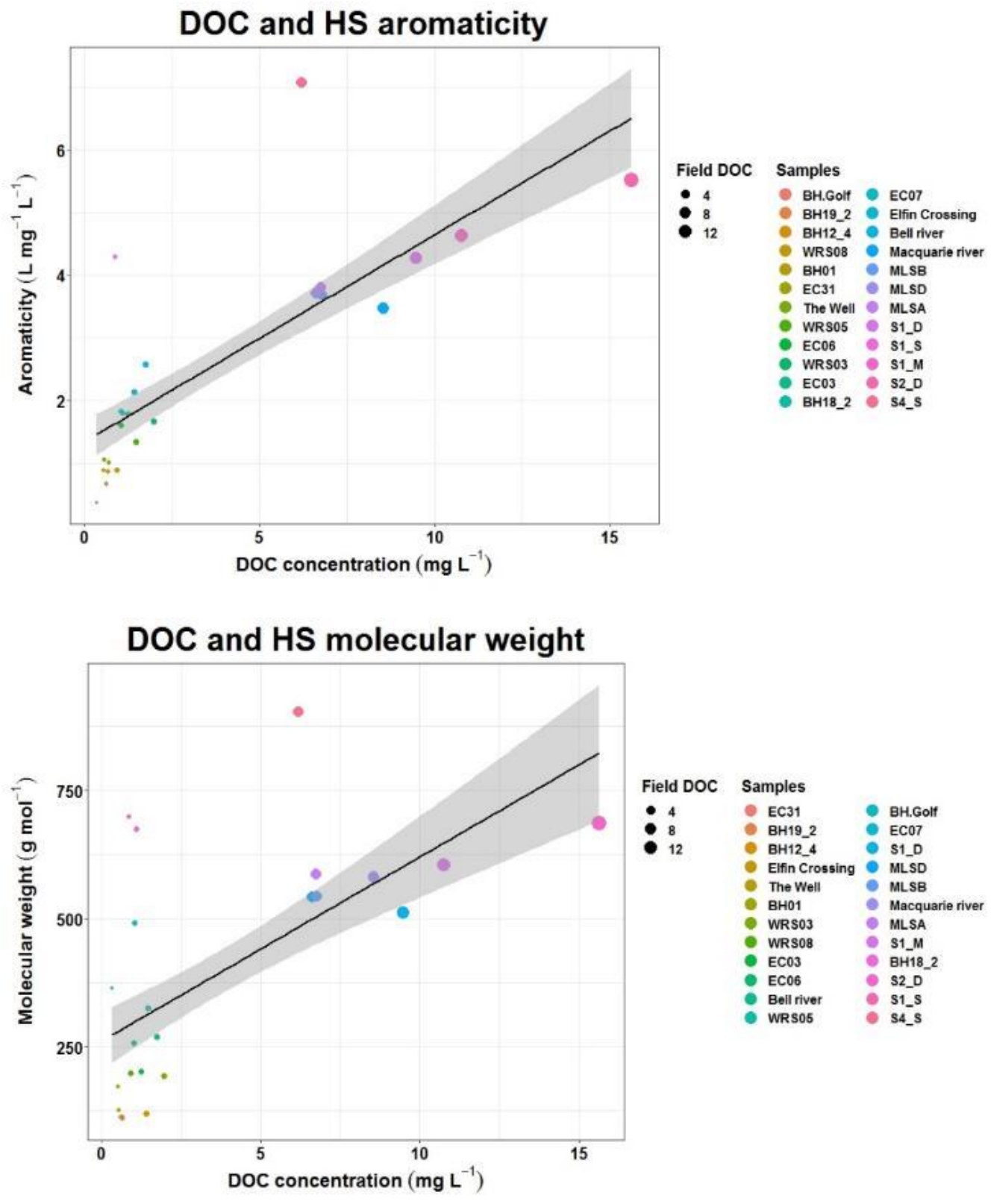

$\begin{array}{lcccc} & \text { Estimate } & \text { SE } & \text { P_value } & \text { Adj R-Squared } \\ \text { (Intercept) } & 1 . E+00 & 2 . E-01 & 3 . E-11 & \\ \text { Aromaticity } & 3 . E-01 & 3 . E-02 & 3 . E-16 & 0.6107 \\ \text { (Intercept) } & 3 . E+02 & 3 . E+01 & 2 . E-13 & \\ \text { Molecular weight } & 4 . E+01 & 5 . E+00 & 2 . E-09 & 0.3929\end{array}$


Supplementary Figure 2: Sorption characteristics of DOC fractions over a mass and mineral range of all samples. The plots are listed with distance of samples is away from adjacent river.
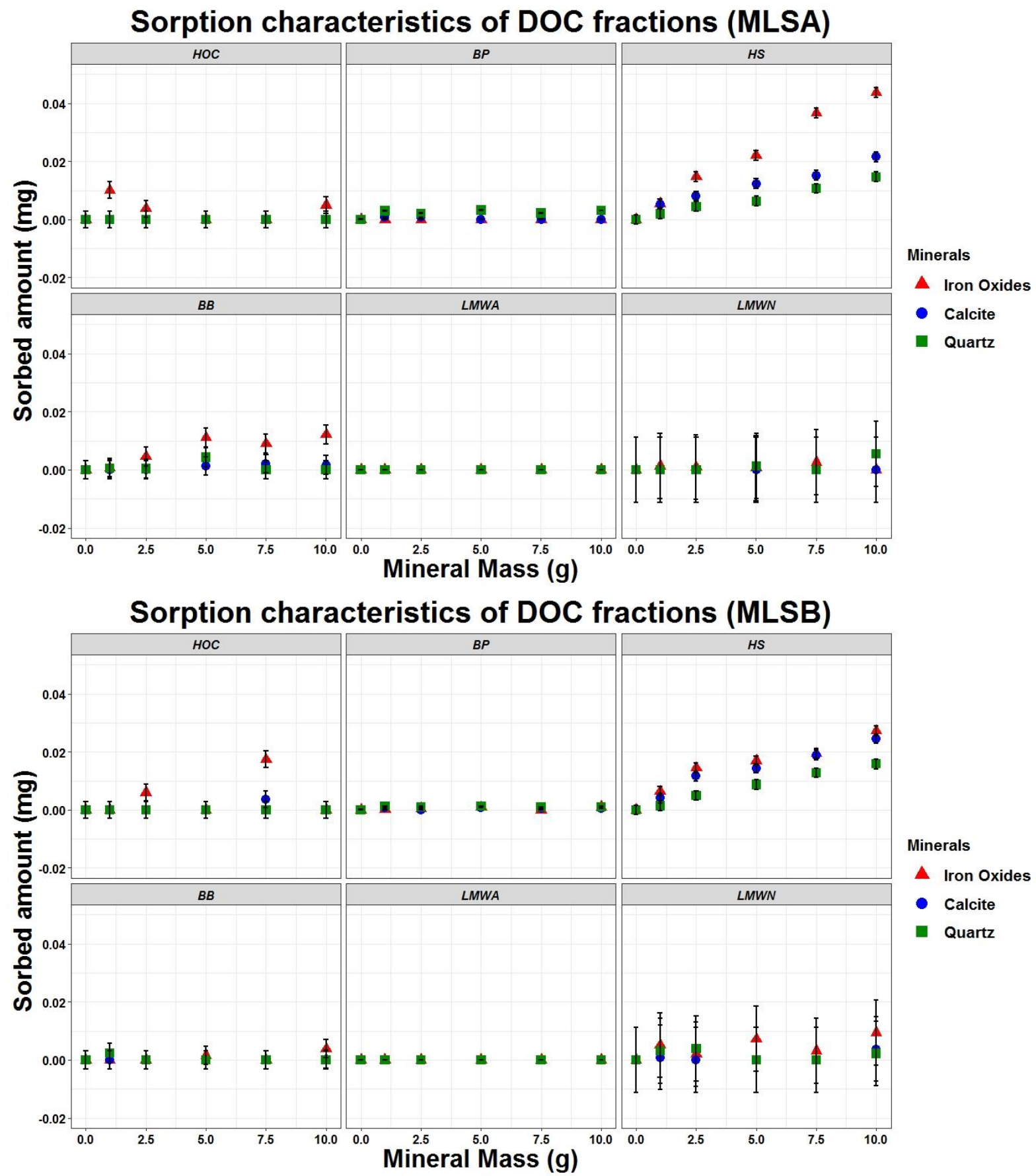

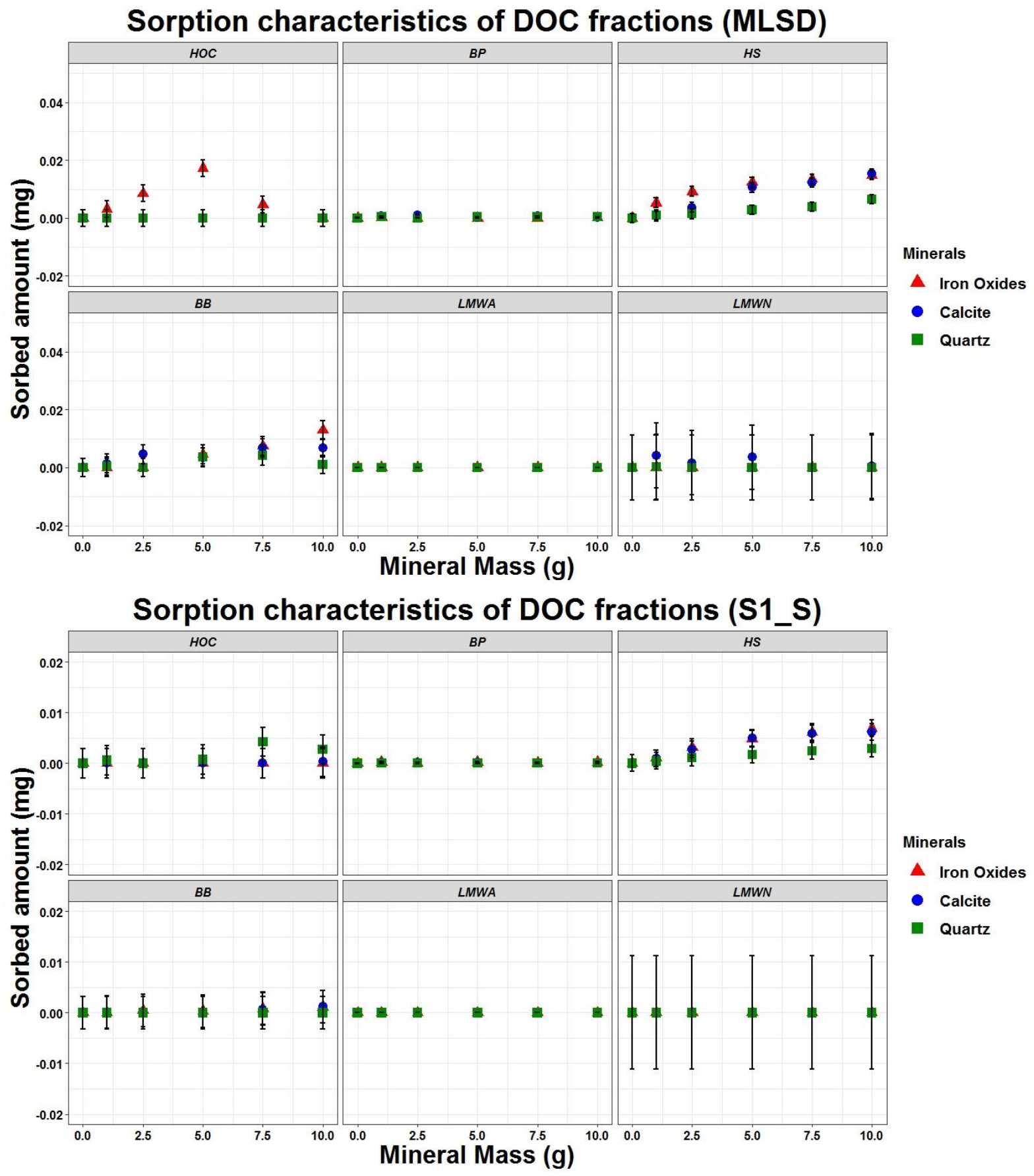

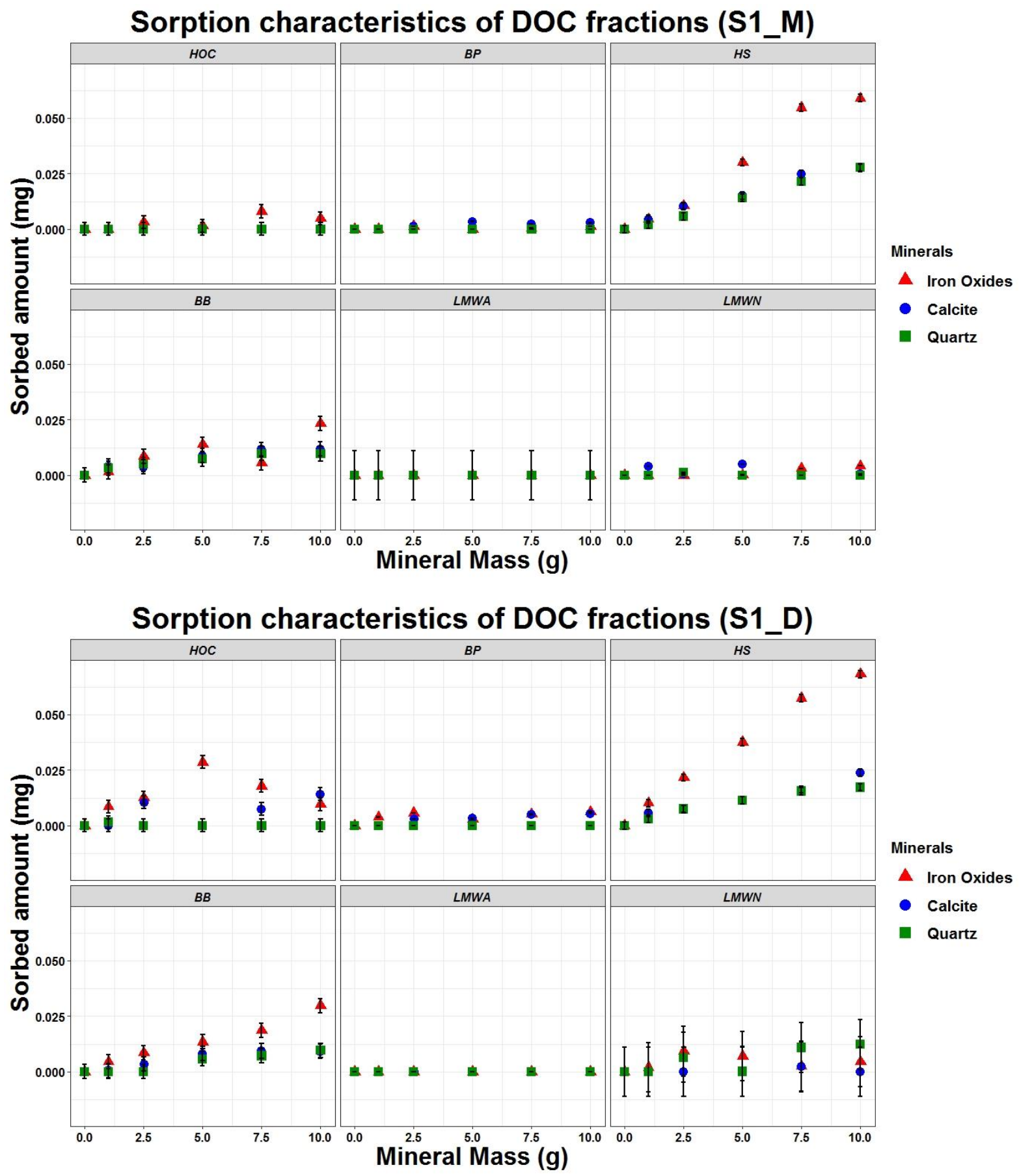


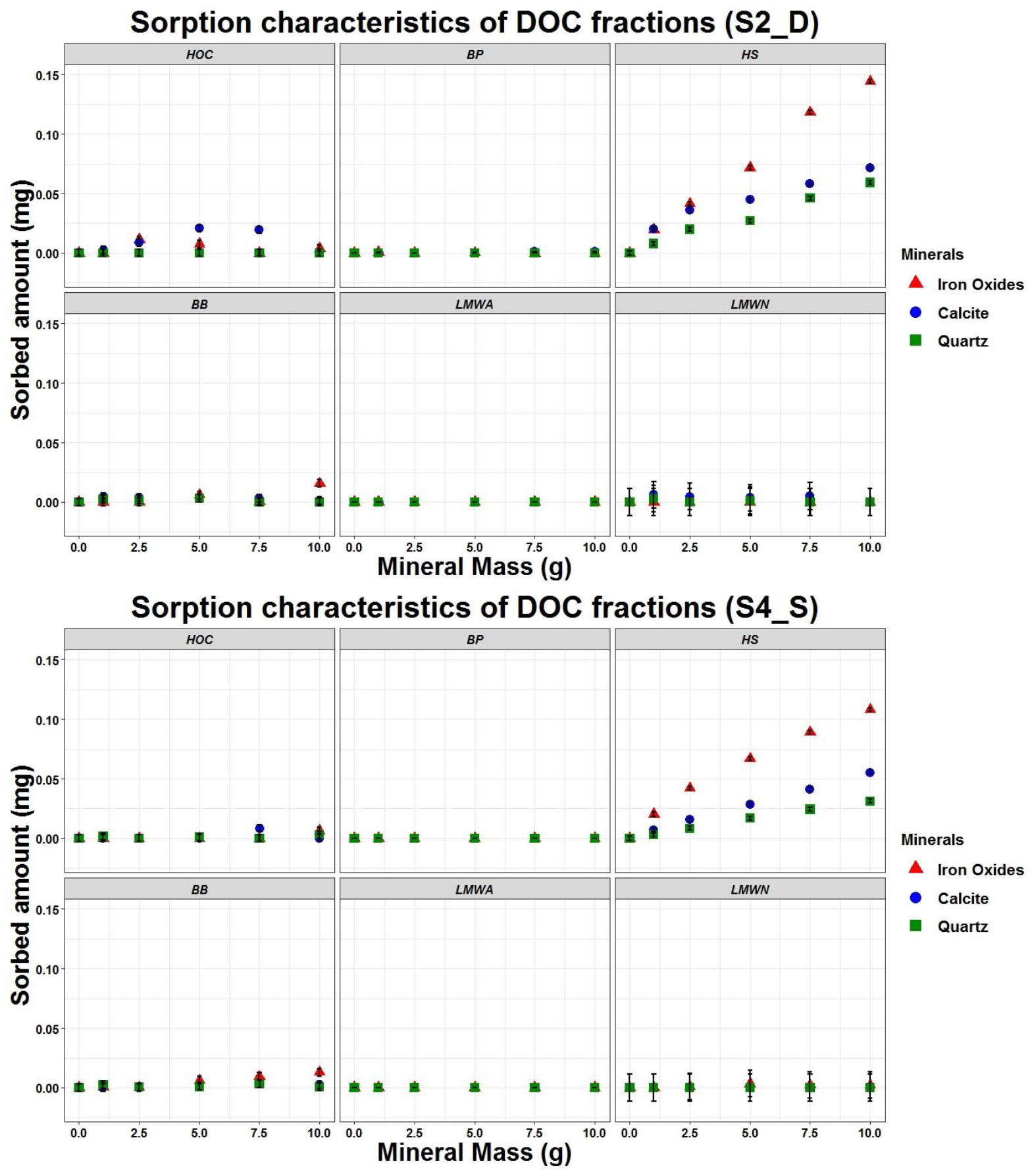



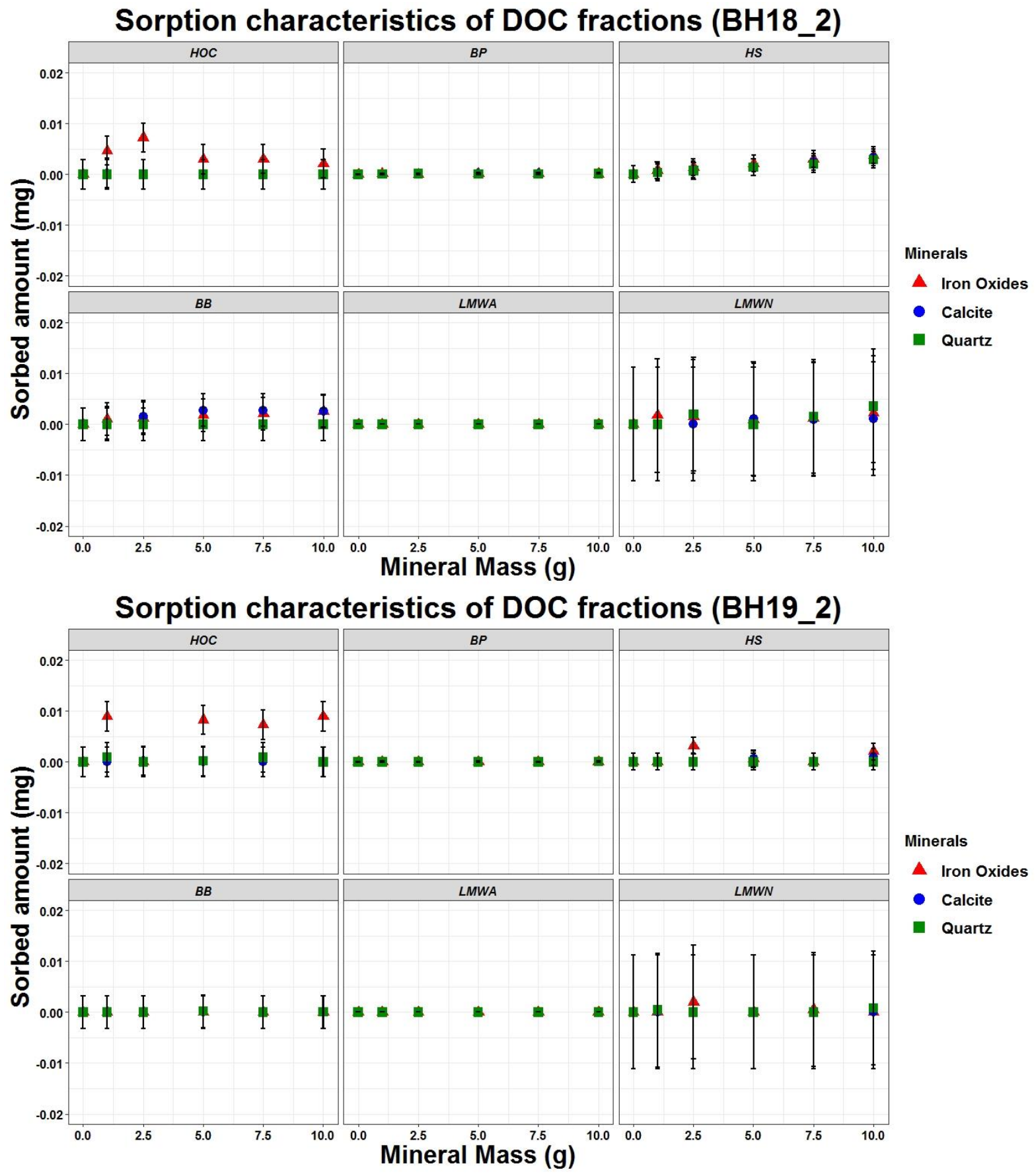

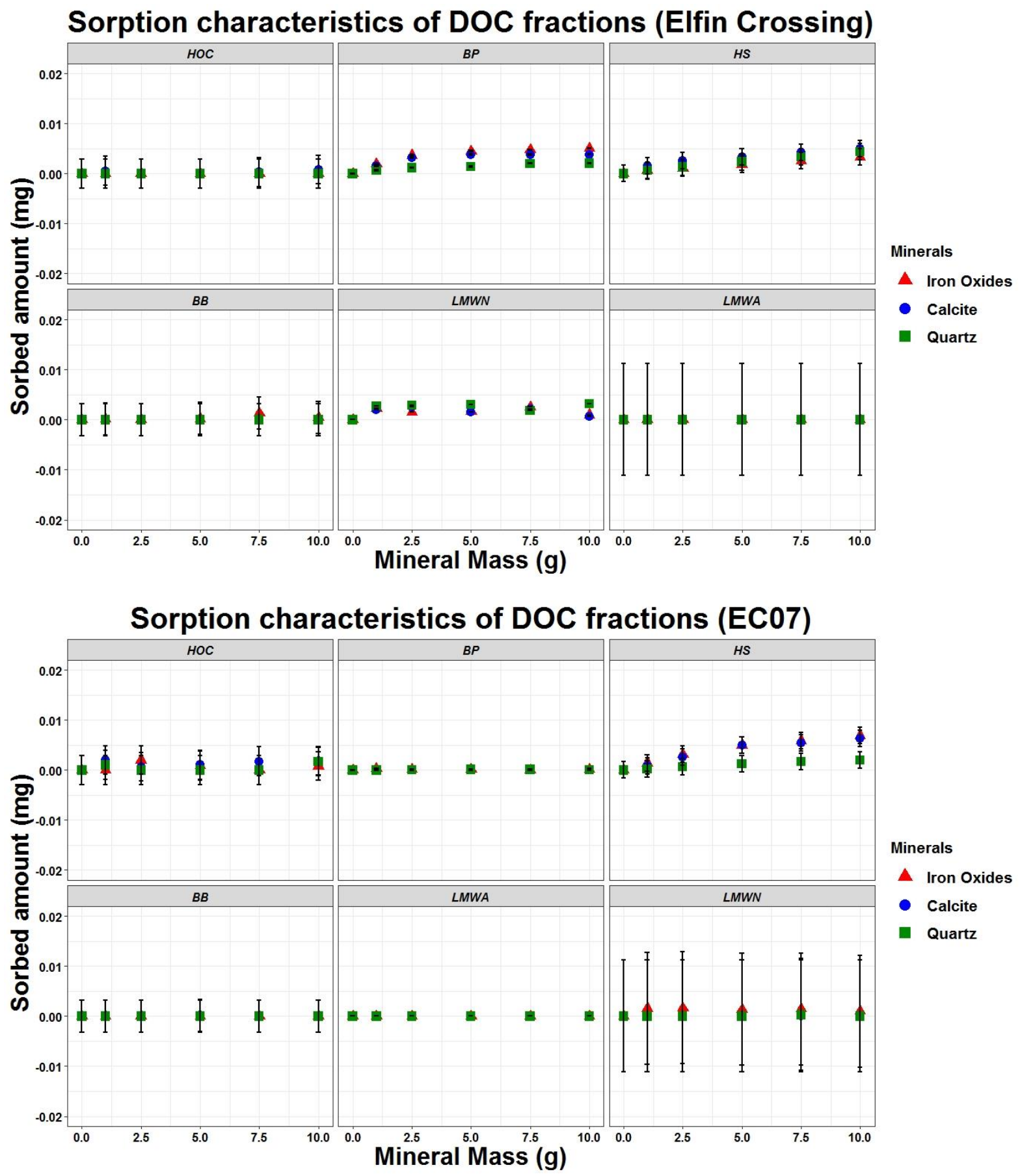

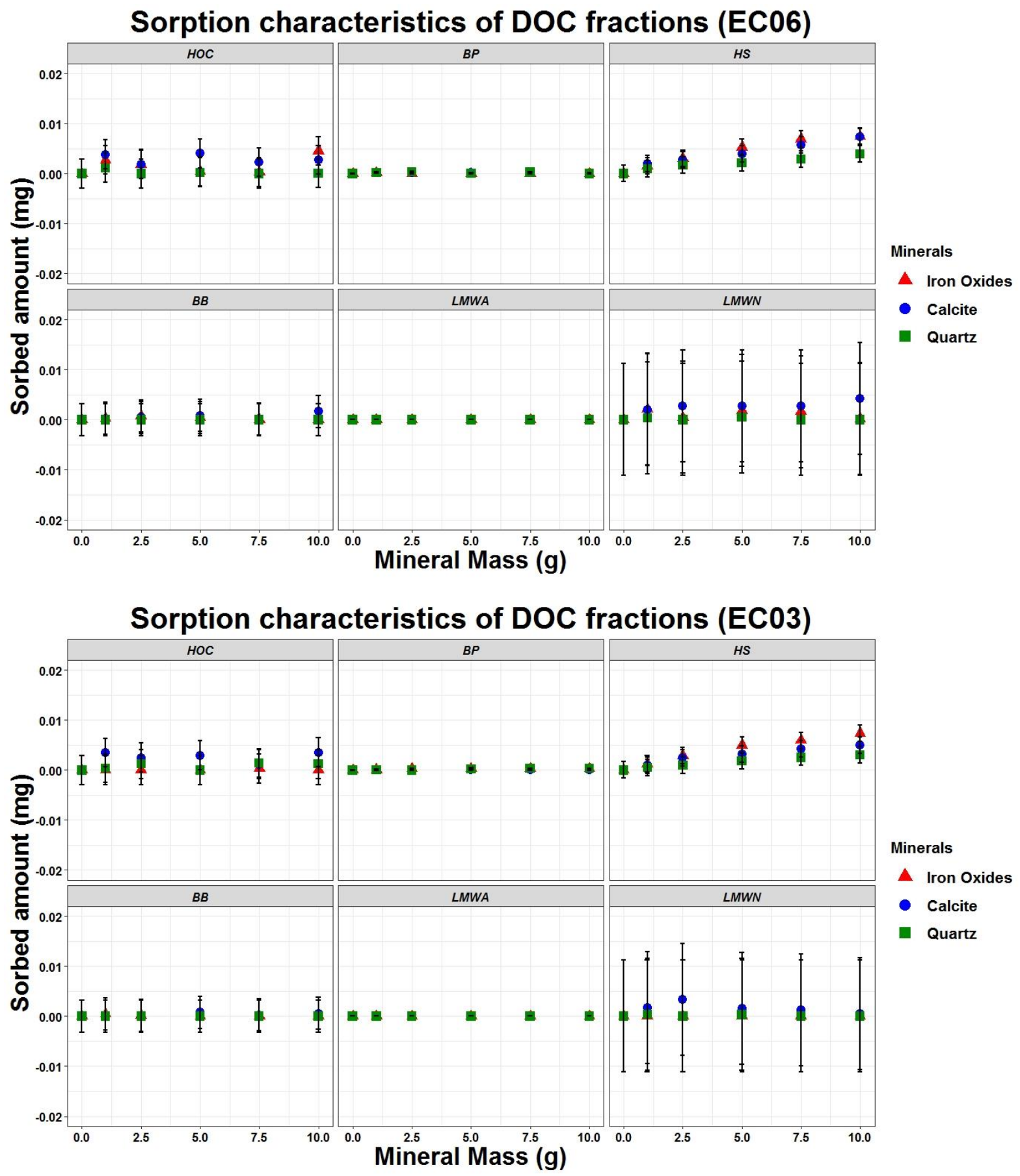

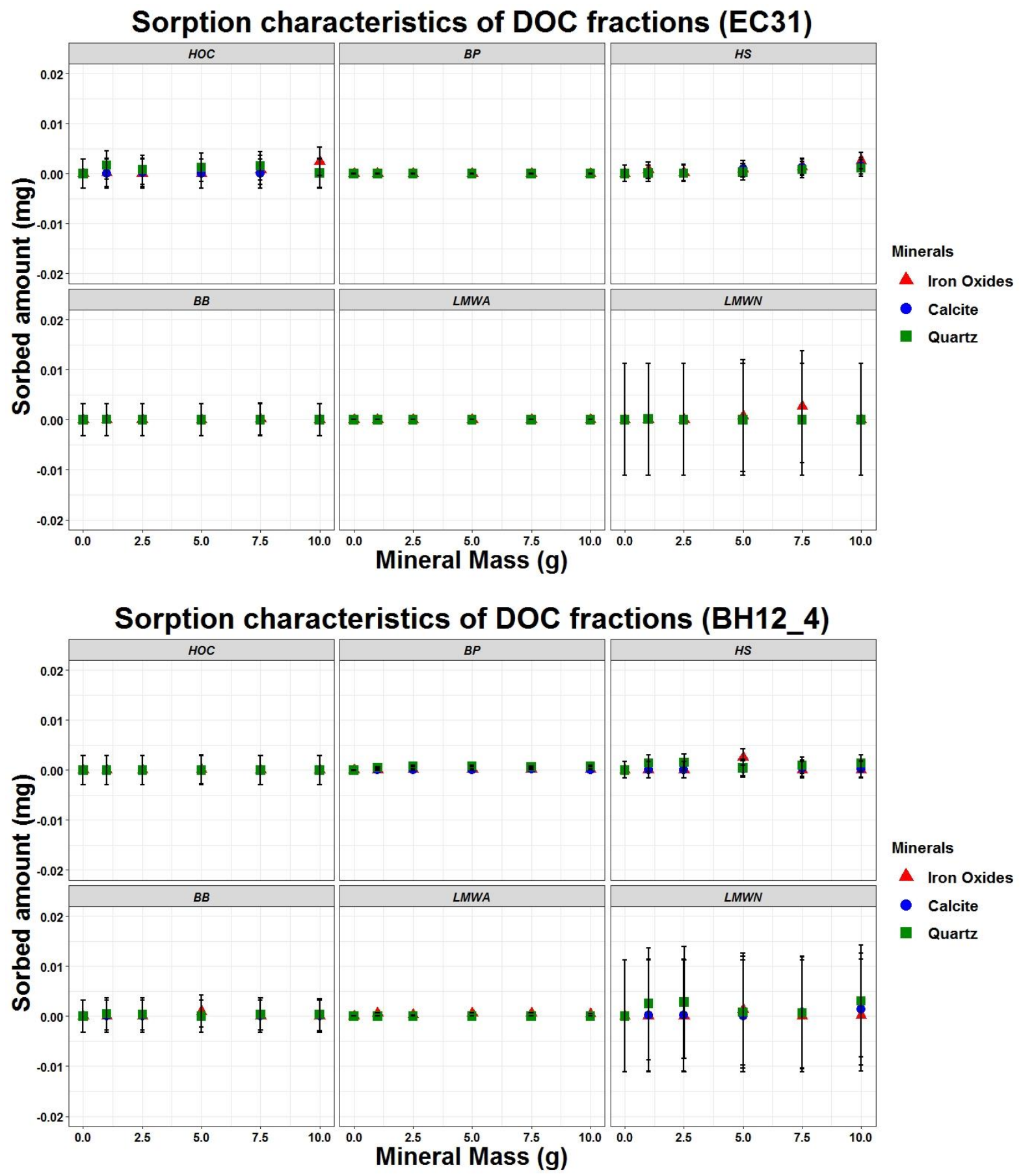

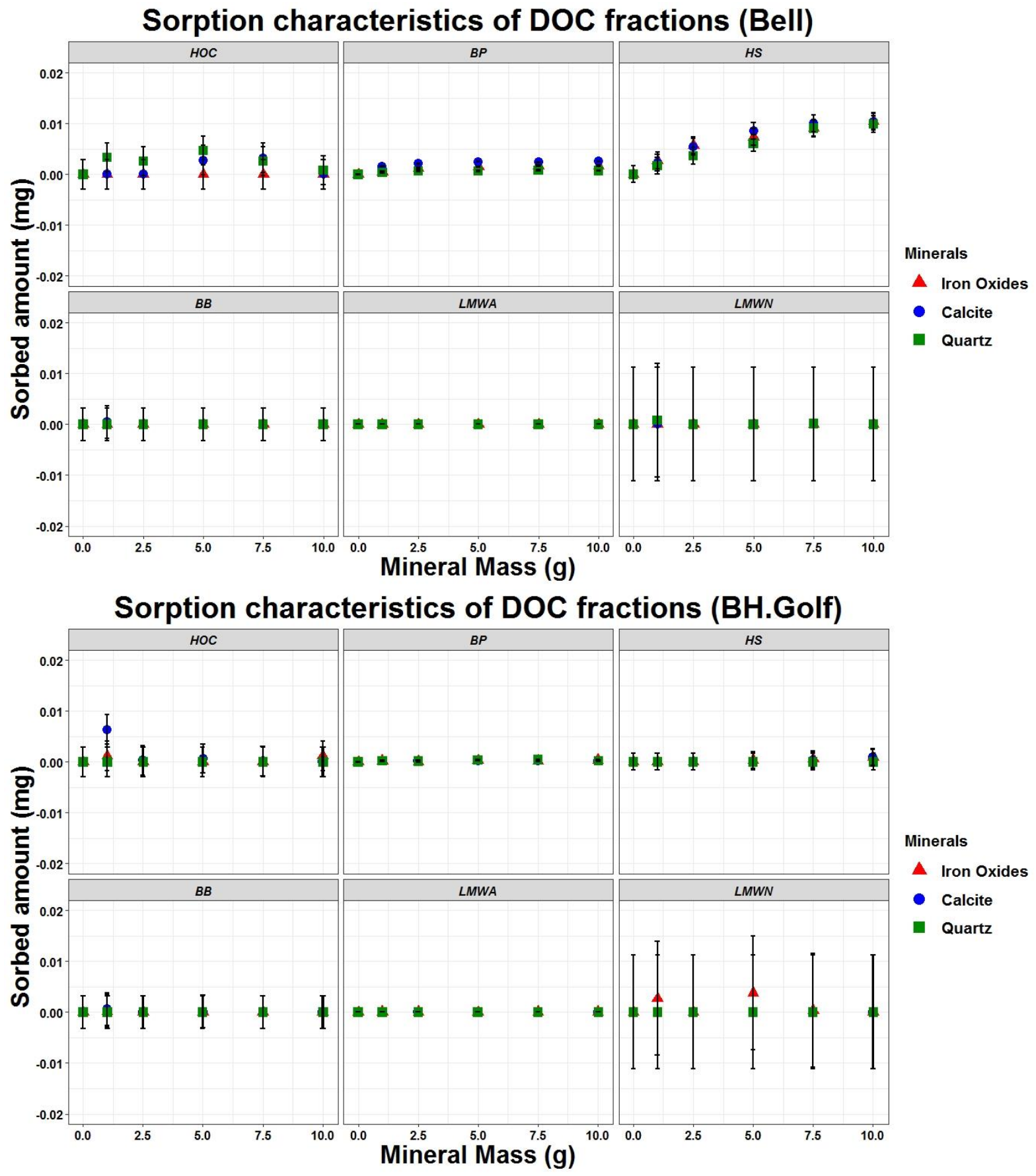

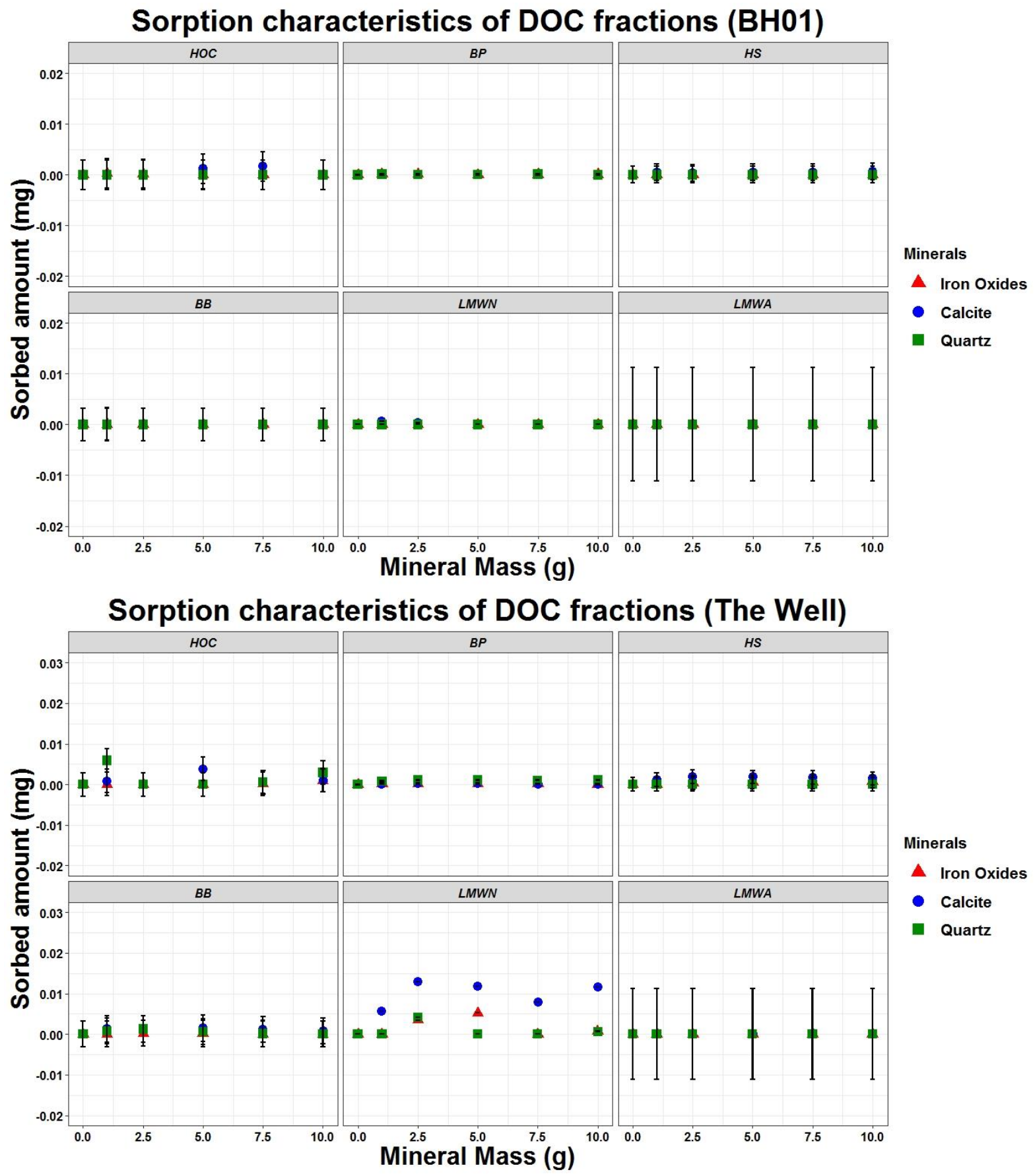

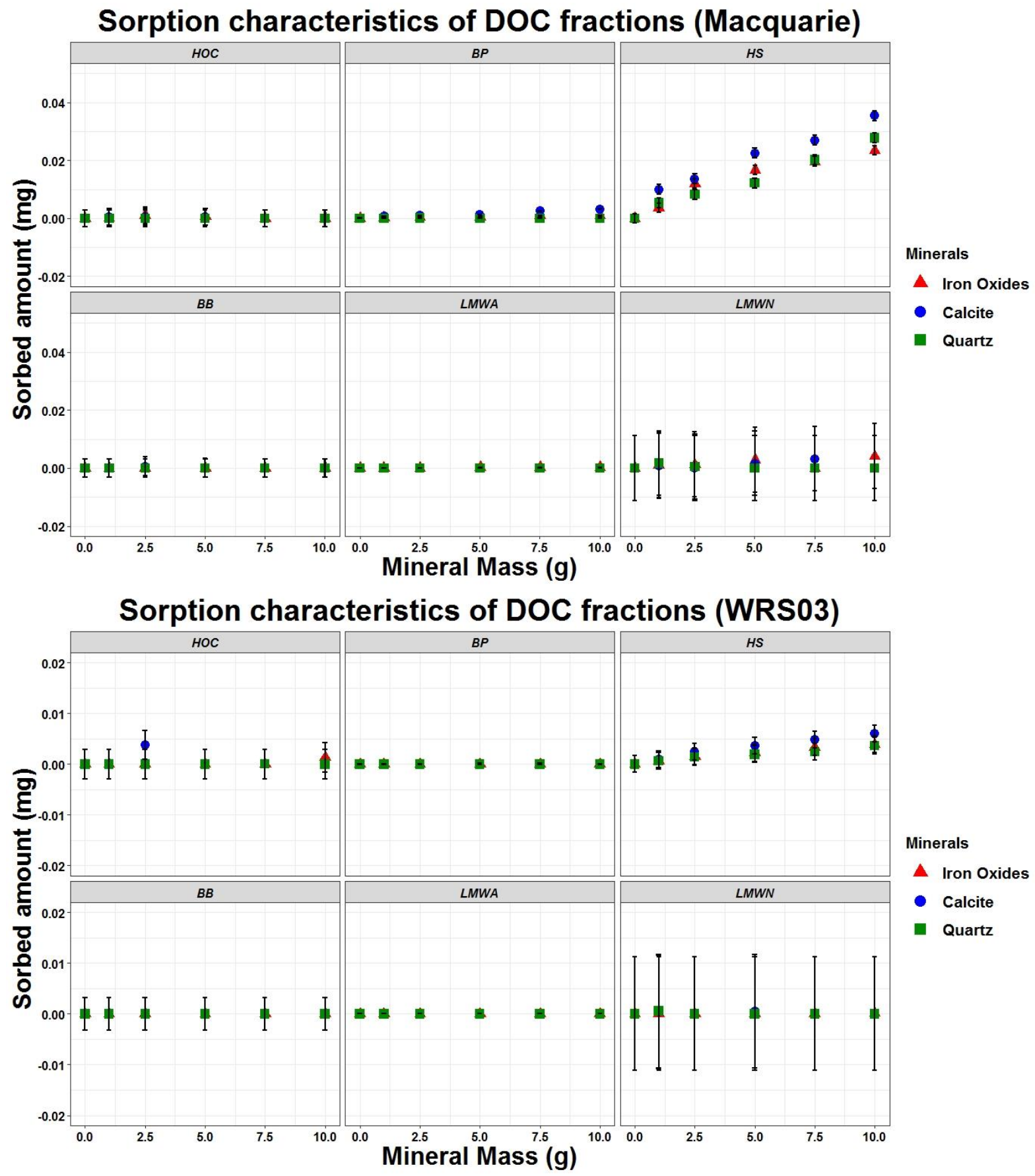


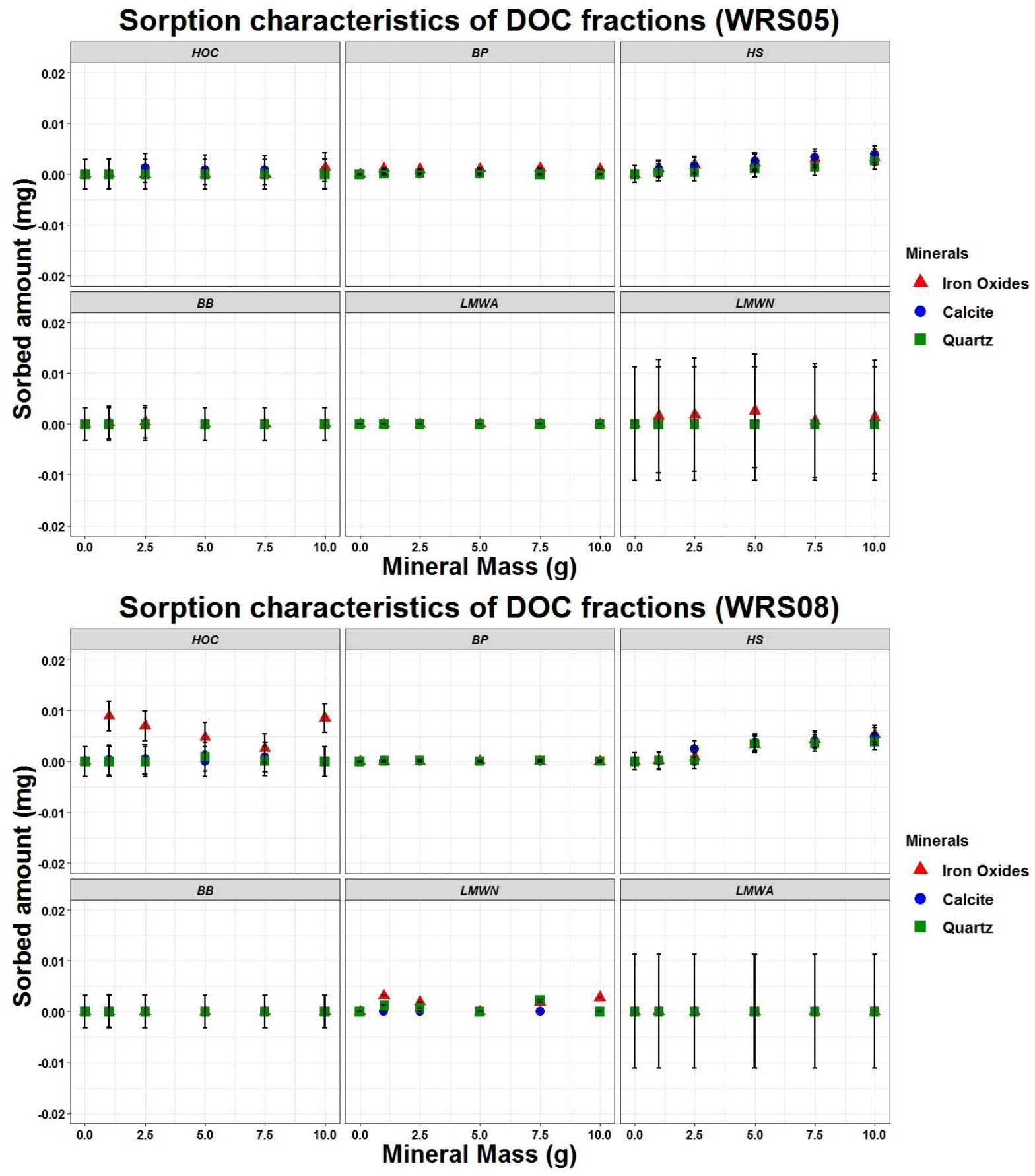

